Supporting Information

for

\title{
Studies of Azetidin-2-one as a Reactive Enolate Synthon of $\beta$-Alanine for Condensations with Aldehydes and Ketones.
}

\author{
David R. Williams, * Andrew F. Donnell, David C. Kammler, Sarah A. Ward \\ and Levin Taylor, IV \\ Department of Chemistry, Indiana University \\ Bloomington, IN 47405, United States \\ williamd@indiana.edu
}

Page

Procedures and Characterization Data for Mosher Ester Analyses $\quad$ S-2 - S-5

${ }^{1} \mathrm{H}$ and ${ }^{13} \mathrm{C}$ NMR Spectra

S-6 - S-64

X-ray Diffraction Study

S-65-S-76 
Mosher ester analysis of (S)-3-[(1S,2R)-2-(benzyloxy)-1-[hydroxypropyl]-1-(4methoxybenzyloxy)azetidin-2-one (33). The assignment of stereochemistry of the chiral secondary alcohol of the anti-azetidin-2-one $\mathbf{3 3}$ (Table 3, entry 7) was made following the preparation of nonracemic $(R)$ - and (S)- $\alpha$-methoxy- $\alpha$-(trifluoromethyl)phenylacetic acid (MTPA) esters followed by an analysis according to the modified Mosher method. ${ }^{1}$ To rt solutions of $(S)$ - or ( $R$ )-MTPA (10 equiv), the reagents DCC (10 equiv), DMAP (5 equiv) in $\mathrm{CH}_{2} \mathrm{Cl}_{2}$ and alcohol $\mathbf{3 3}$ were added. The white suspensions were stirred at $\mathrm{rt}$ for $24 \mathrm{~h}$, then directly purified by preparative TLC (hexanes/EtOAc) to provide the derivative esters with the ${ }^{1} \mathrm{H}$ NMR signals compiled in SI-Table 1 below:

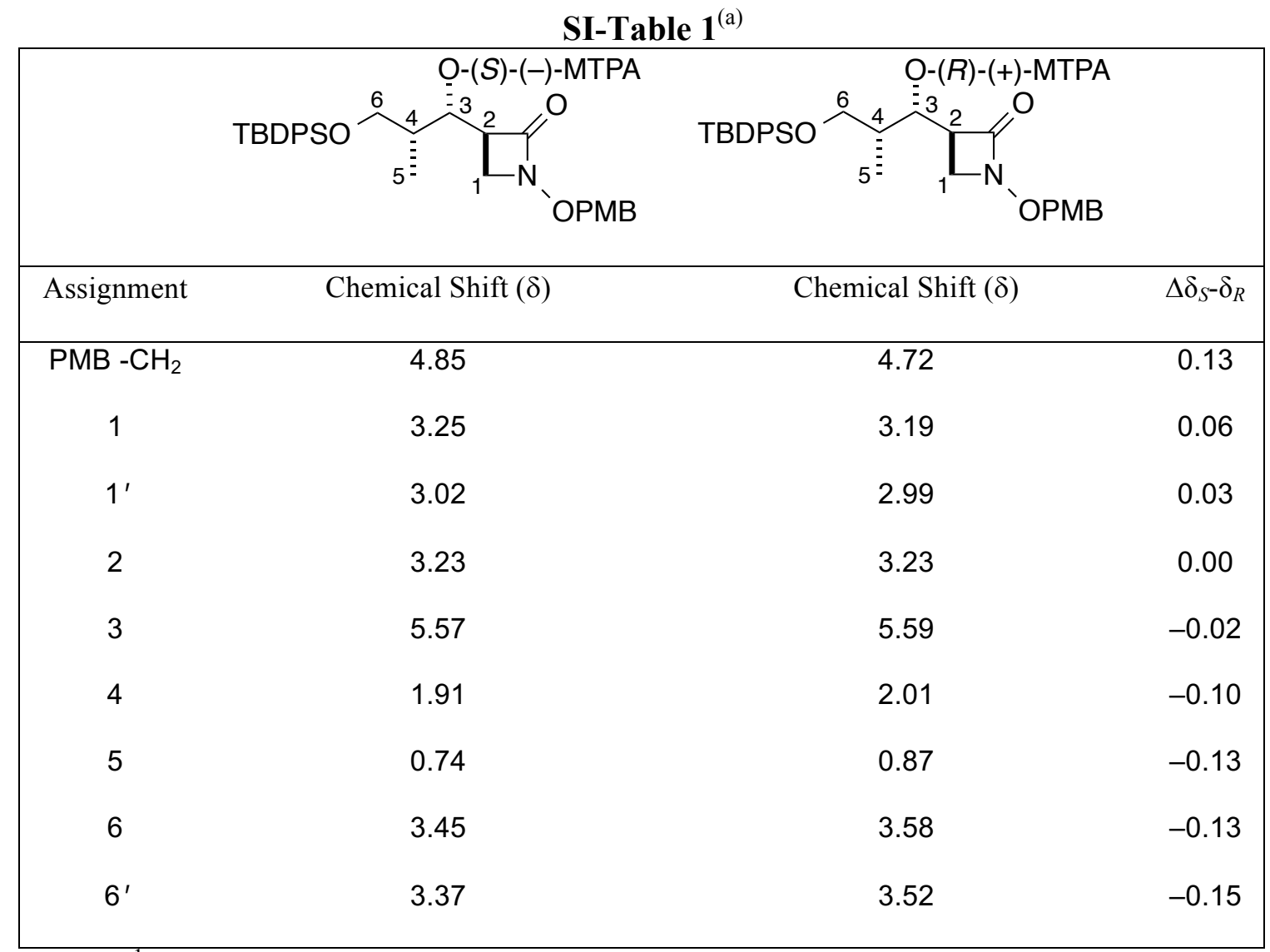

(a) ${ }^{\mathrm{I}} \mathrm{H}$ NMR data are recorded using a $400 \mathrm{MHz}$ instrument and $\mathrm{CDCl}_{3}$ solutions of MTPA esters. 


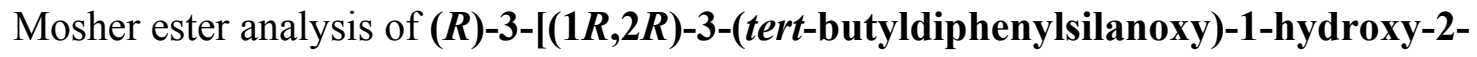
methylpropyl]-1-(4-methoxybenzyloxy)-azetidin-2-one (33a). The assignment of stereochemistry of the chiral secondary alcohol of the minor product azetidin-2-one 33a of entry 7 (Table 3) was made following the preparation of nonracemic $(R)$ - and $(S)$ - $\alpha$-methoxy- $\alpha-$ (trifluoromethyl)phenylacetic acid (MTPA) esters followed by analysis according to the modified Mosher method. ${ }^{1}$ To rt solutions of $(S)$ - and $(R)$-MTPA (10 equiv), DCC (10 equiv), DMAP (5 equiv) in $\mathrm{CH}_{2} \mathrm{Cl}_{2}$ and alcohol 33a were added. The white suspensions were stirred at $\mathrm{rt}$ for $24 \mathrm{~h}$, then directly purified by preparative TLC (hexanes/EtOAc) to provide the esters with the ${ }^{1} \mathrm{H}$ NMR signals compiled in SI-Table 2 below.

SI-Table $2^{(\text {a) }}$

\begin{tabular}{|c|c|c|c|}
\hline & & \multicolumn{2}{|c|}{ 'OPMB } \\
\hline 1 ' & 2.98 & 3.08 & -0.10 \\
\hline 2 & 3.30 & 3.36 & -0.06 \\
\hline 3 & 5.47 & 5.45 & 0.02 \\
\hline 4 & 2.14 & 2.04 & 0.10 \\
\hline 5 & 0.95 & 0.79 & 0.16 \\
\hline TBDPS $t$-Bu & 1.04 & 1.02 & 0.02 \\
\hline
\end{tabular}

(a) ${ }^{1} \mathrm{H}$ NMR data are recorded using a $400 \mathrm{MHz}$ instrument and $\mathrm{CDCl}_{3}$ solutions of MTPA esters. 
Mosher ester analysis of 35a. The assignment of stereochemistry for the pair of antialdol products $\mathbf{3 5}$ and 35a was advanced by the Mosher ester analysis of the minor diastereomer pure, anti-35a.<smiles>[R16]ON1CC(C(O)C(C)OCc2ccccc2)C1=O</smiles>

35a (minor product)

The stereochemistry was assigned by the preparation of $\alpha$-methoxy- $\alpha$ (trifluoromethyl)phenylacetic acid (MTPA) esters and analysis according to the modified Mosher method. ${ }^{1}$ To rt solutions of $R$ - and $S$-MTPA (10 equiv), the reagents DCC (10 equiv), DMAP (5 equiv) in $\mathrm{CH}_{2} \mathrm{Cl}_{2}$ and alcohol 35a were added. The white suspensions were stirred at $\mathrm{rt}$ for $24 \mathrm{~h}$, then directly purified by preparative TLC to provide derivative esters with the following ${ }^{1} \mathrm{H}$ NMR data tabulated in SI-Table 3 below:

SI-Table 3

\begin{tabular}{|c|c|c|c|}
\hline $\mathrm{H}$ & OPMB & $\underbrace{-(R)-(+}_{1}$ & $\delta_{S^{-}} \delta_{R}$ \\
\hline $\mathrm{PMB}-\mathrm{CH}_{2}$ & 4.67 & 4.86 & -0.19 \\
\hline 1 & 3.19 & 3.24 & -0.05 \\
\hline $1^{\prime}$ & 3.07 & 3.17 & -0.10 \\
\hline 2 & 3.30 & 3.28 & 0.02 \\
\hline 3 & 5.37 & 5.35 & 0.02 \\
\hline
\end{tabular}




\begin{tabular}{|cccc|}
4 & 3.89 & 3.73 & 0.16 \\
5 & 1.25 & 1.05 & 0.20 \\
$\mathrm{Bn}-\mathrm{CH}_{2}$ & 4.50 & 4.41 & 0.09 \\
\hline
\end{tabular}

1. (a) Dale, J. A.; Mosher, H. S. J. Am. Chem. Soc. 1973, 95, 512-519. (b) For a detailed description of this protocol: Hoye, T. R.; Jeffrey, C. S.; Shao, F. Nat. Protoc. 2007, 2, $2451-$ 2458. 


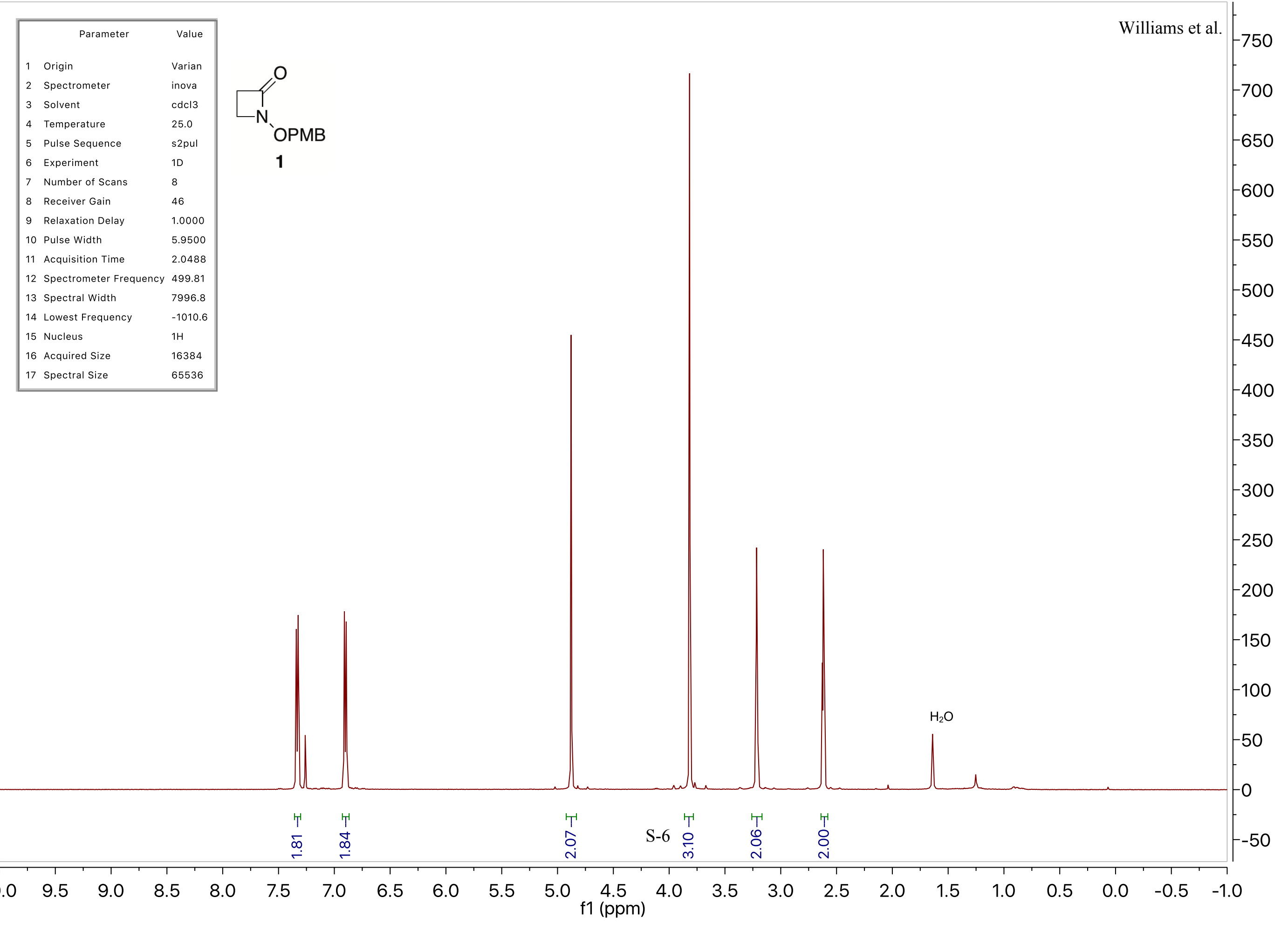




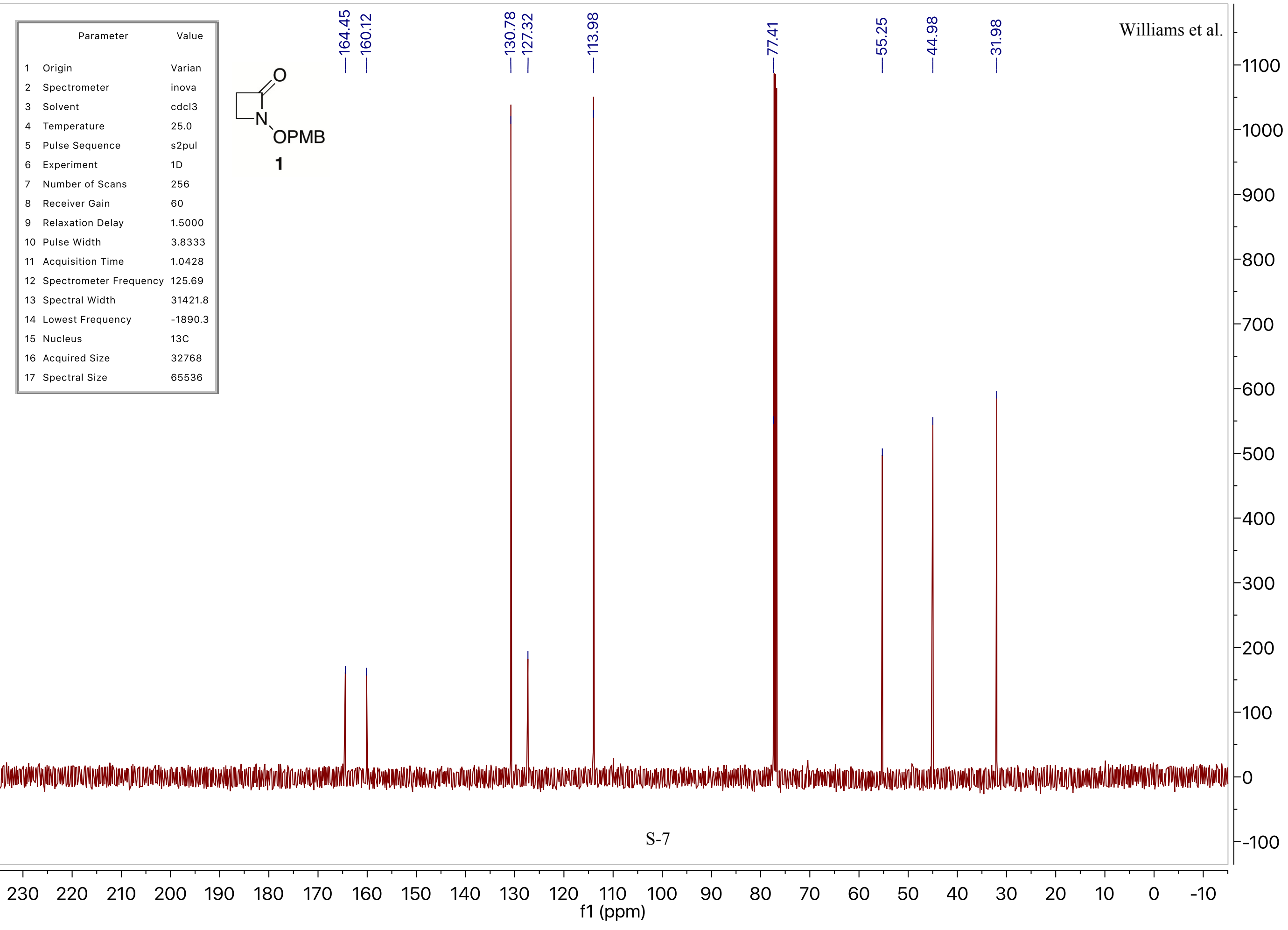




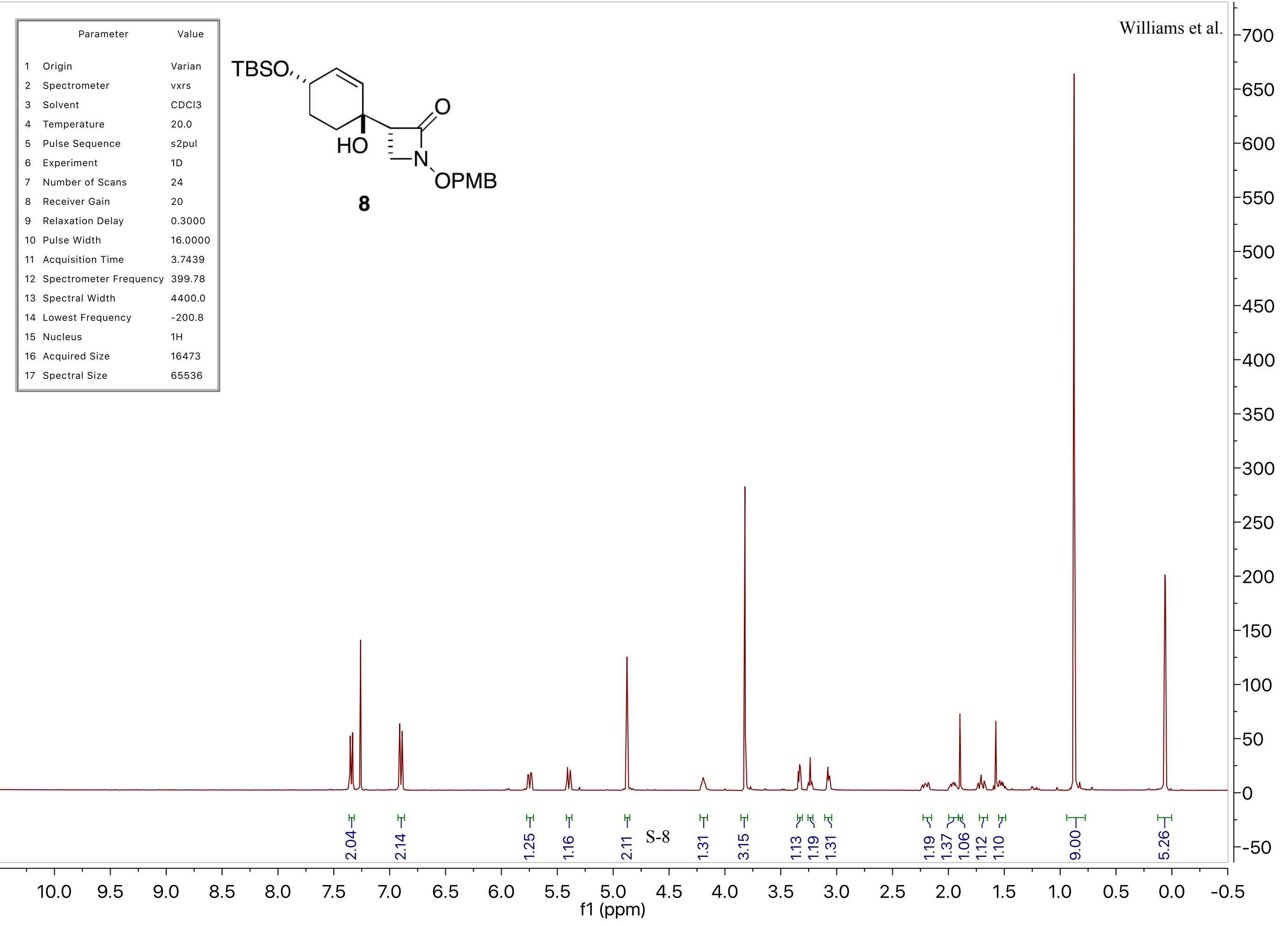




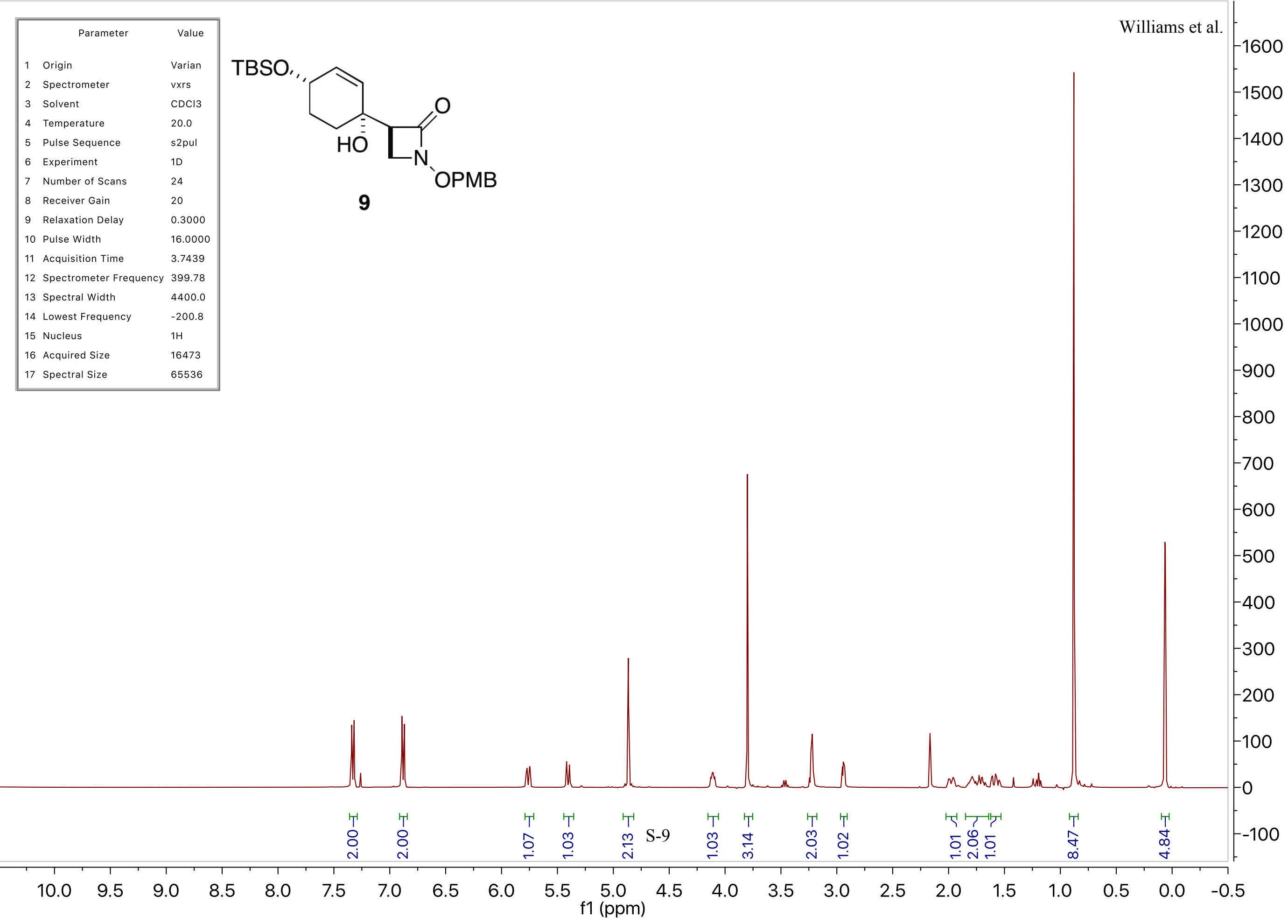




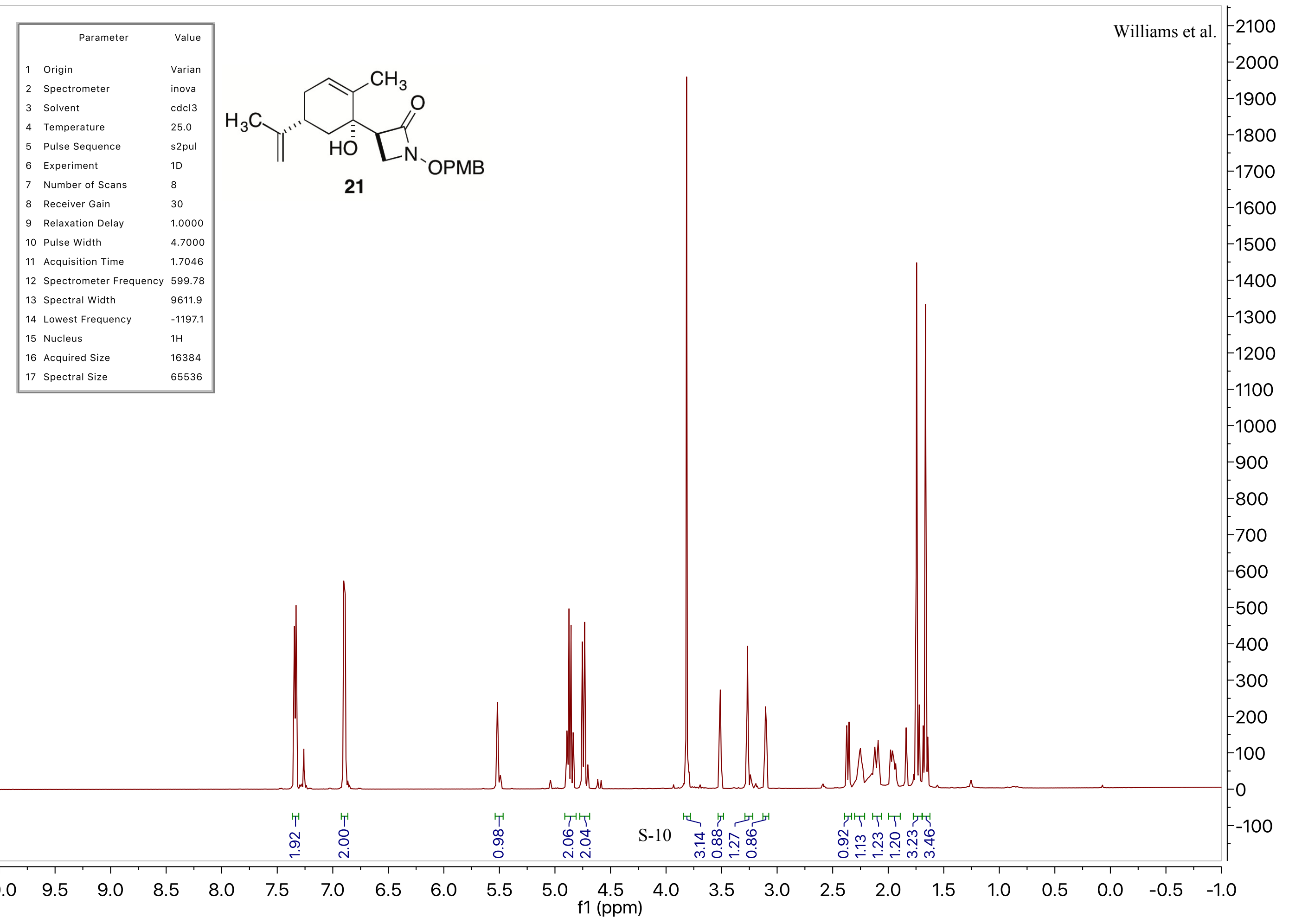




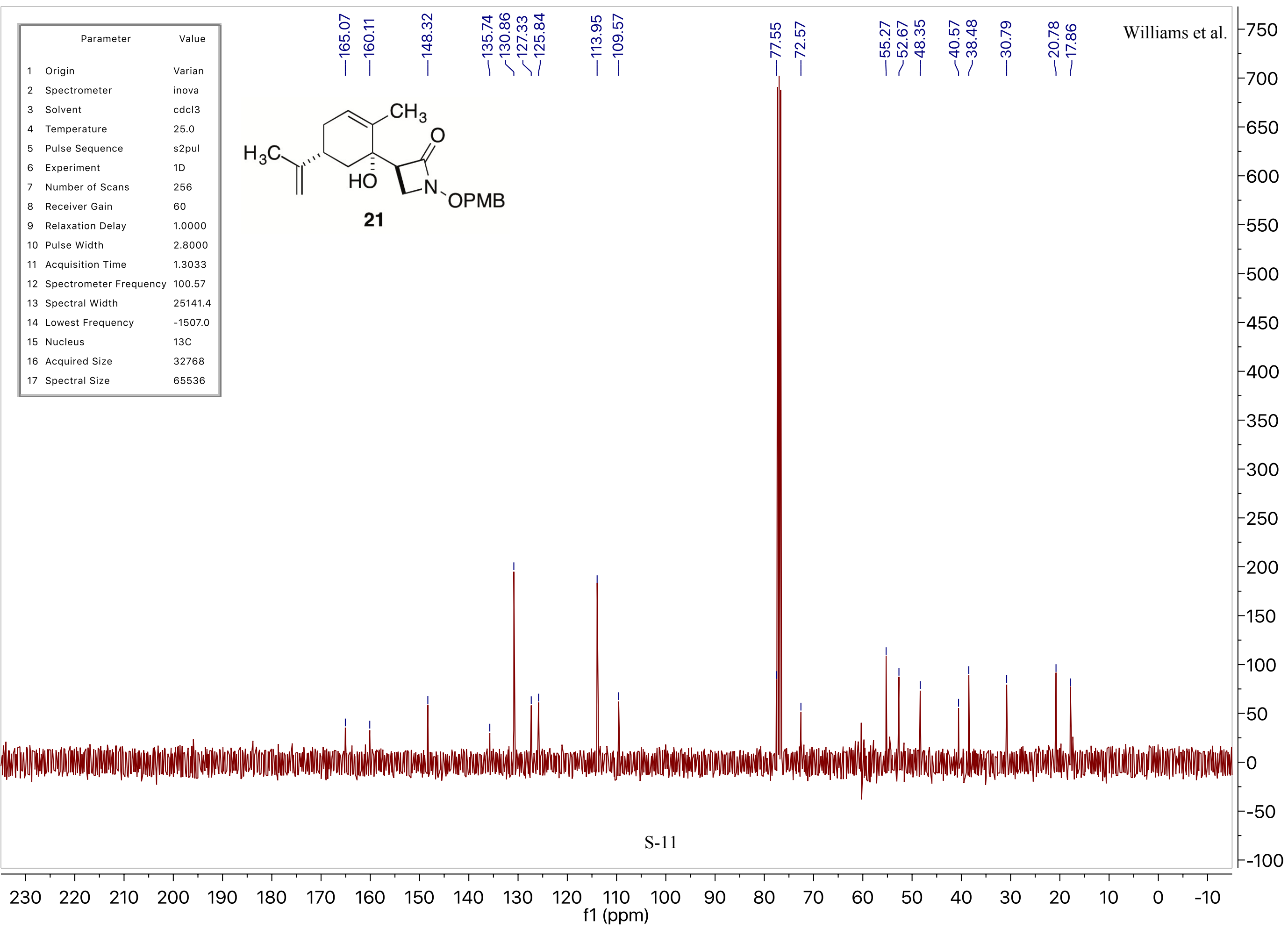




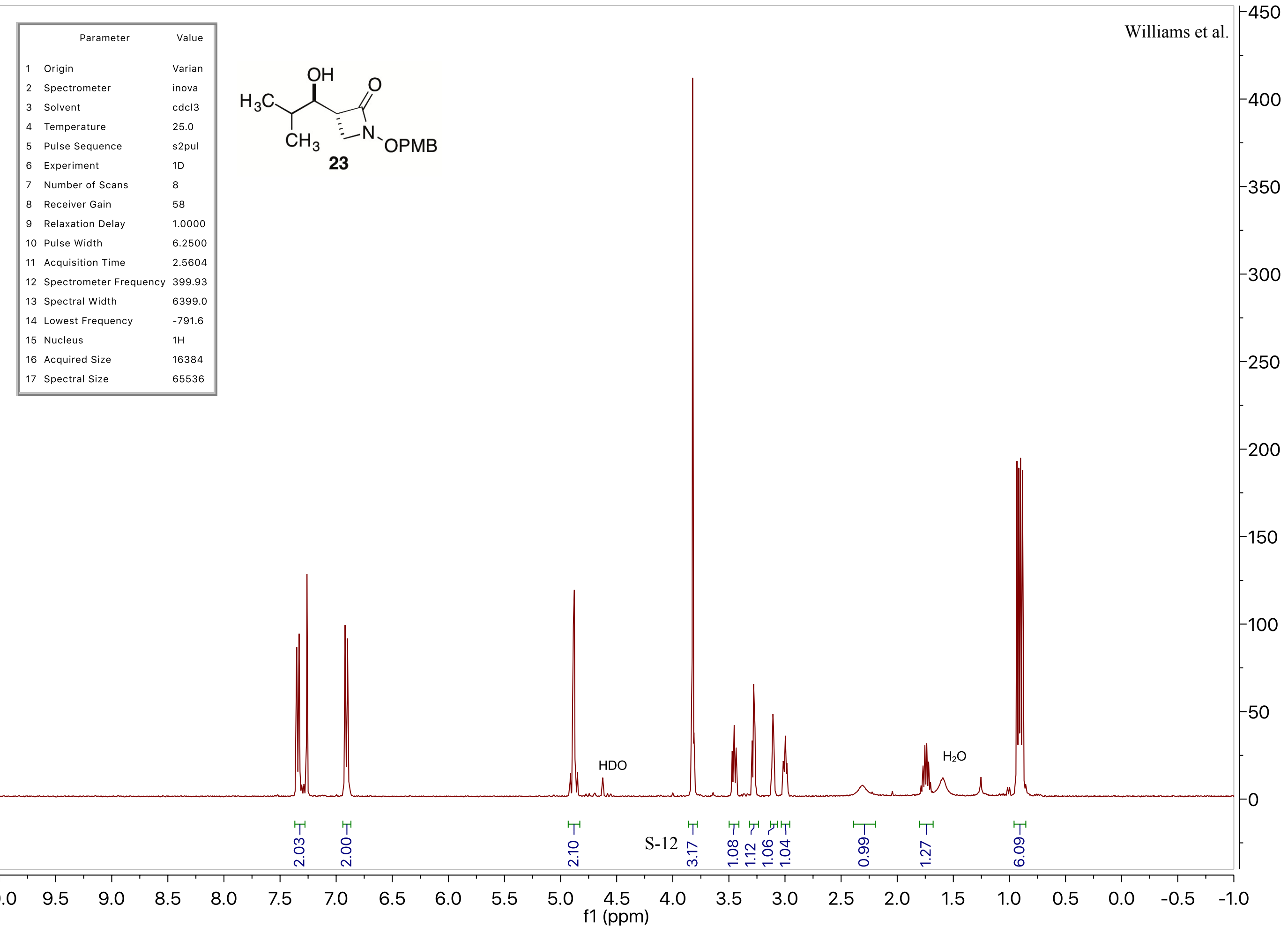




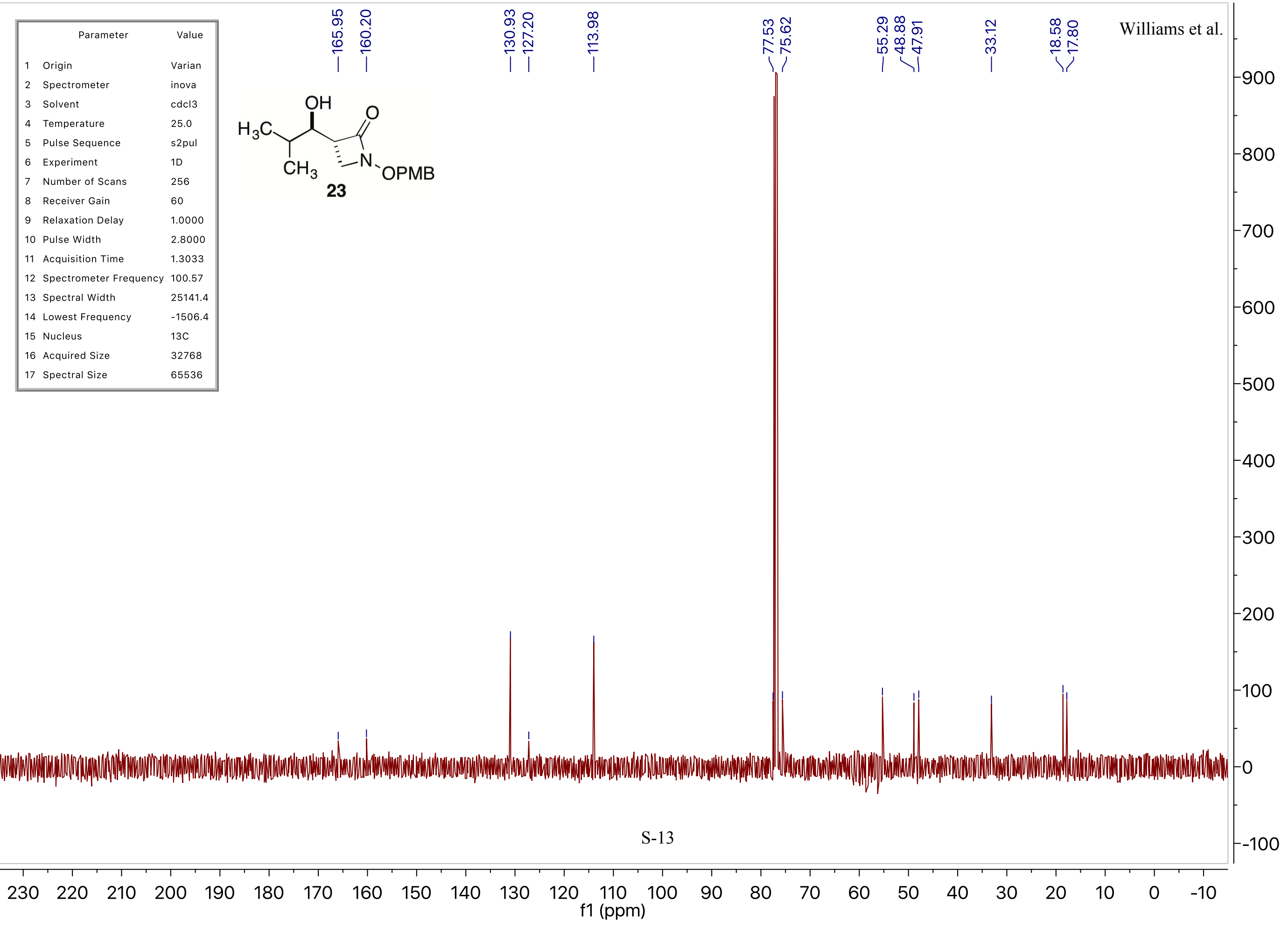




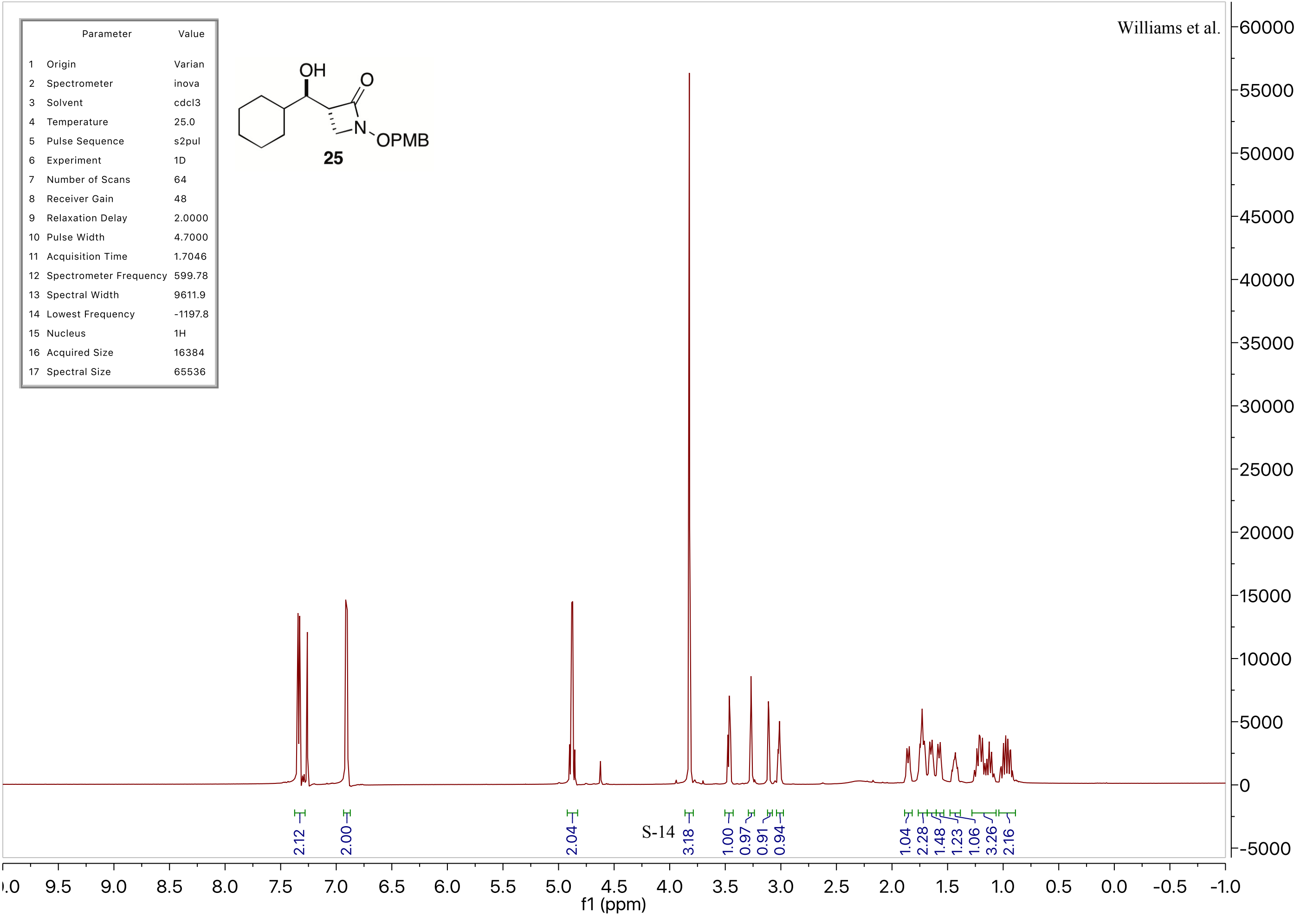




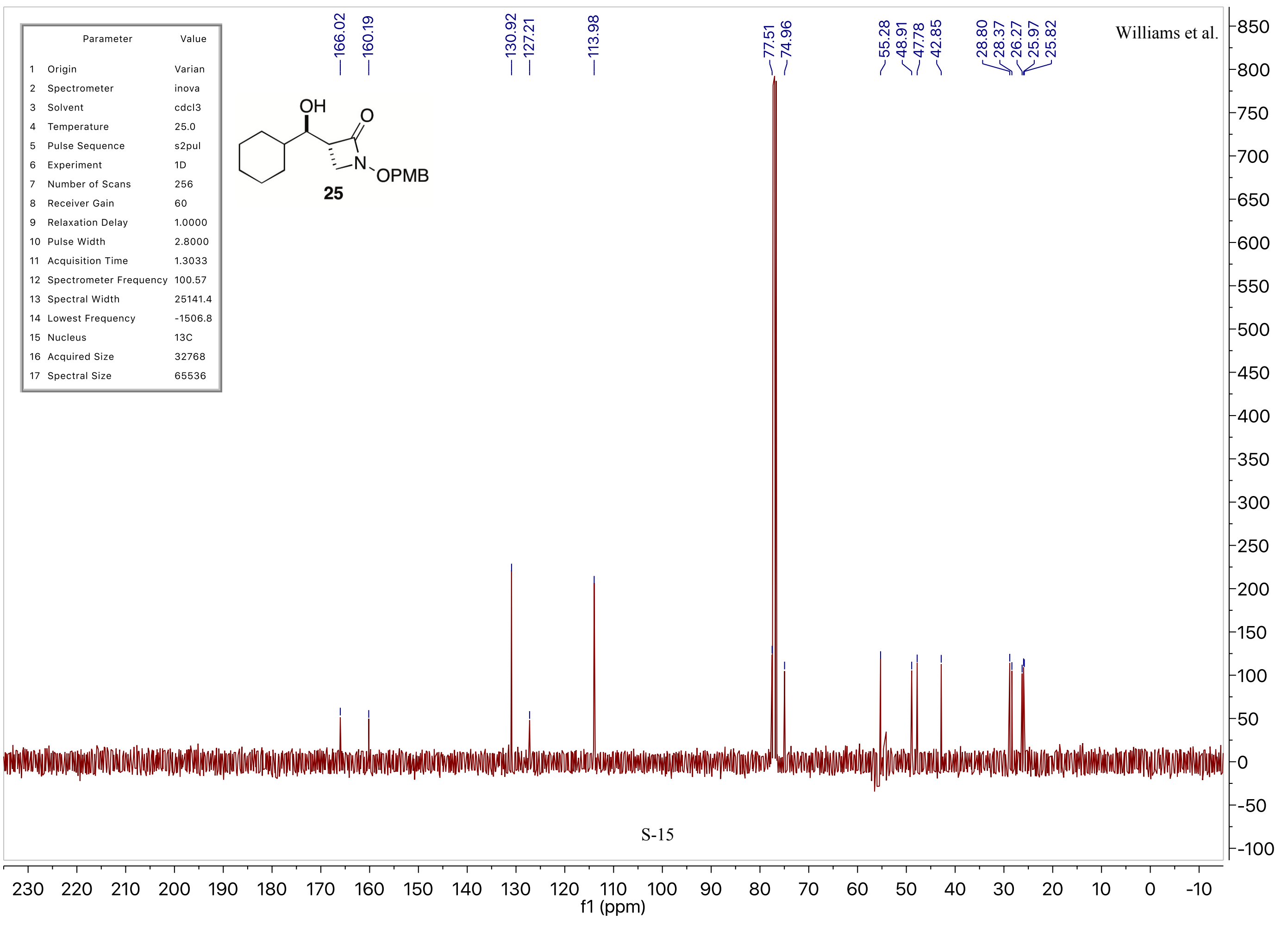




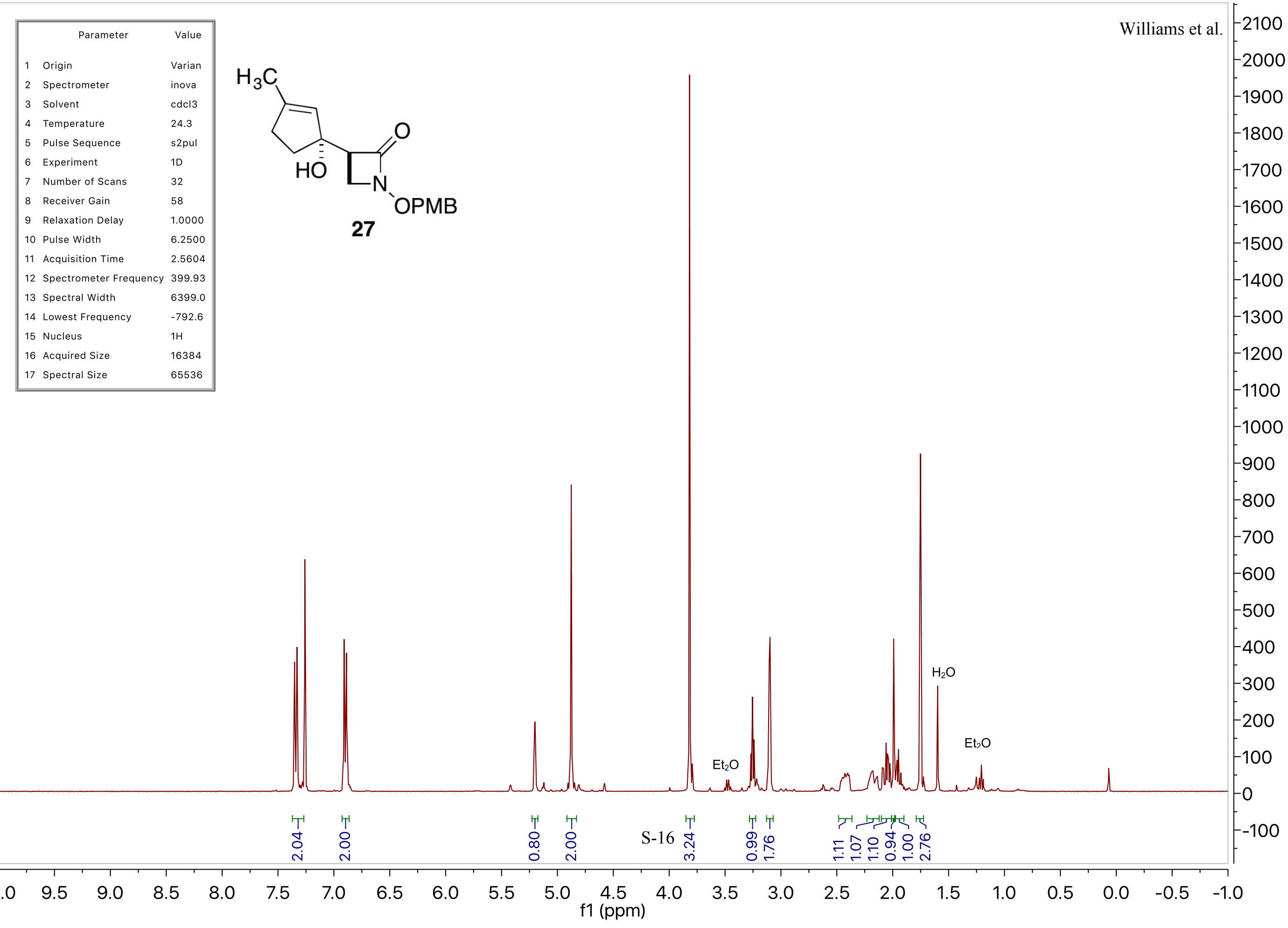




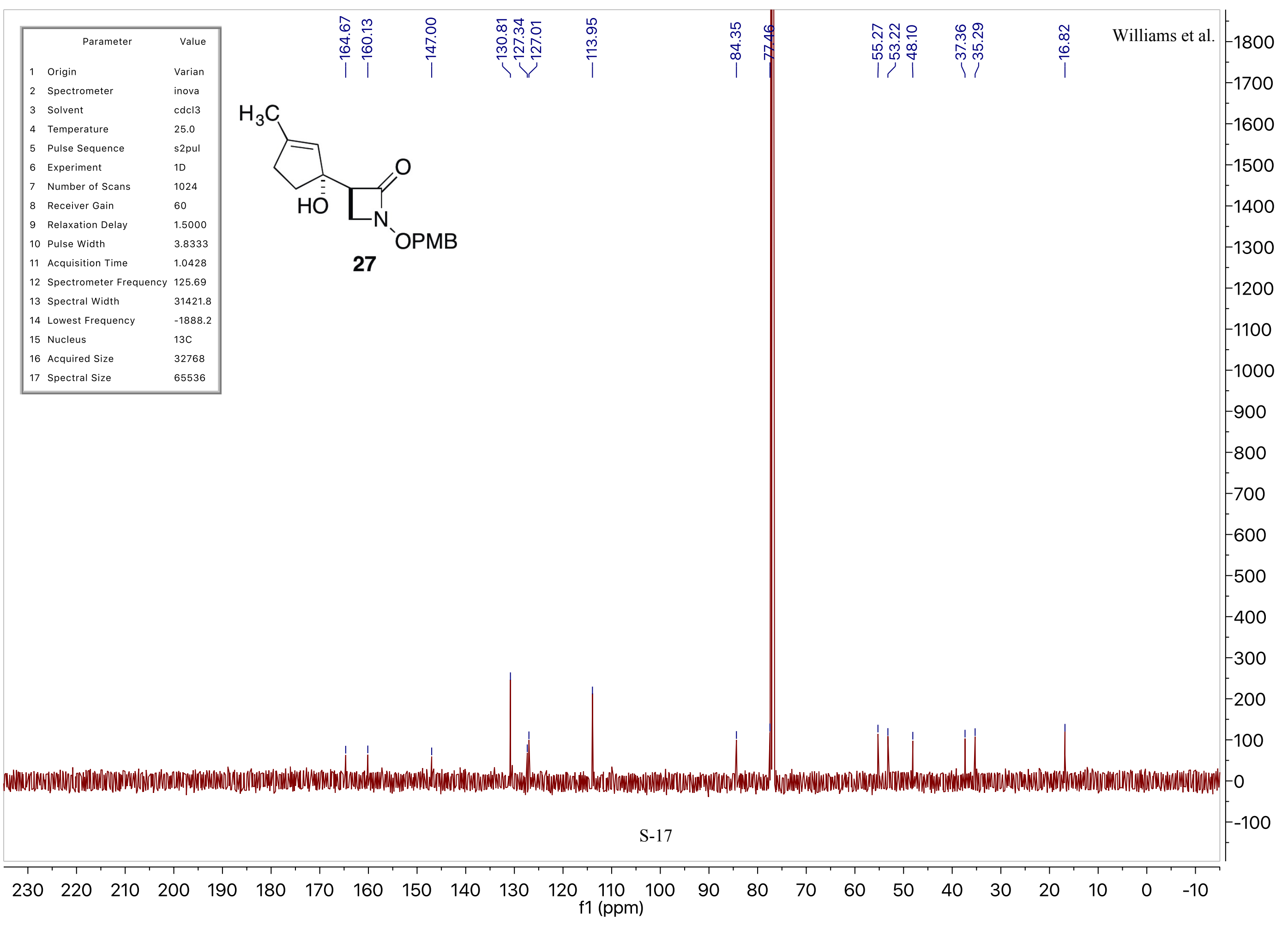



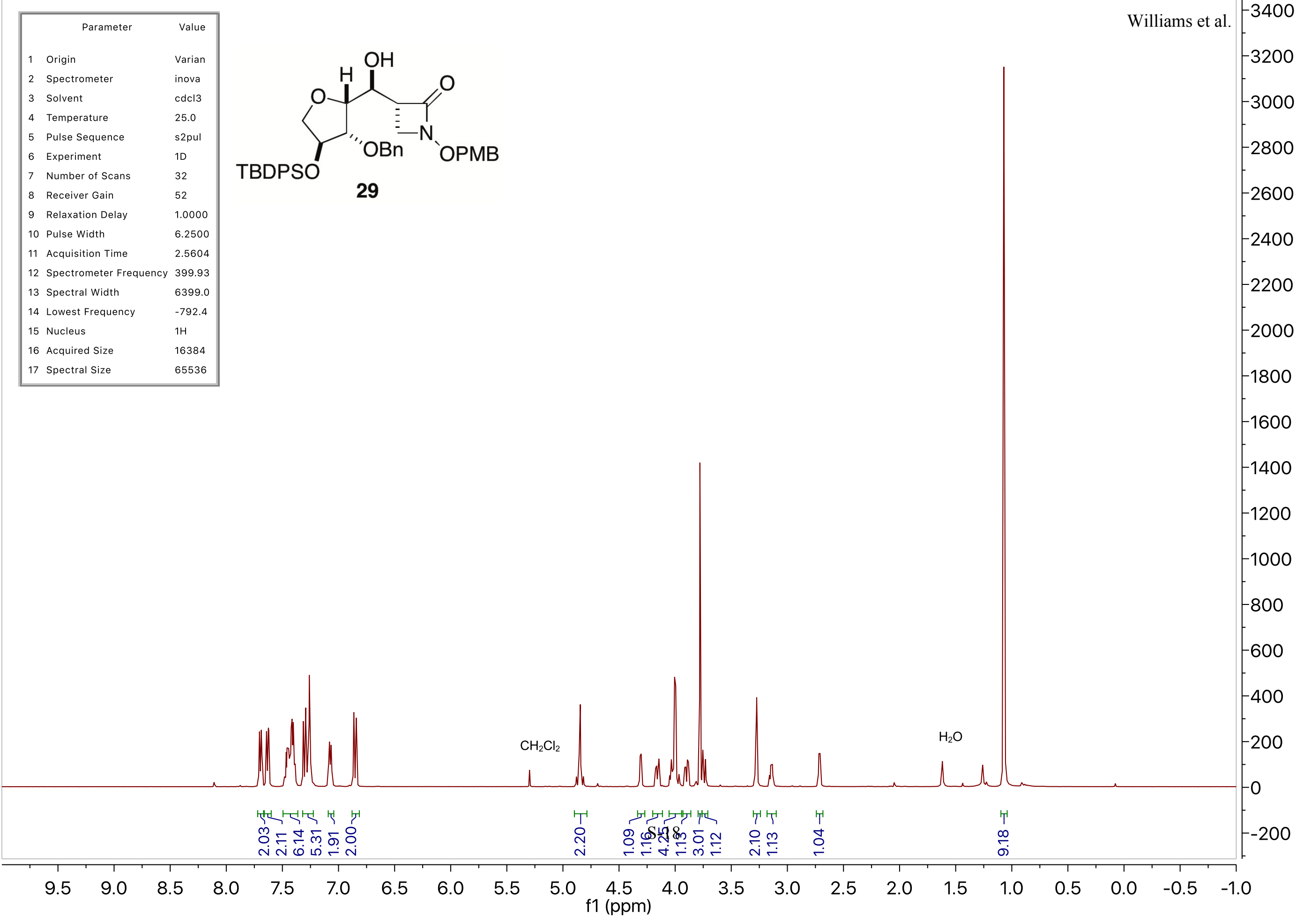


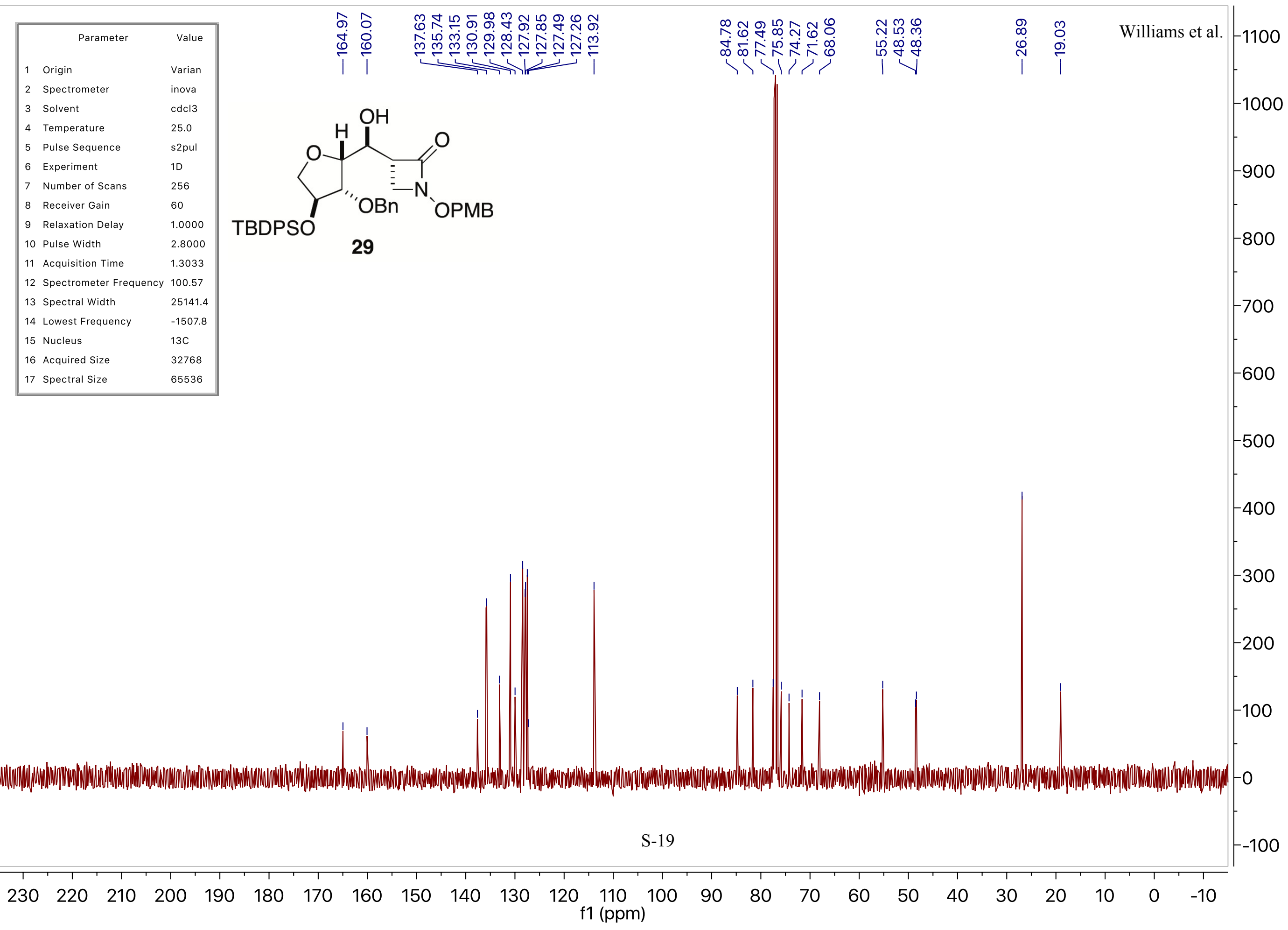




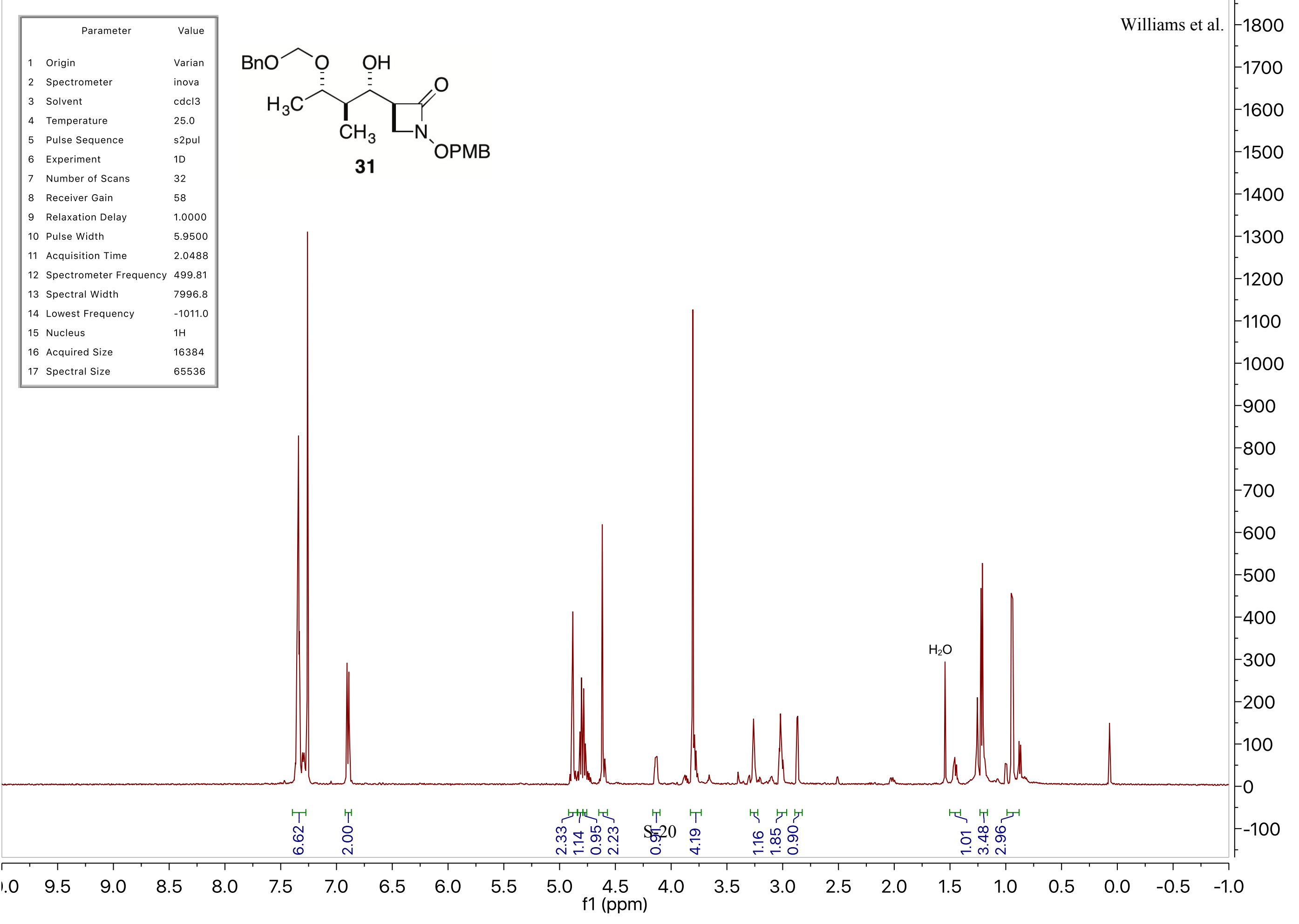




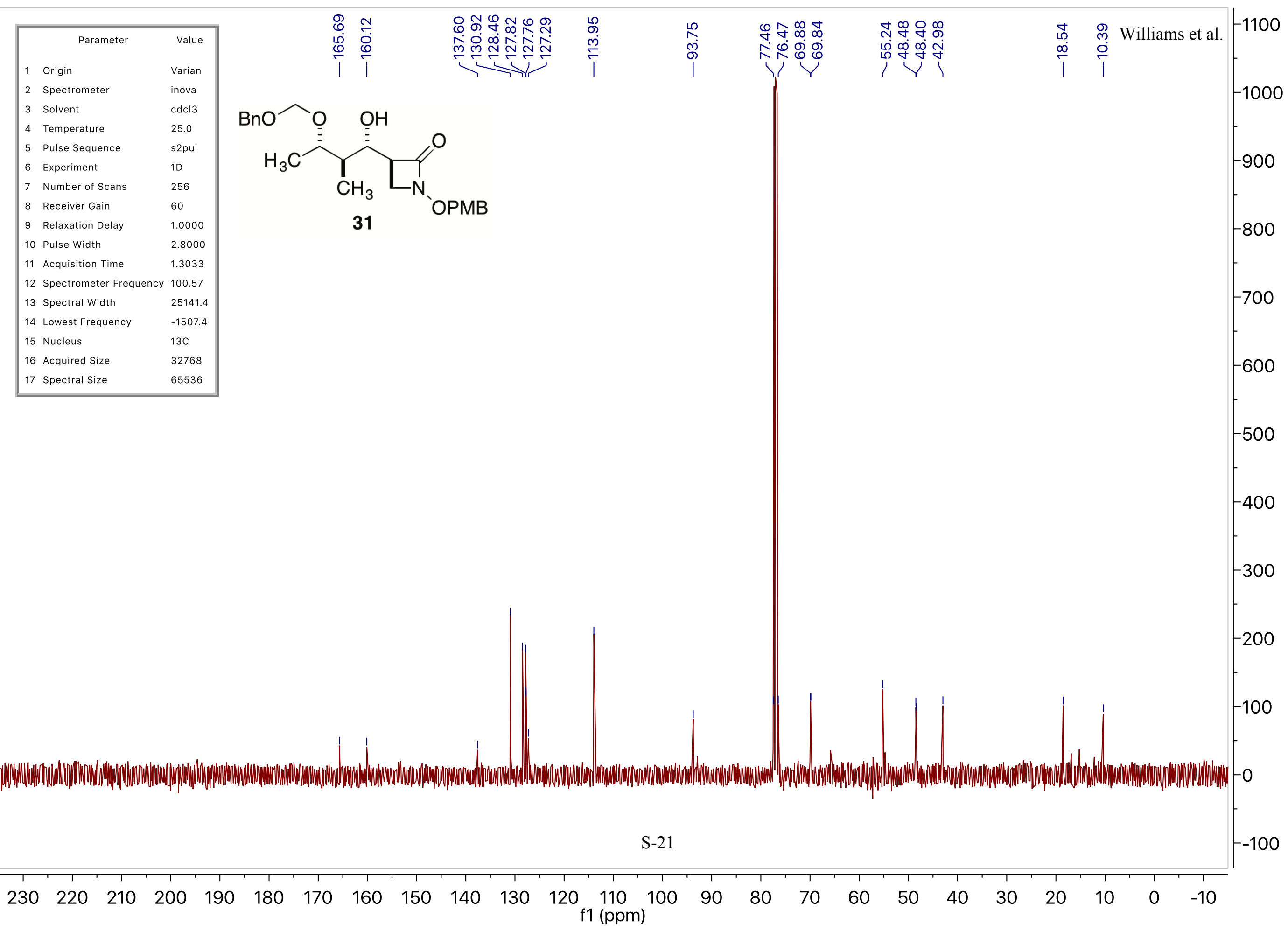




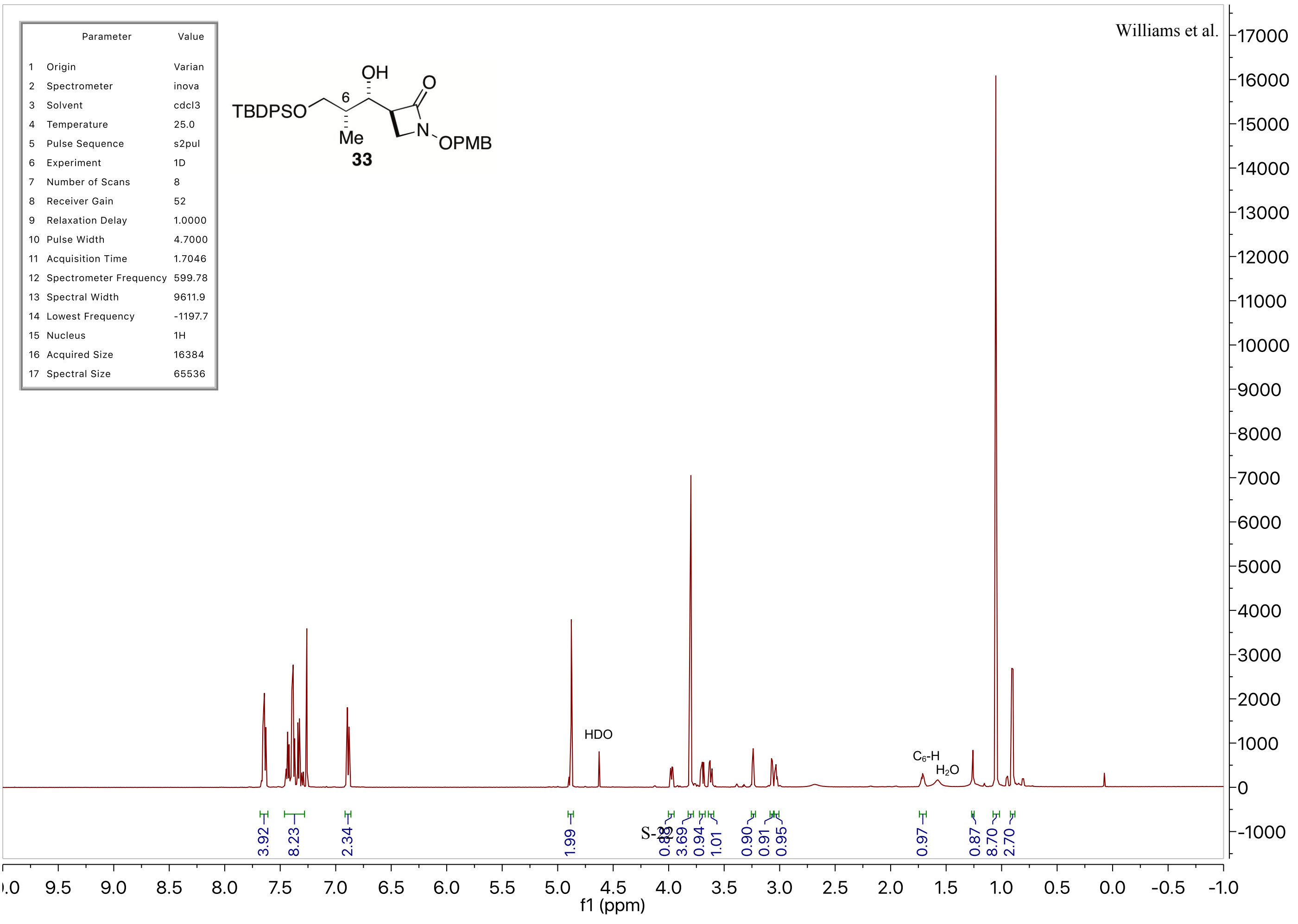




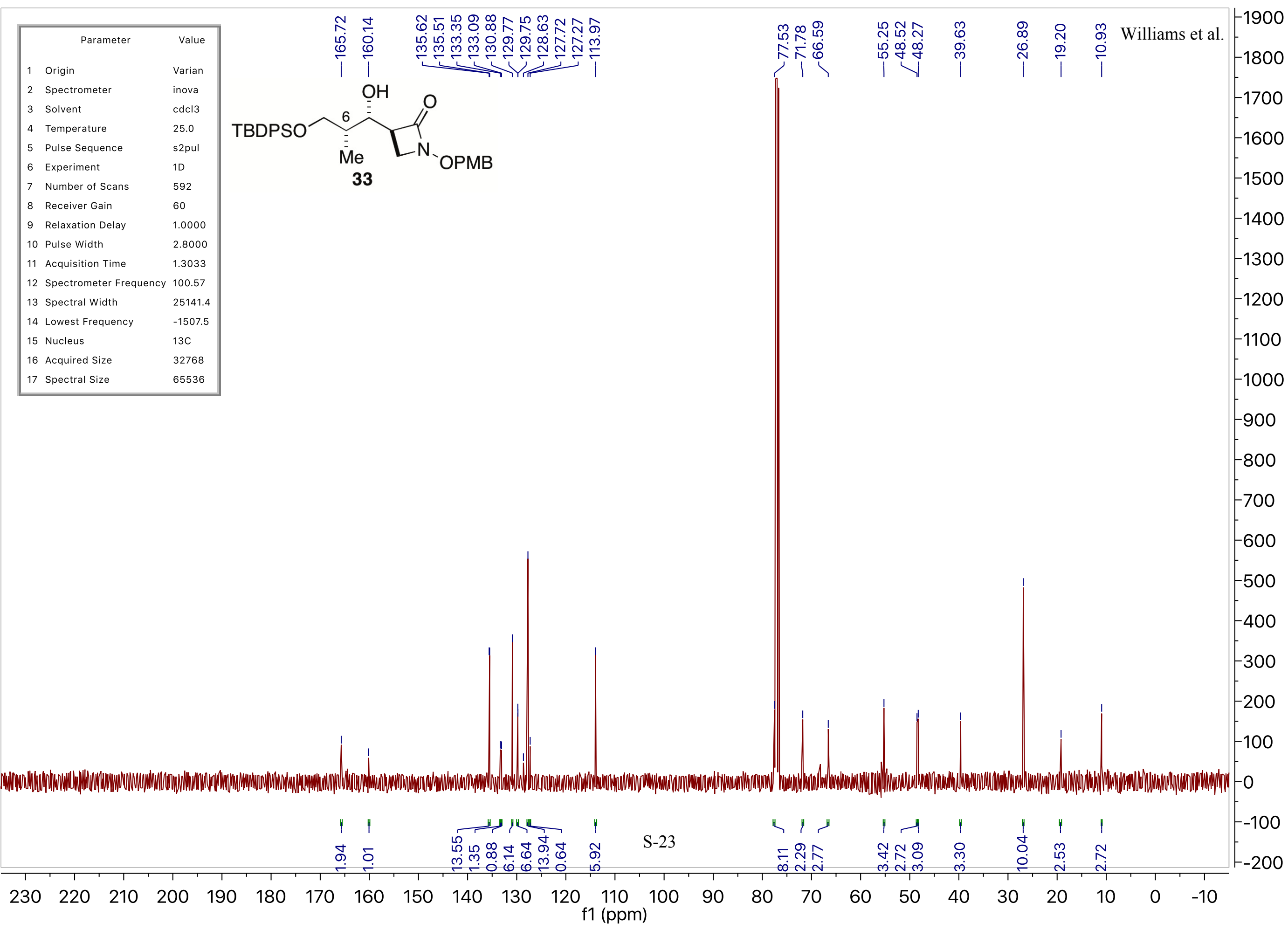




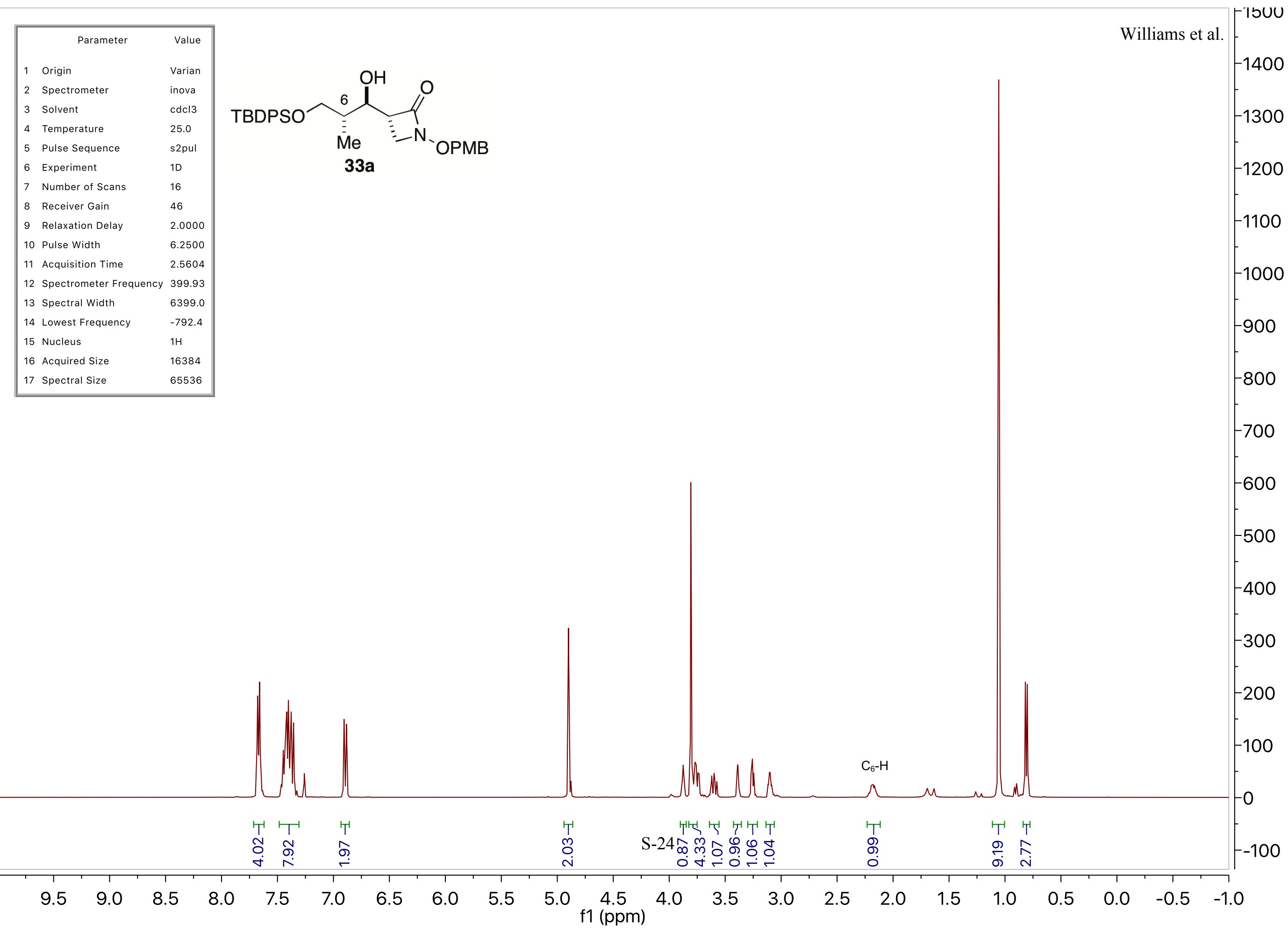




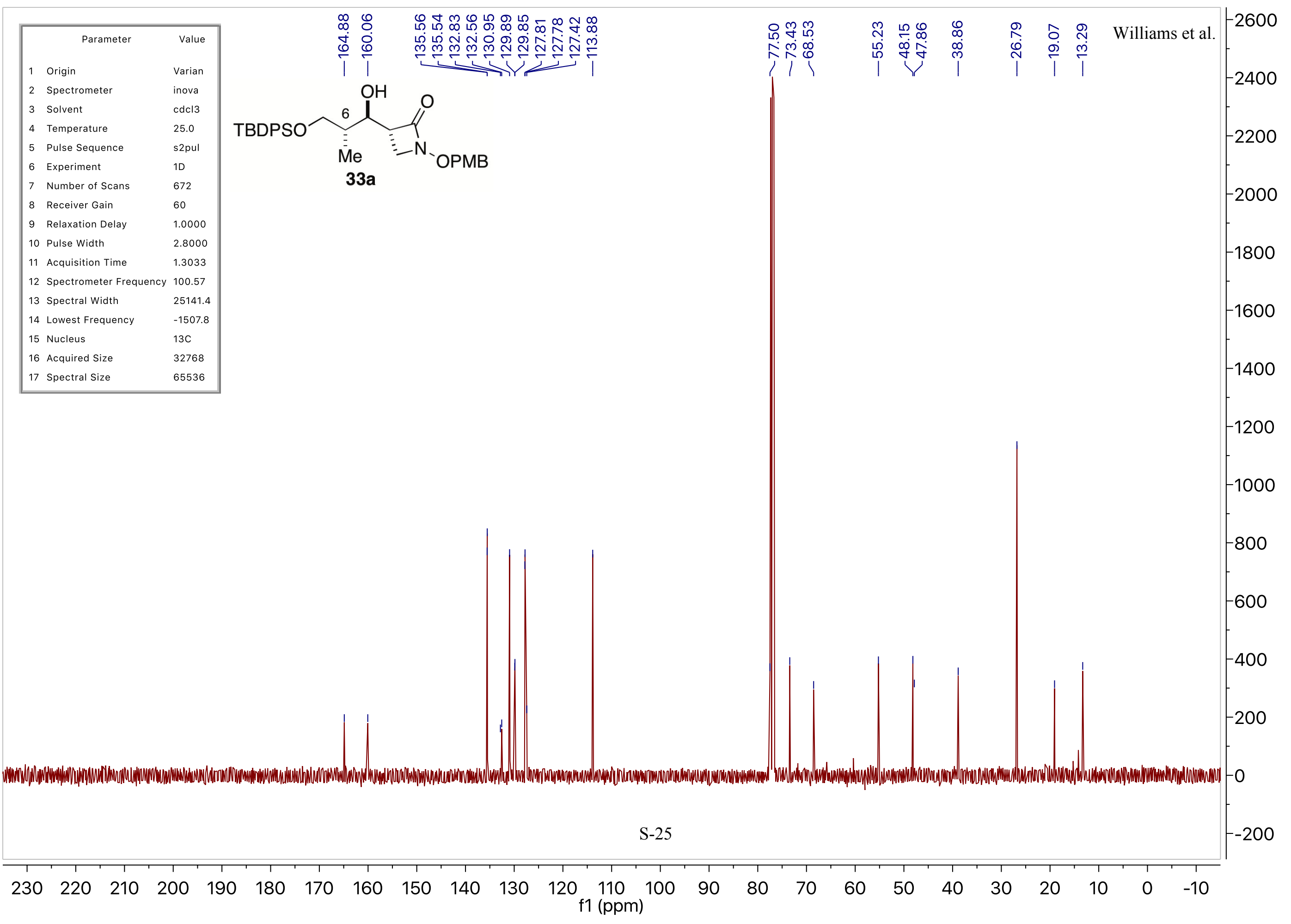




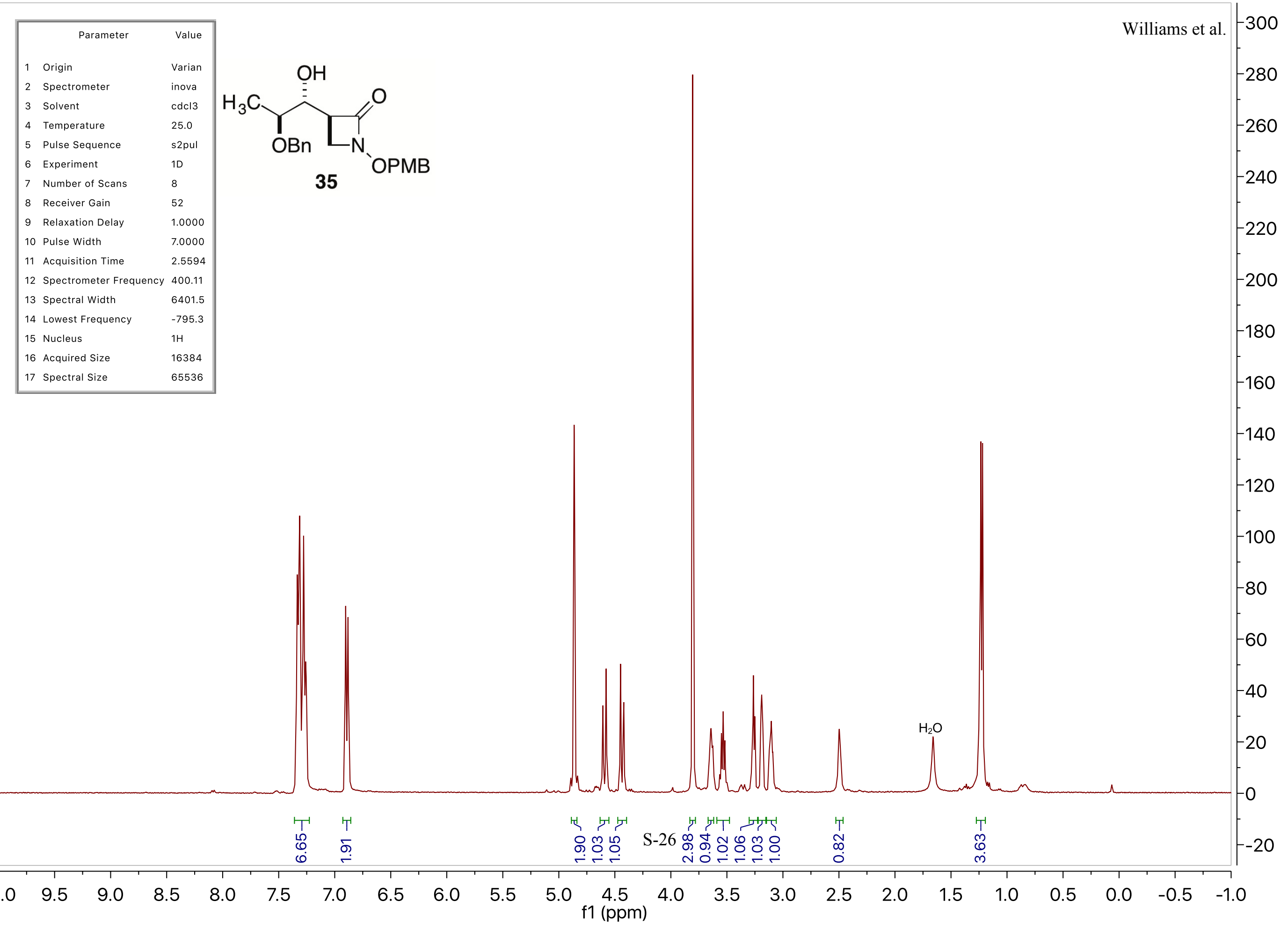




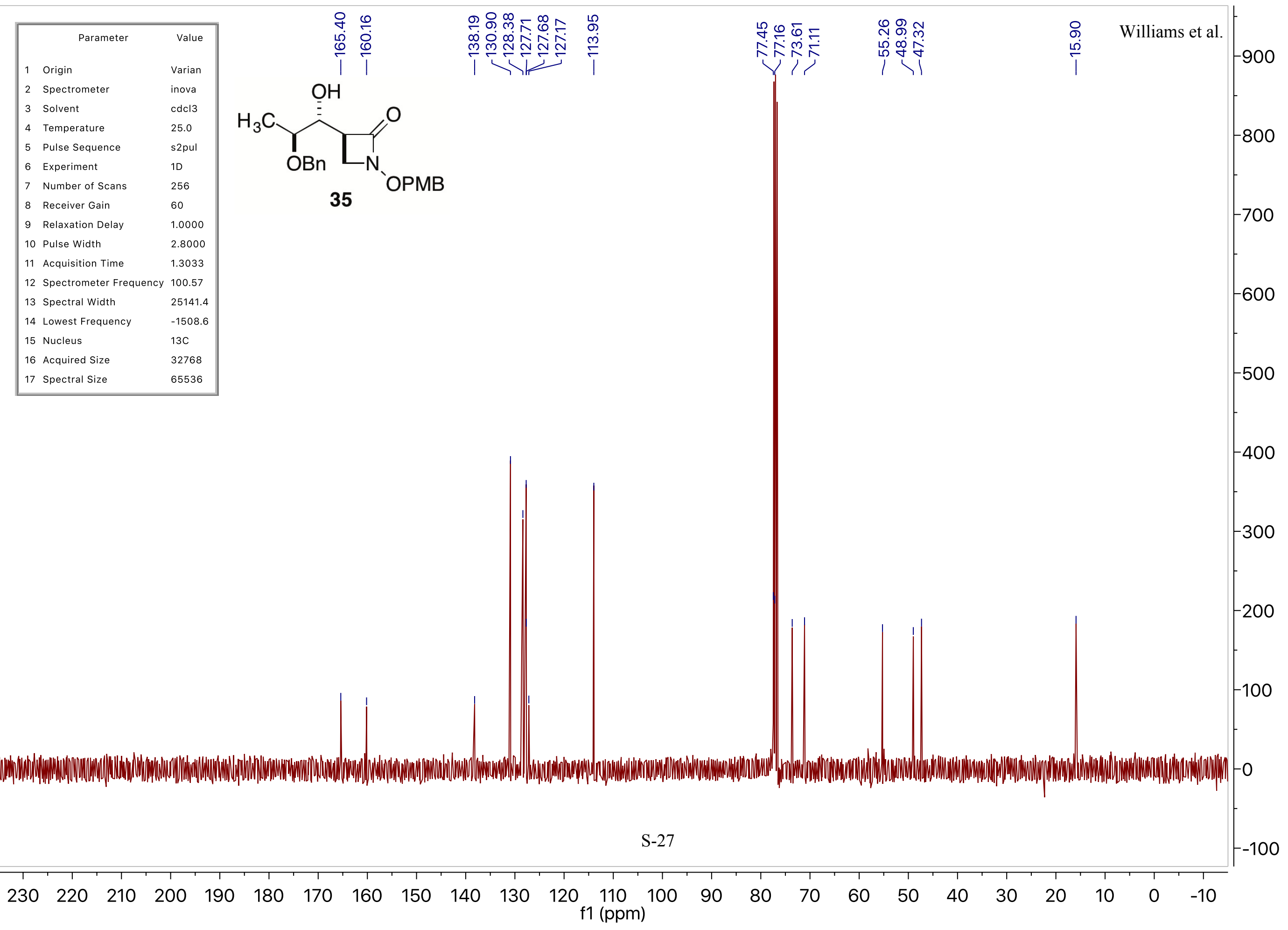




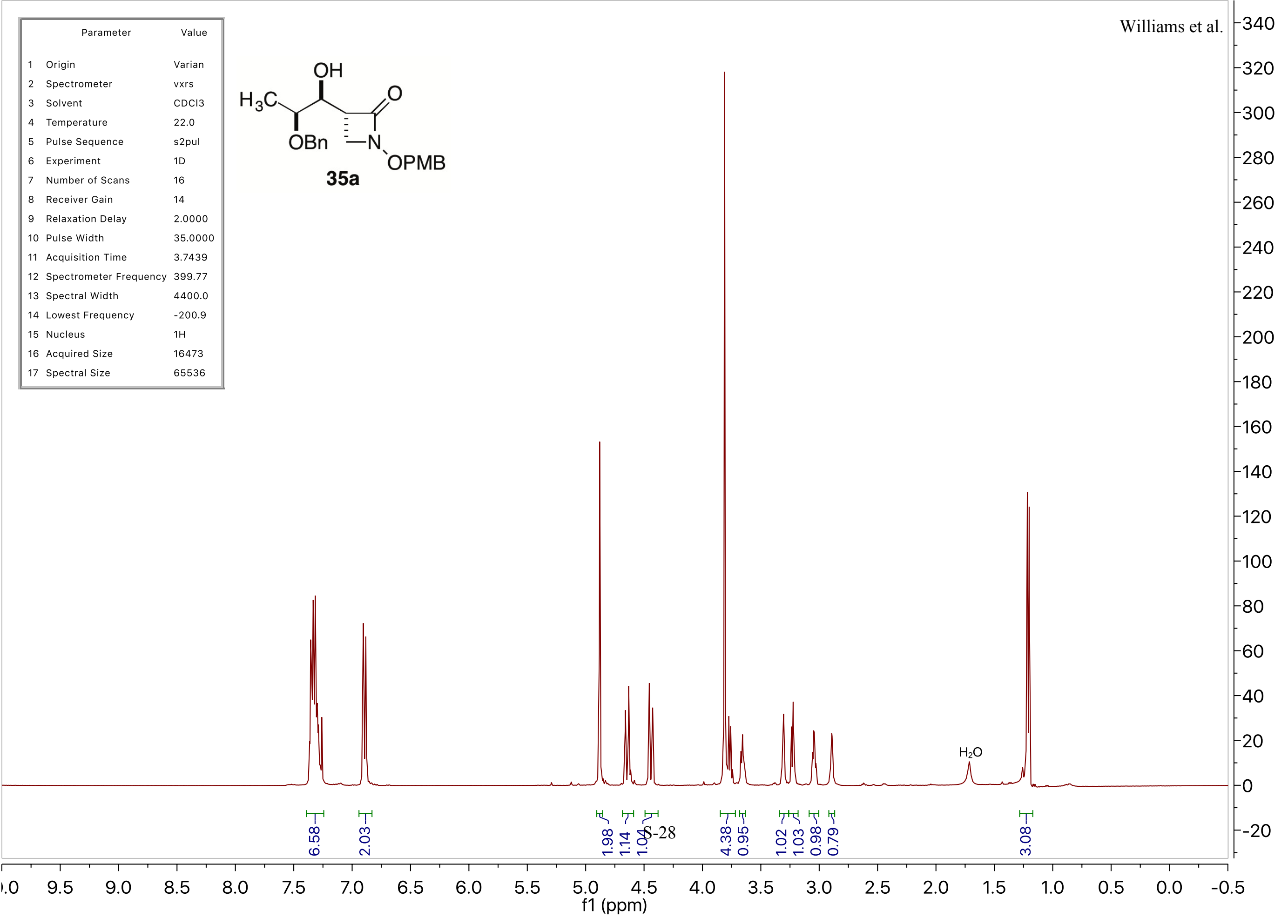




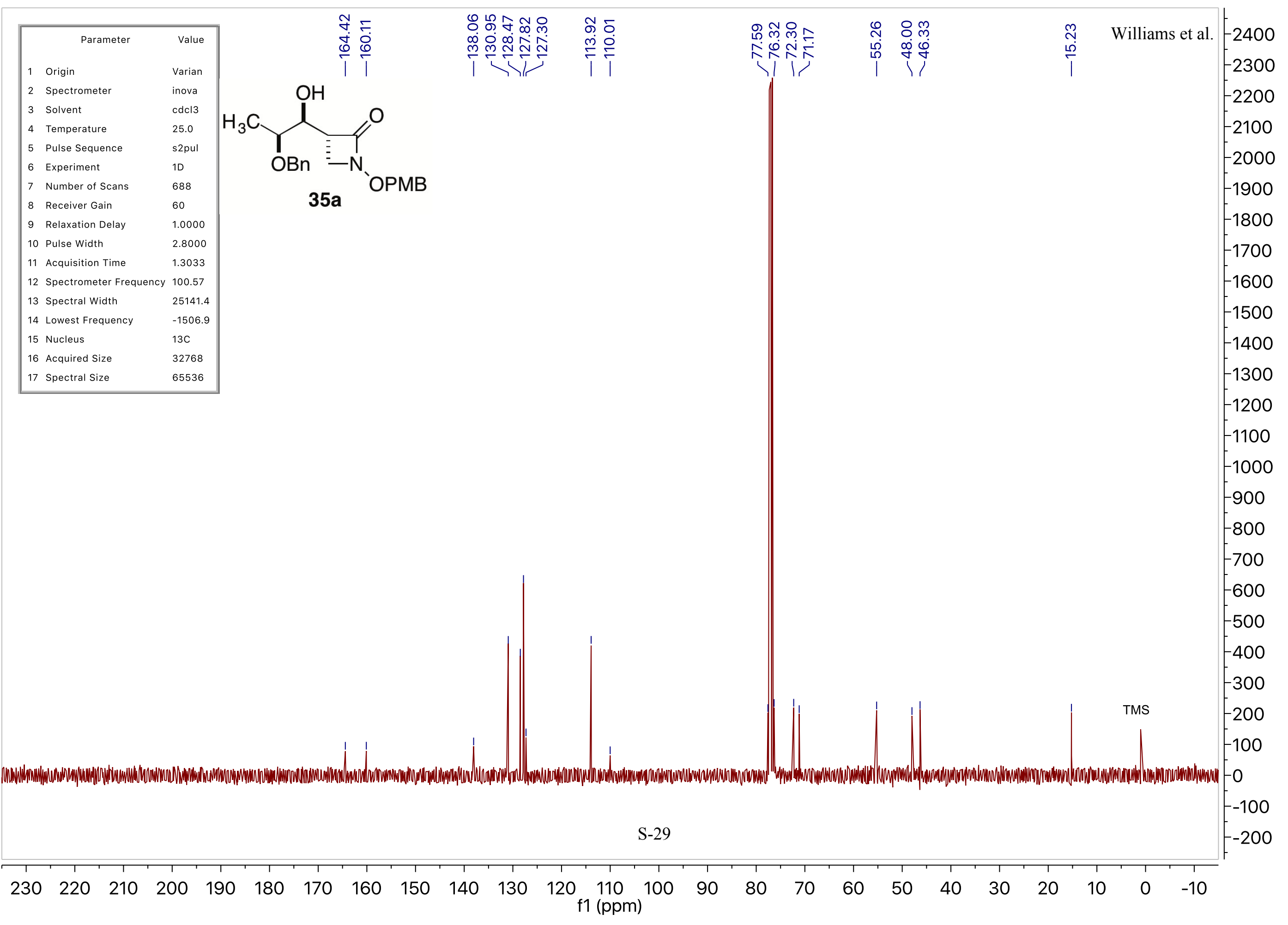




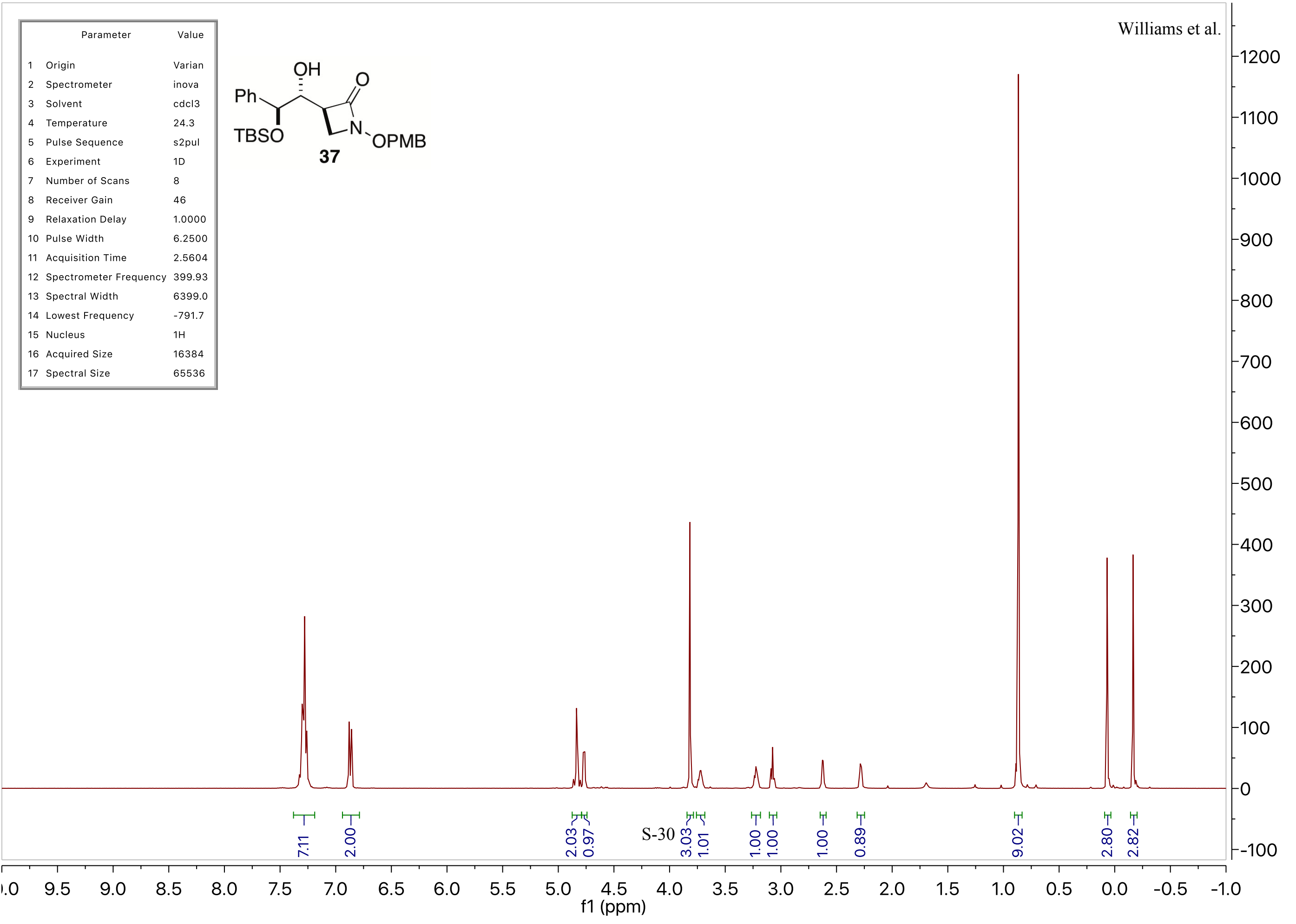




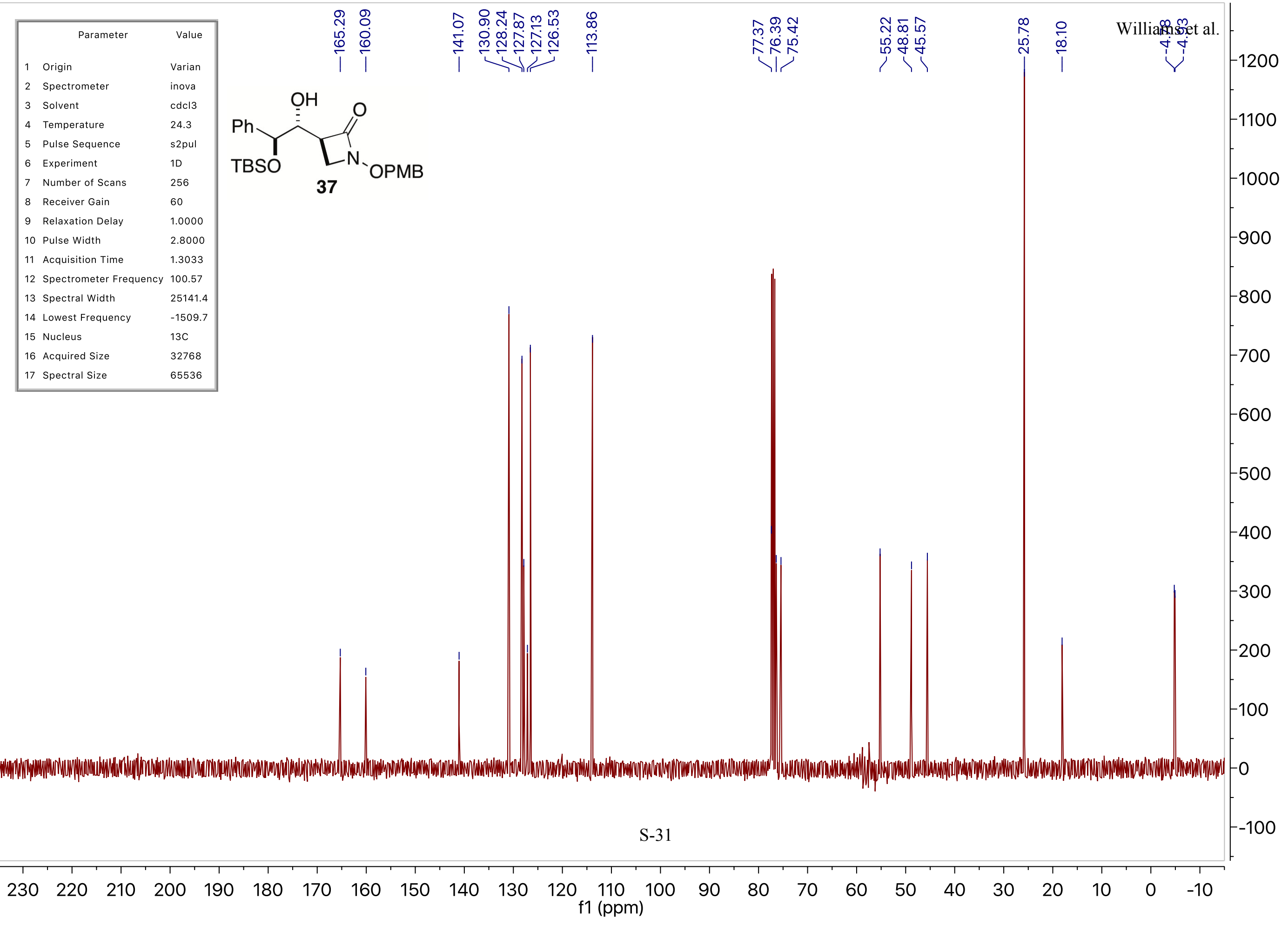




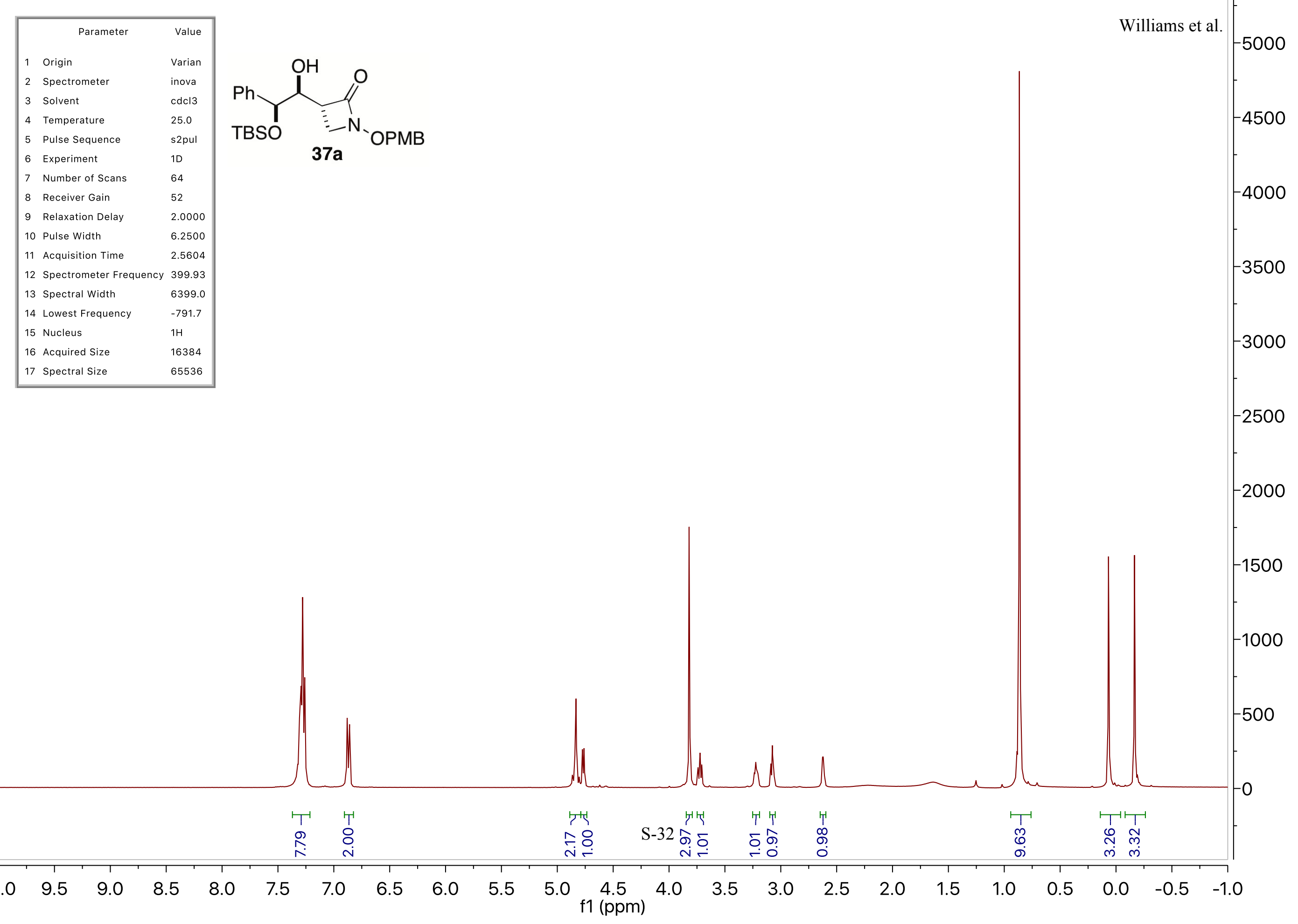




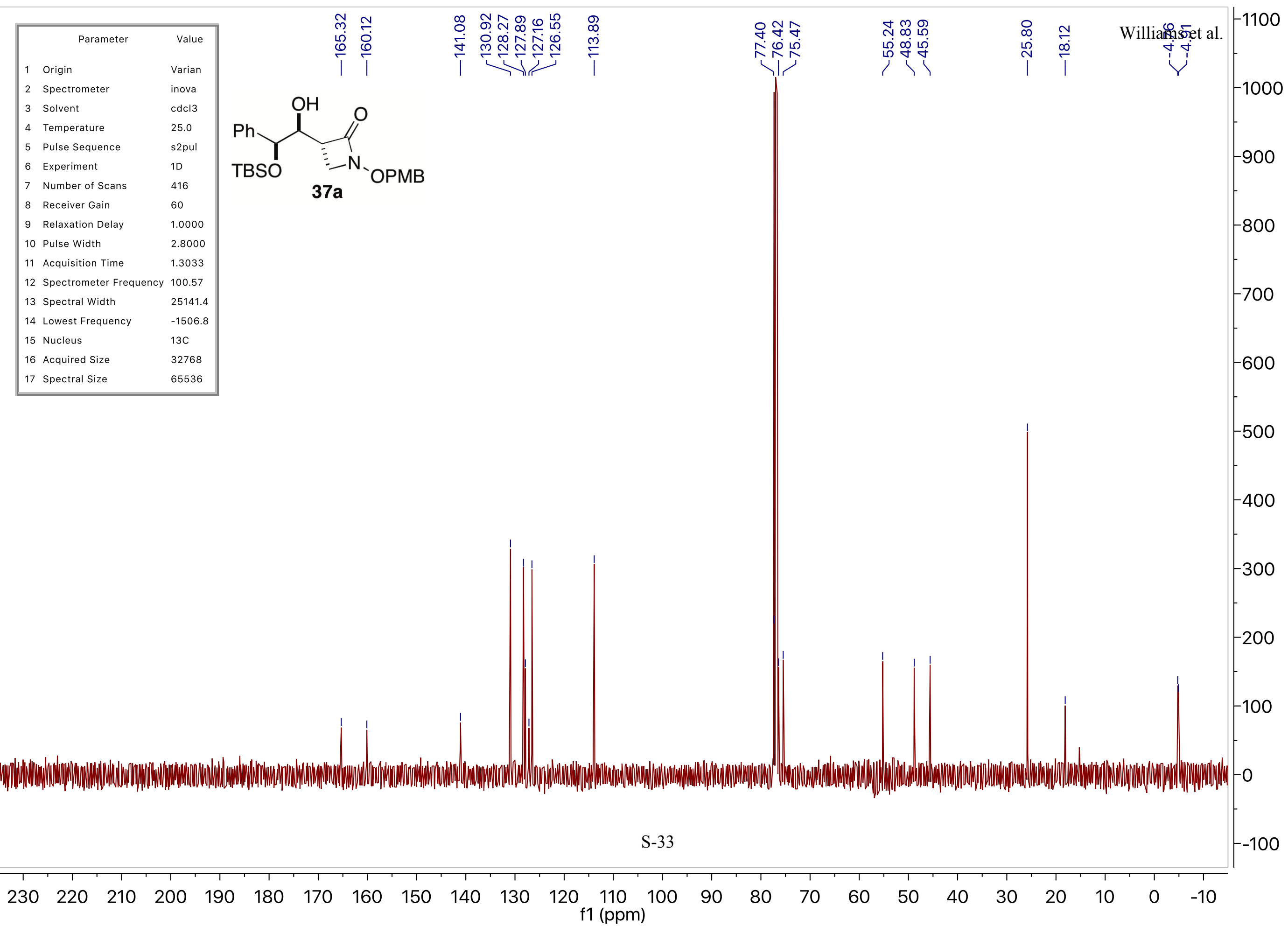




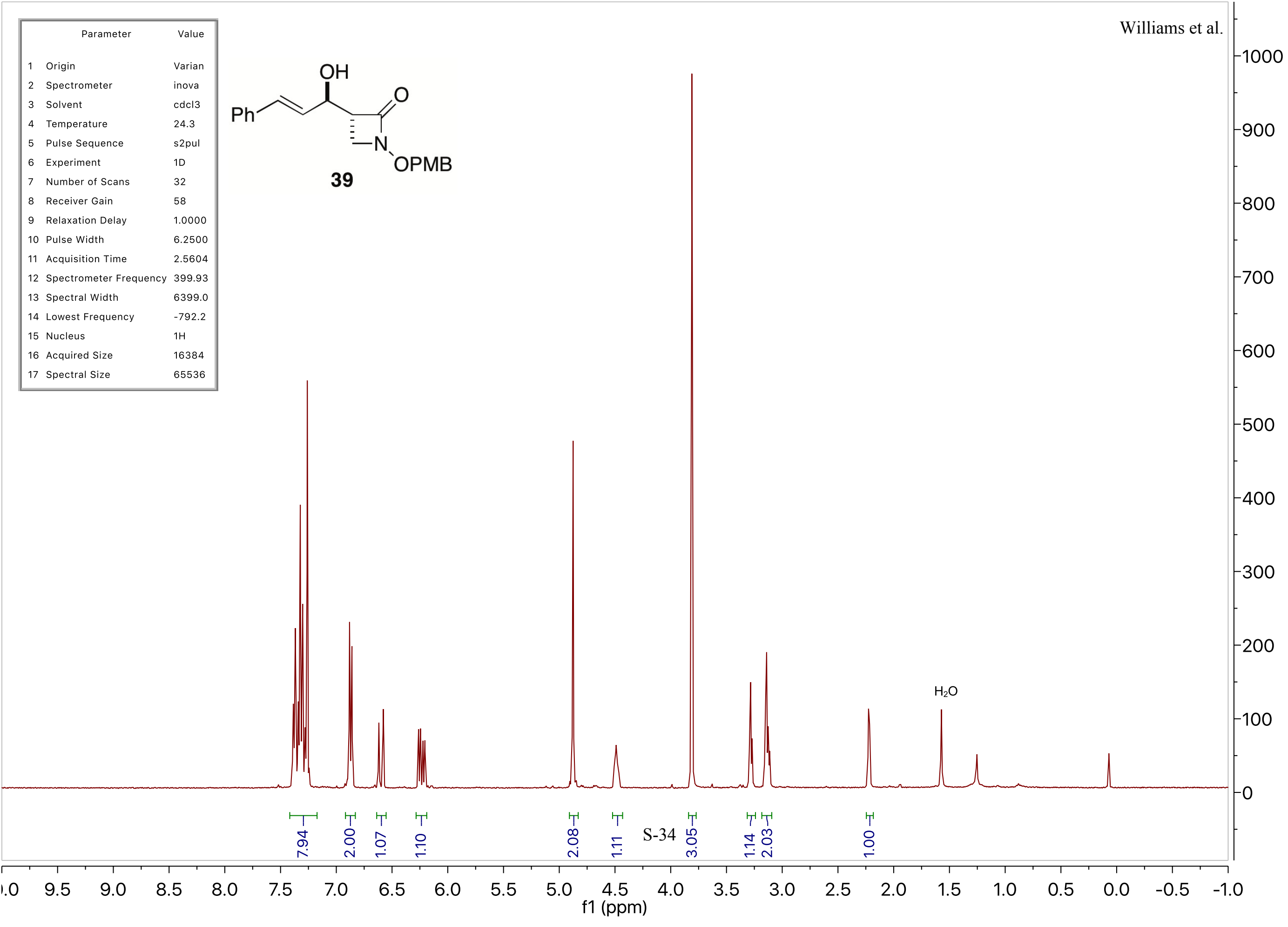




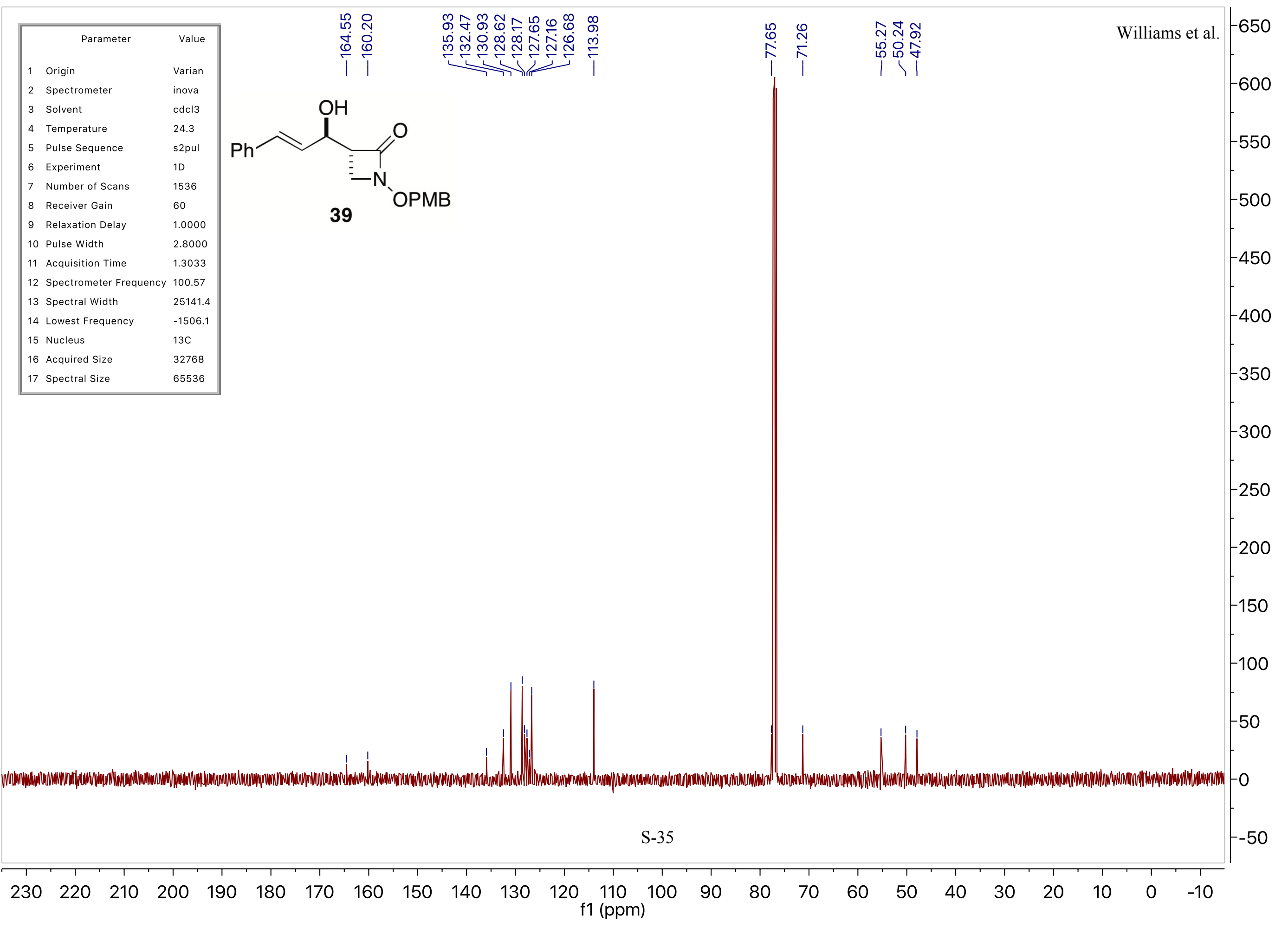




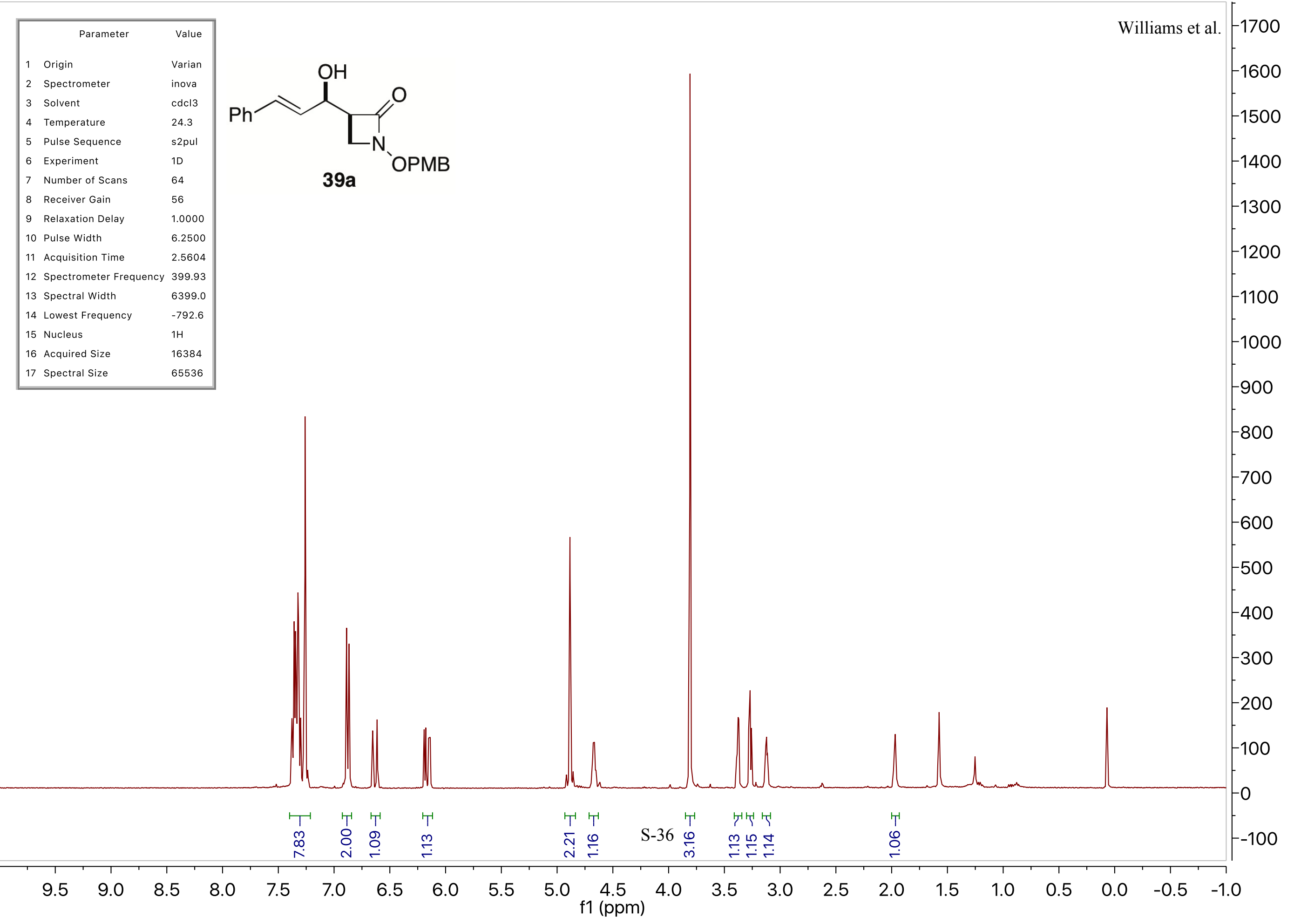




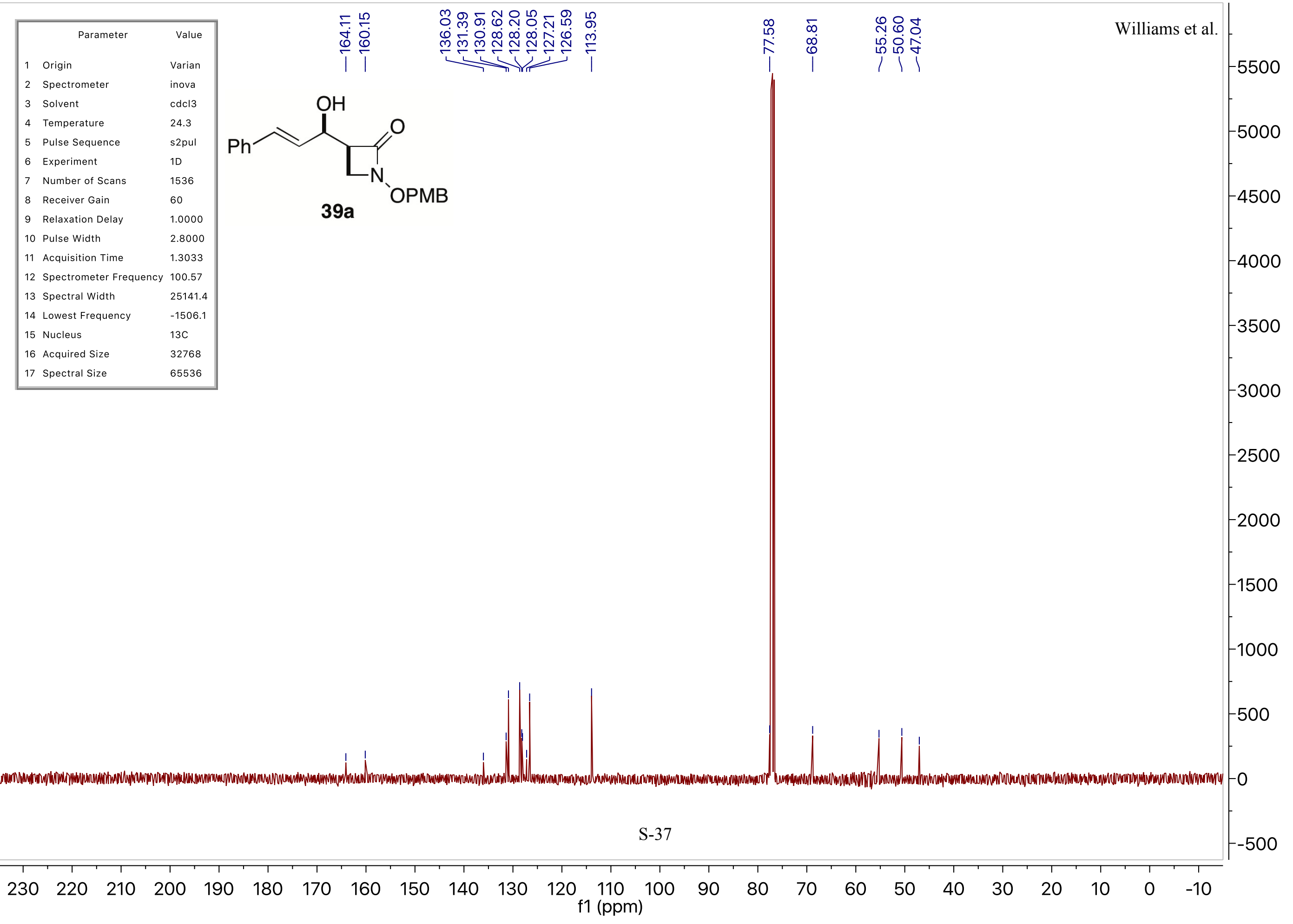




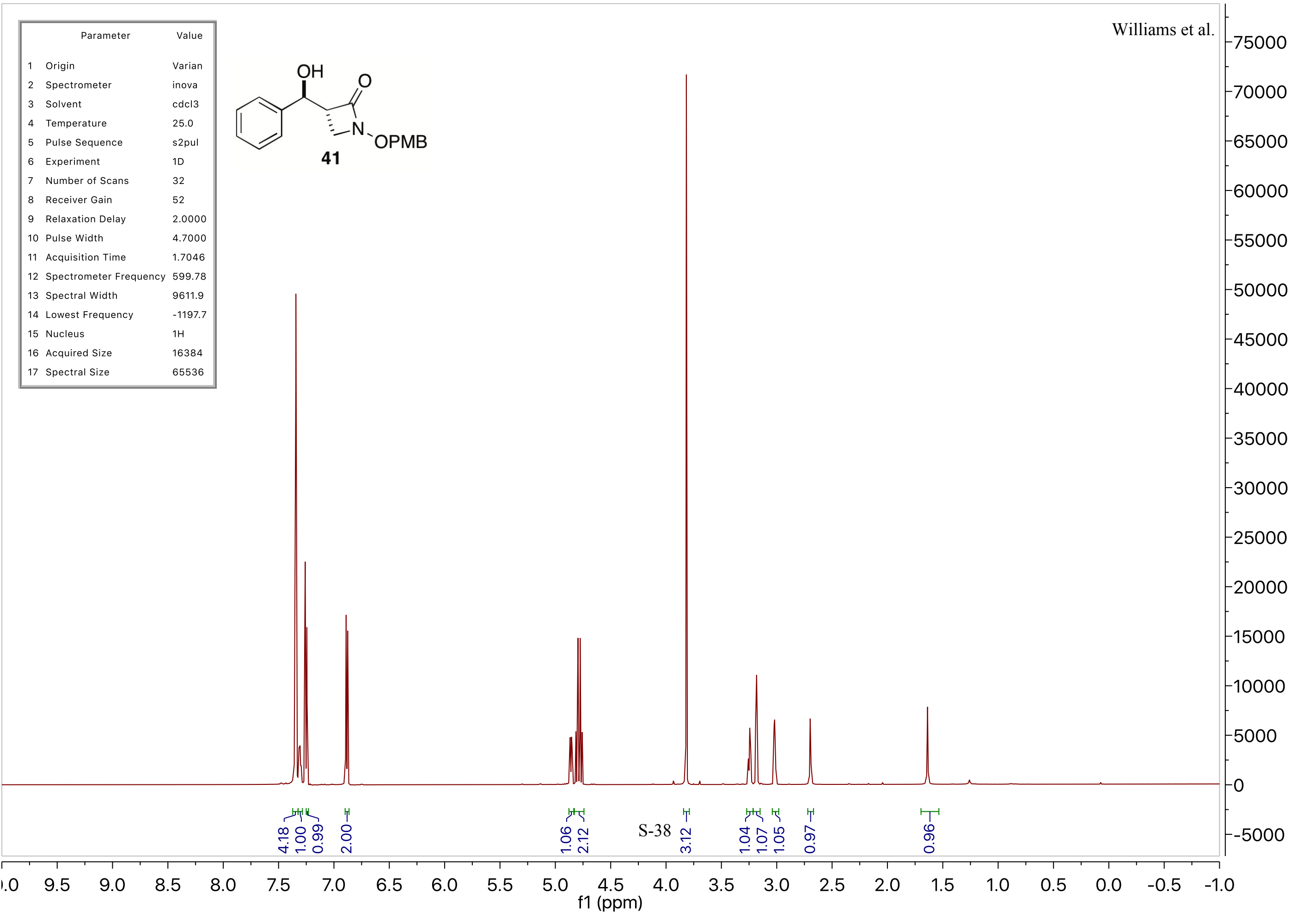




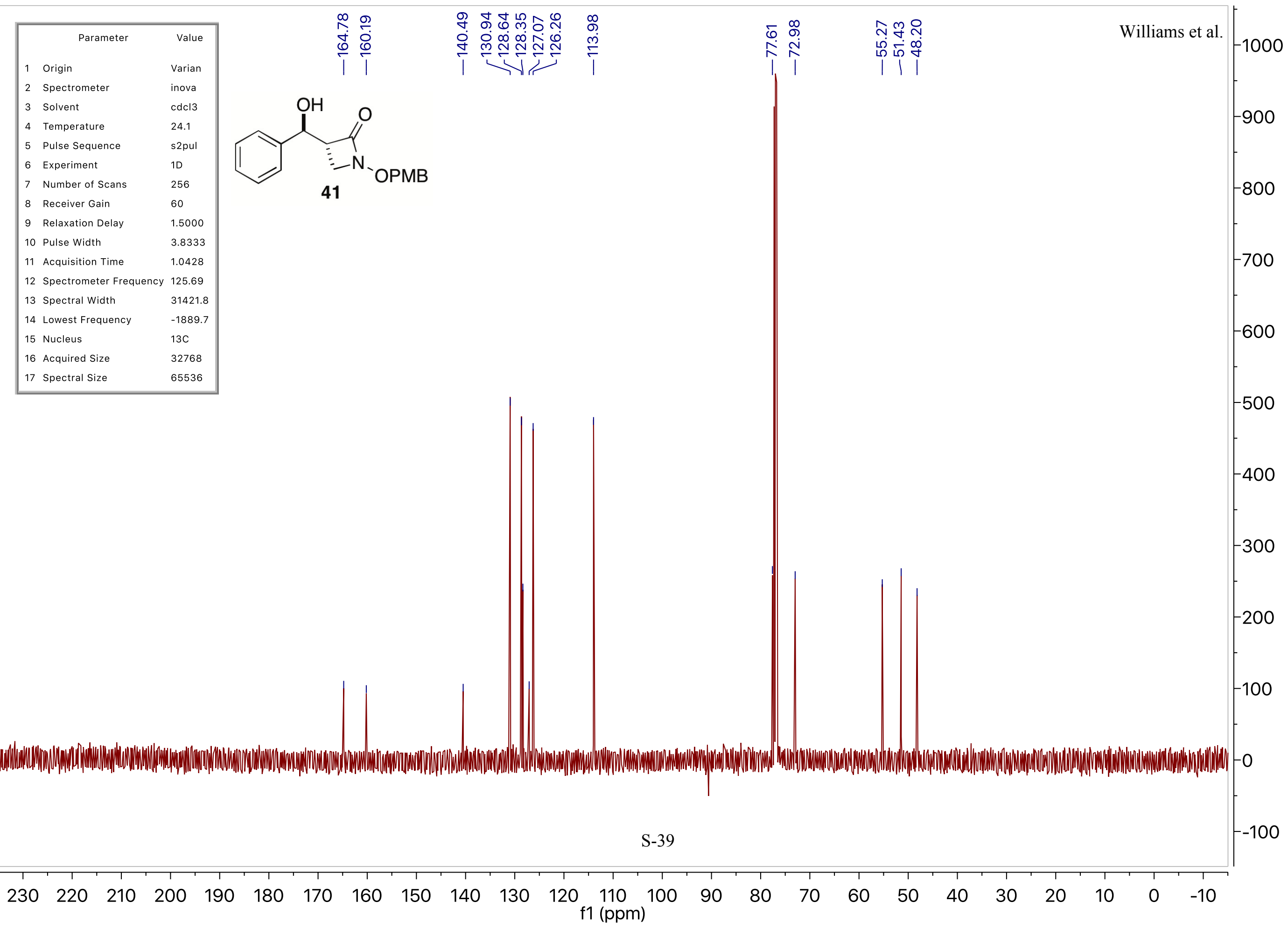




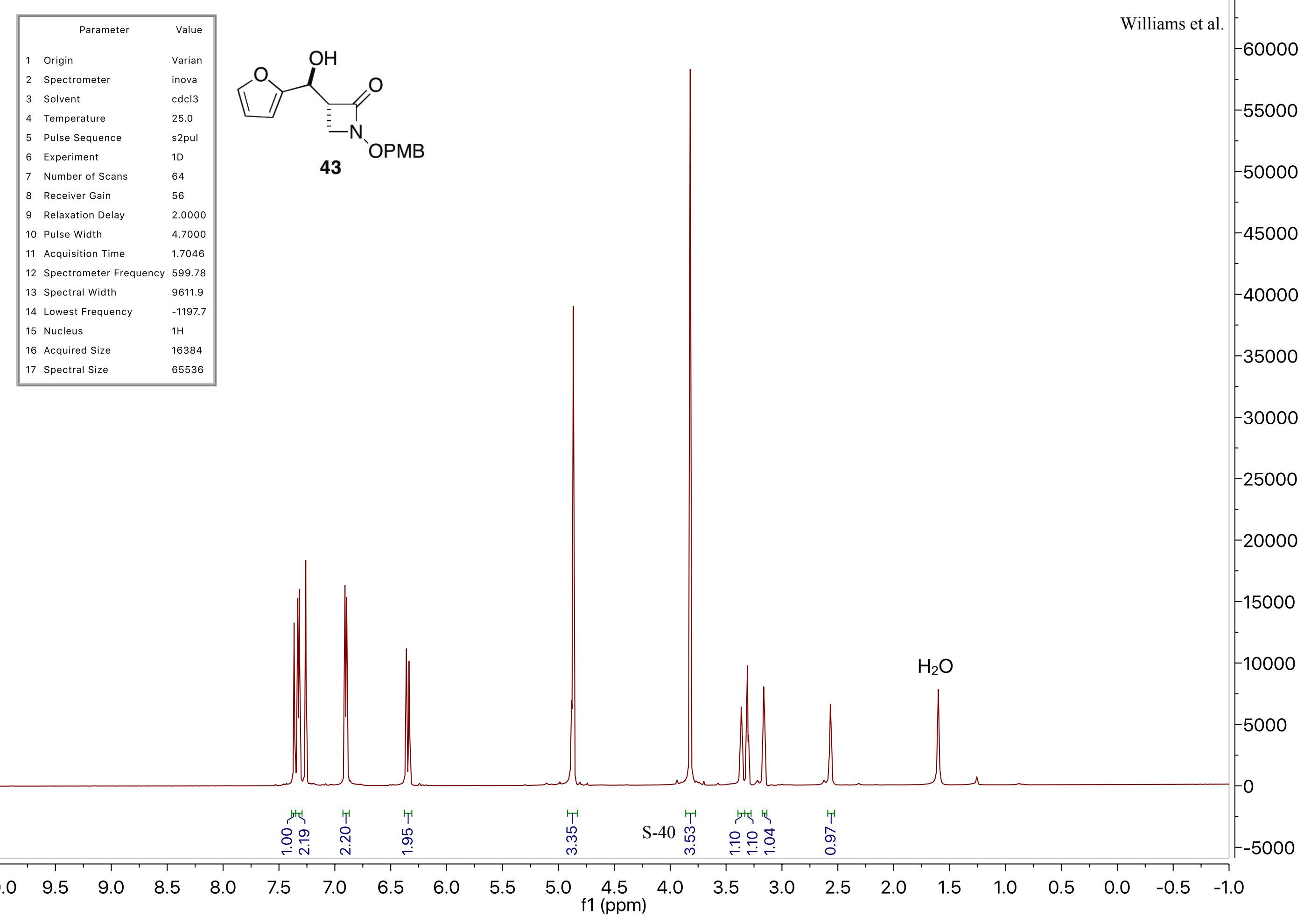




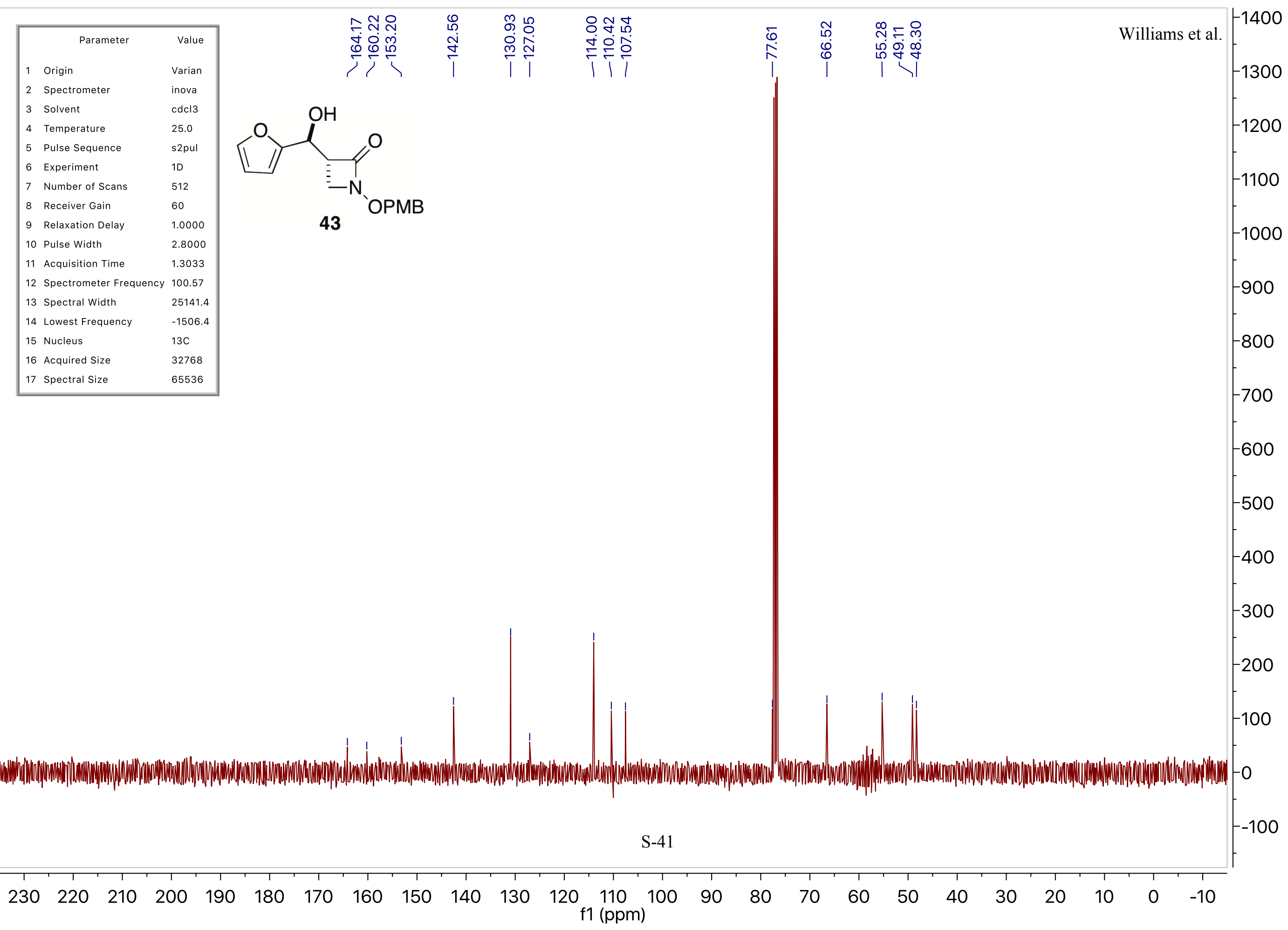




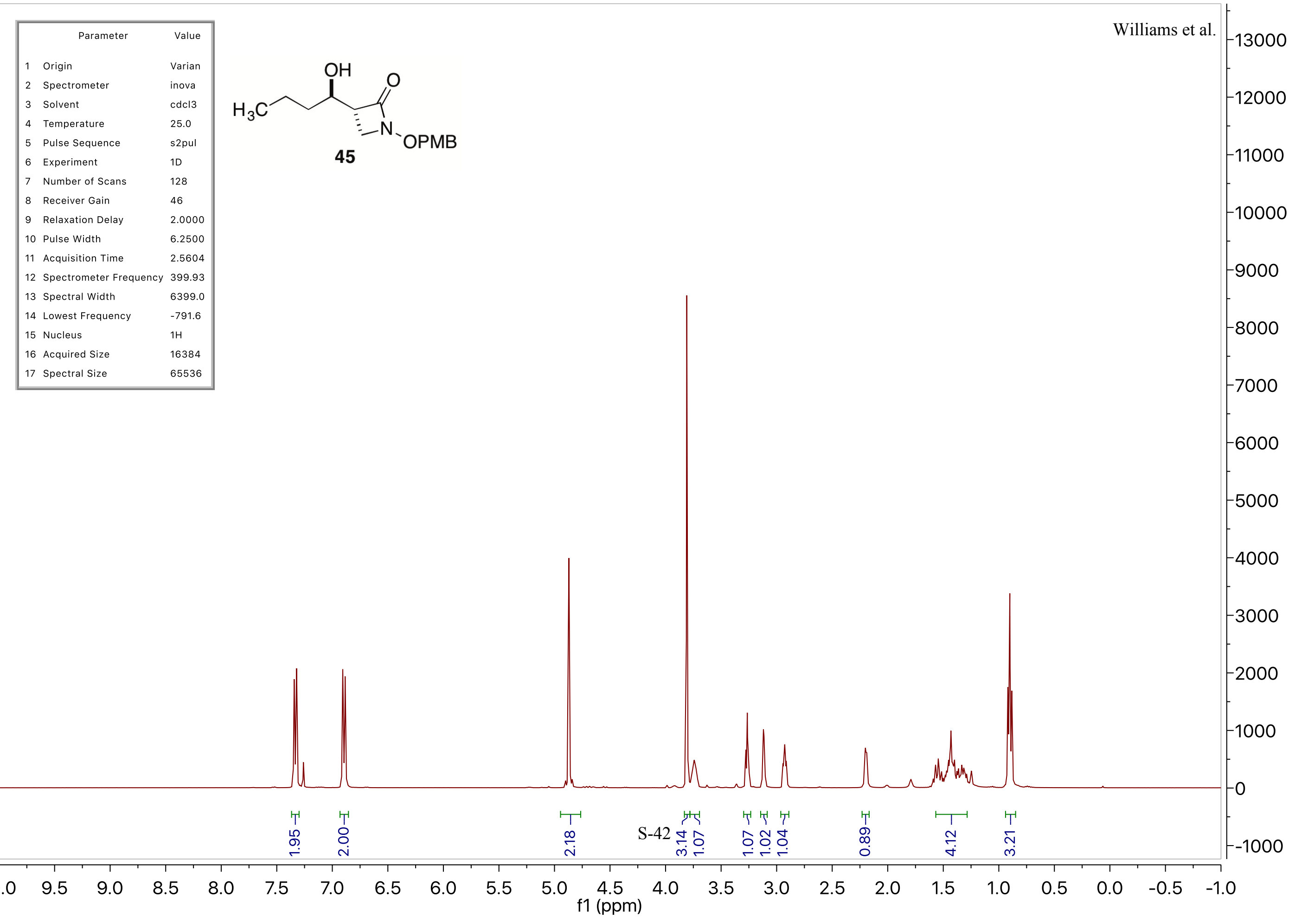




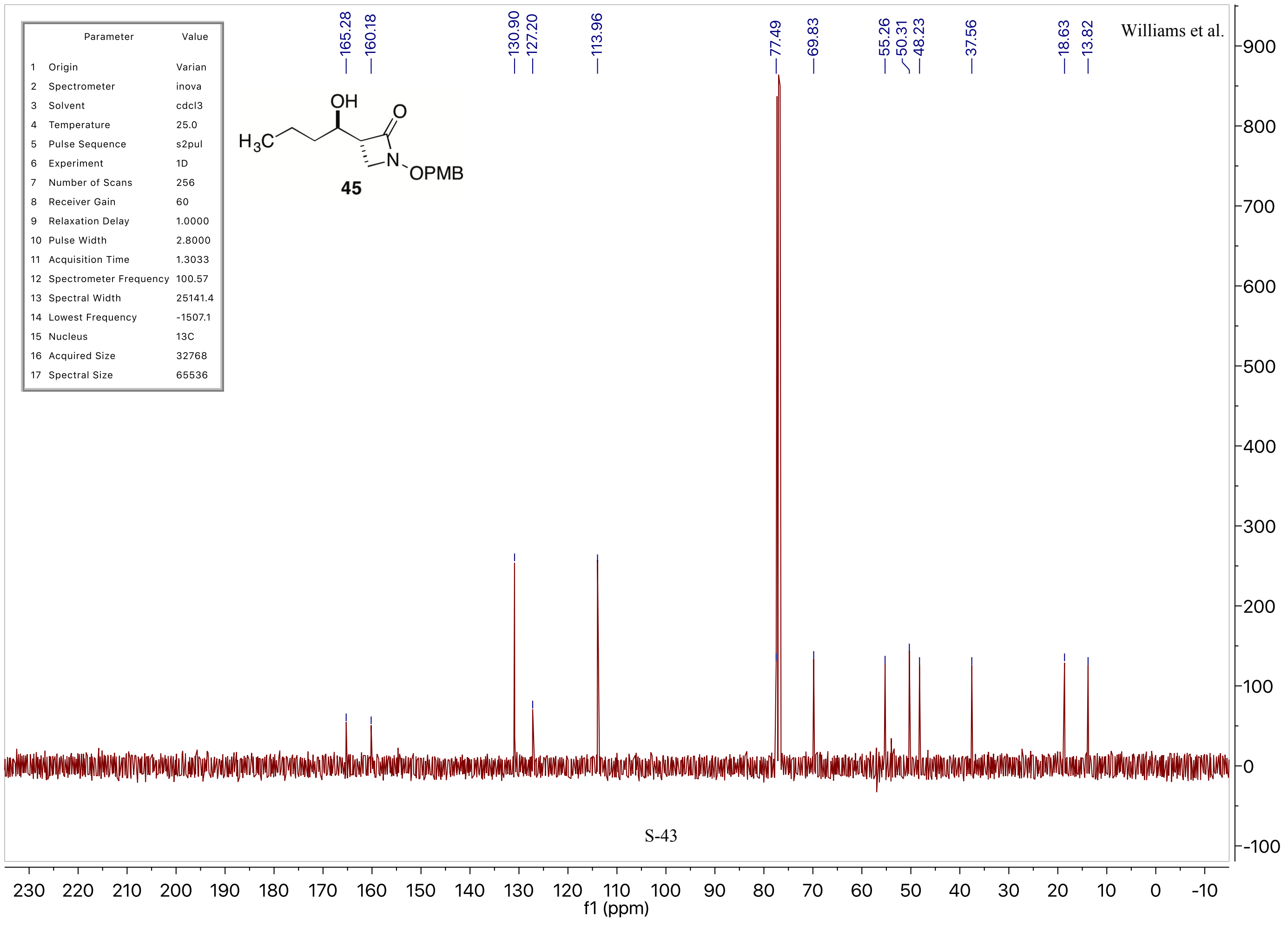




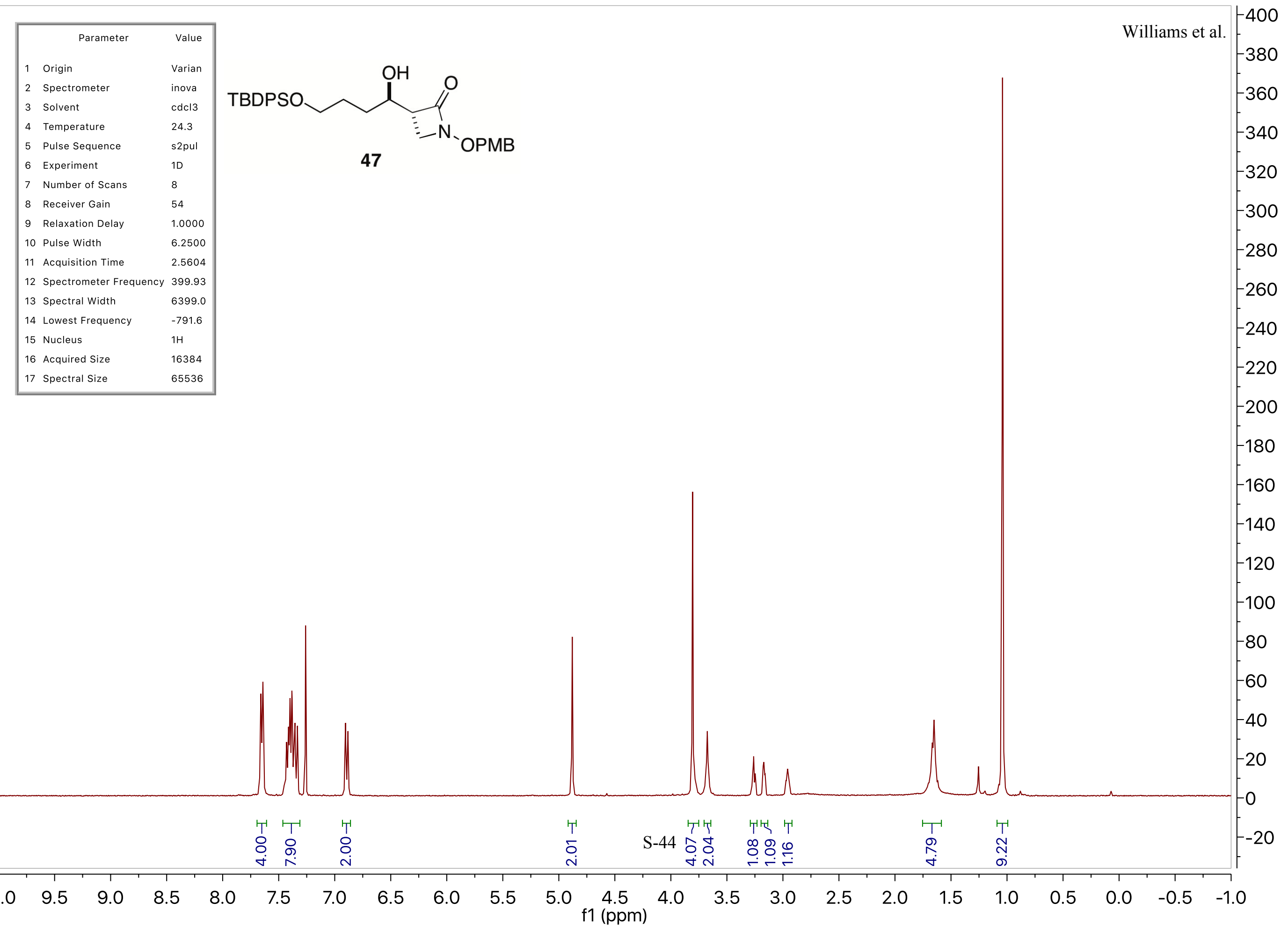




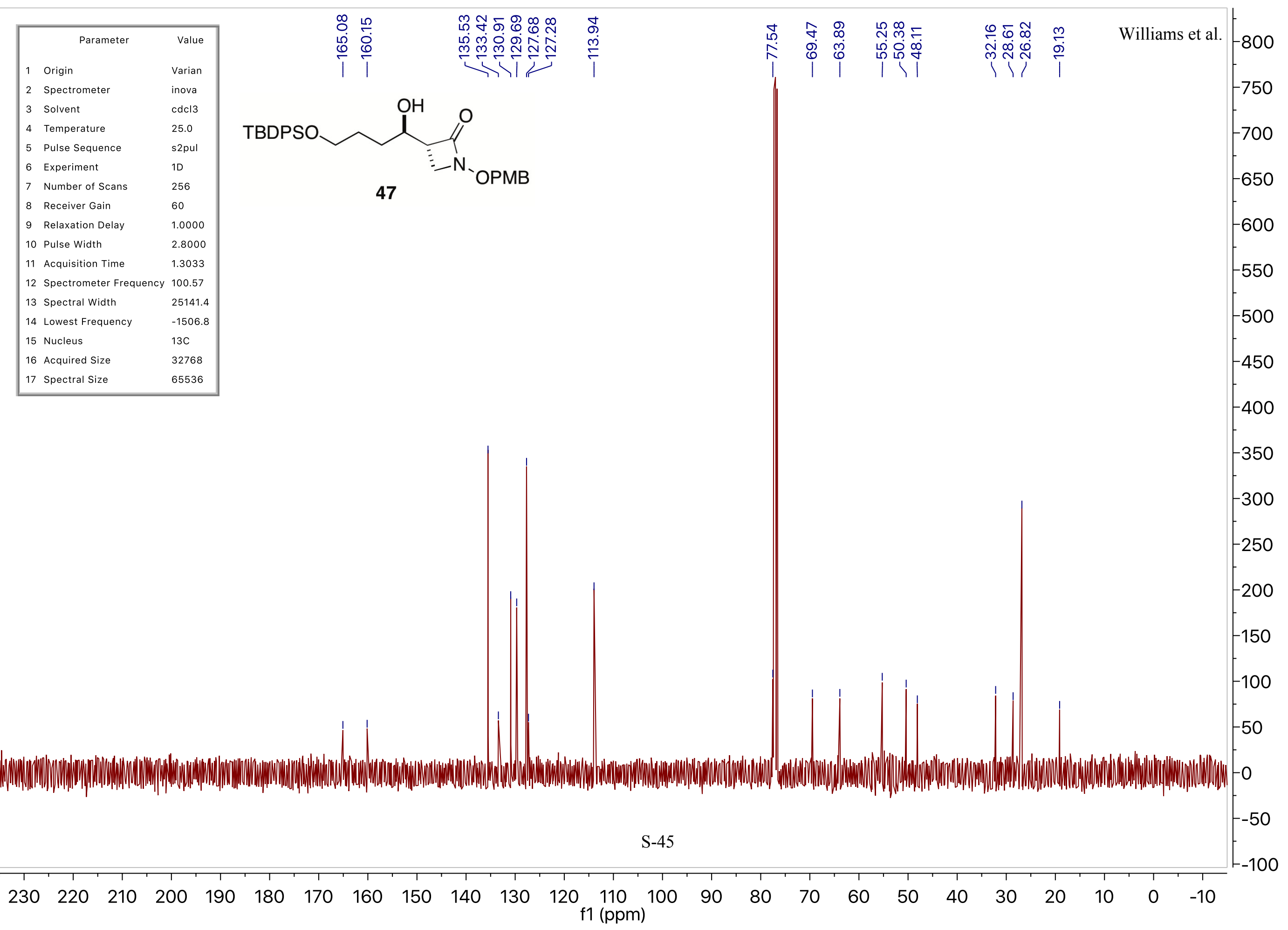




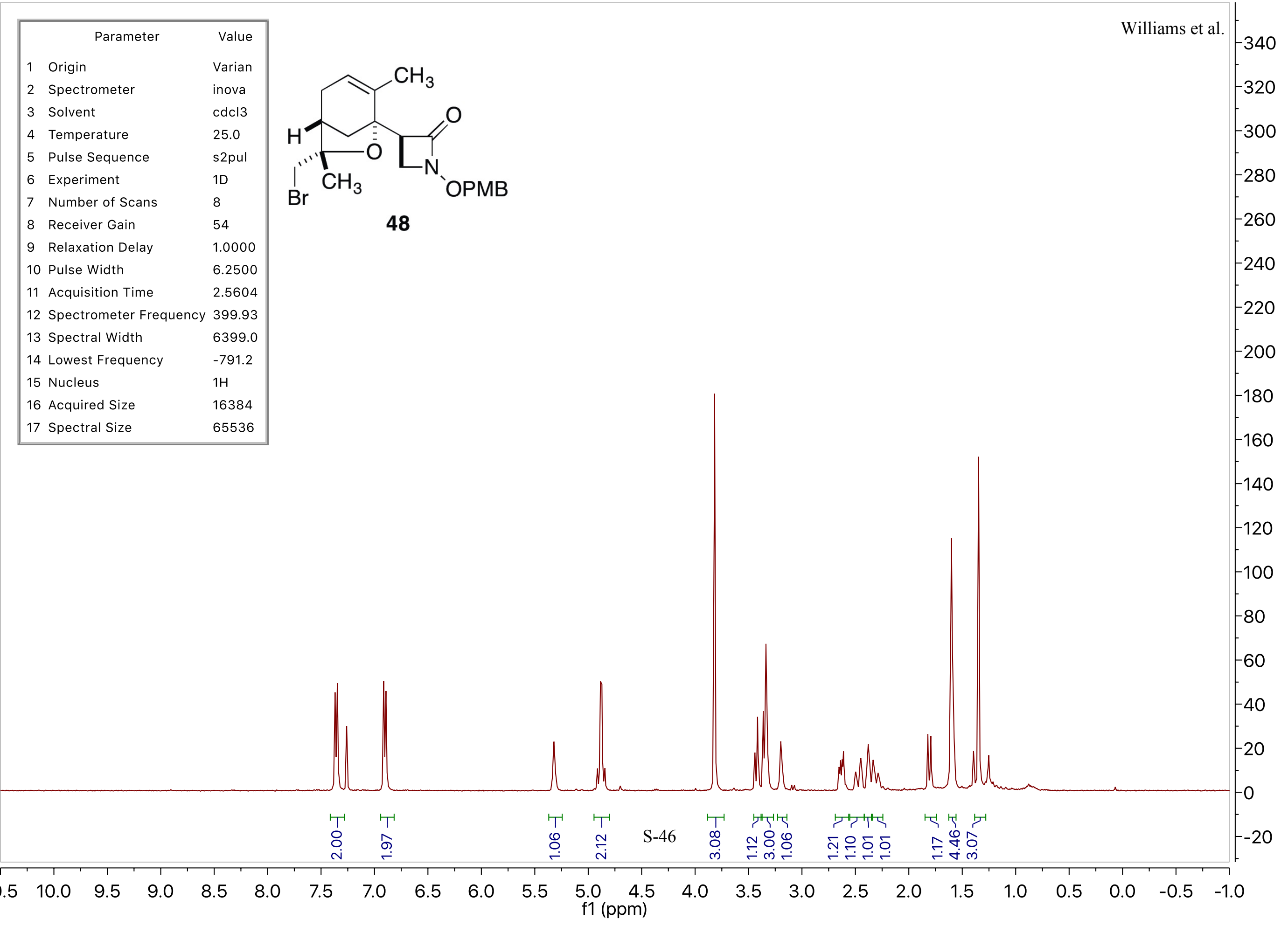




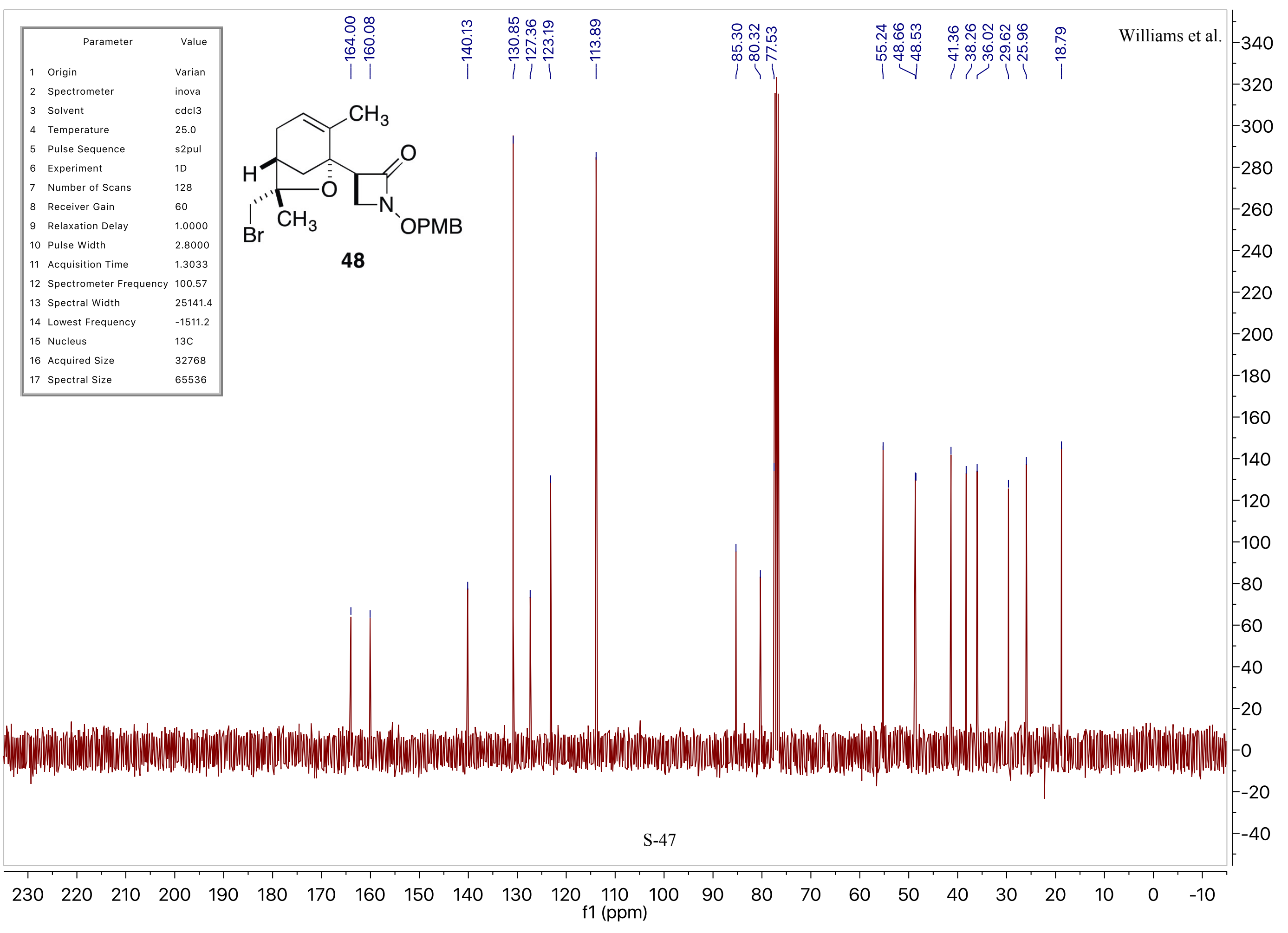




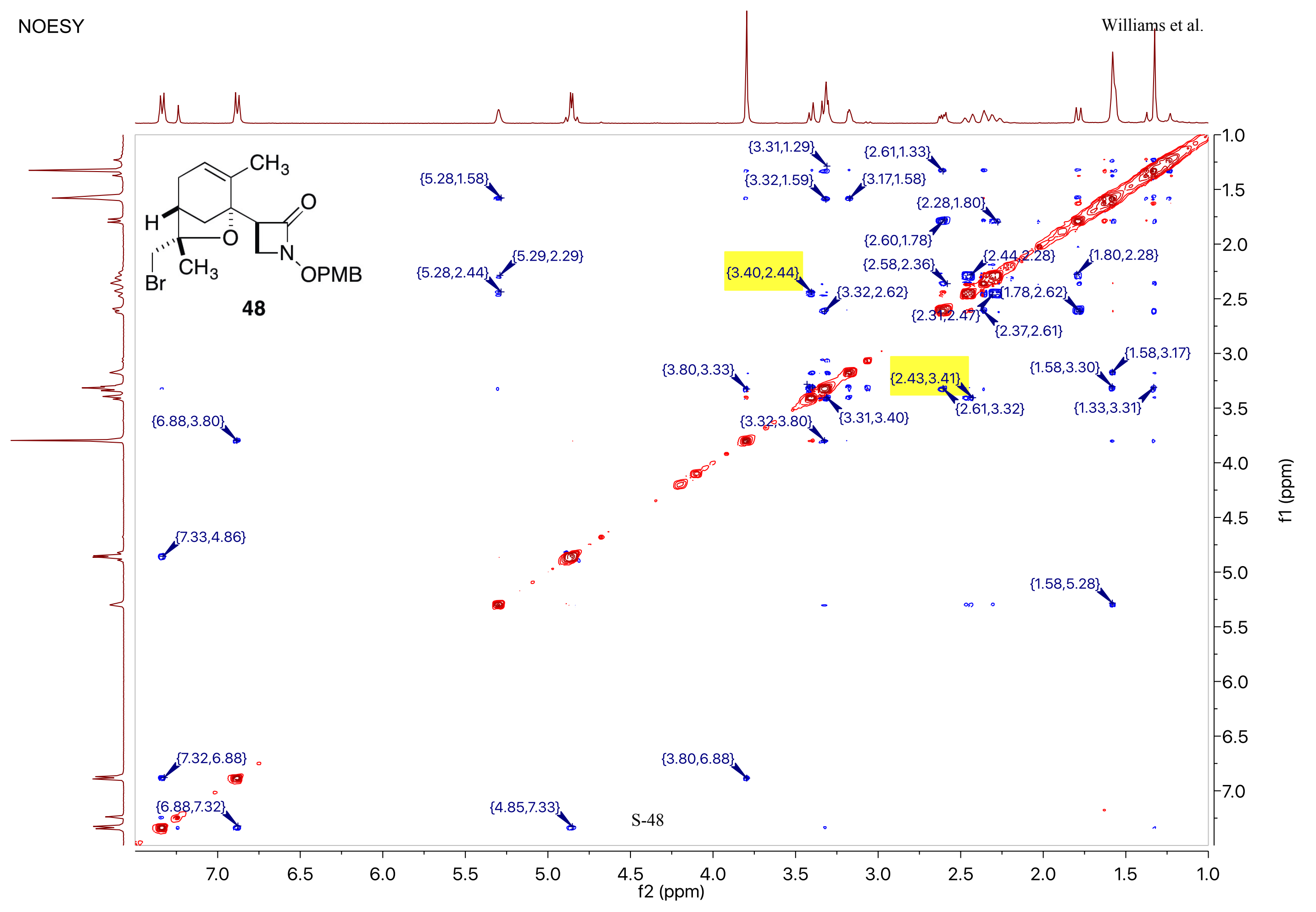




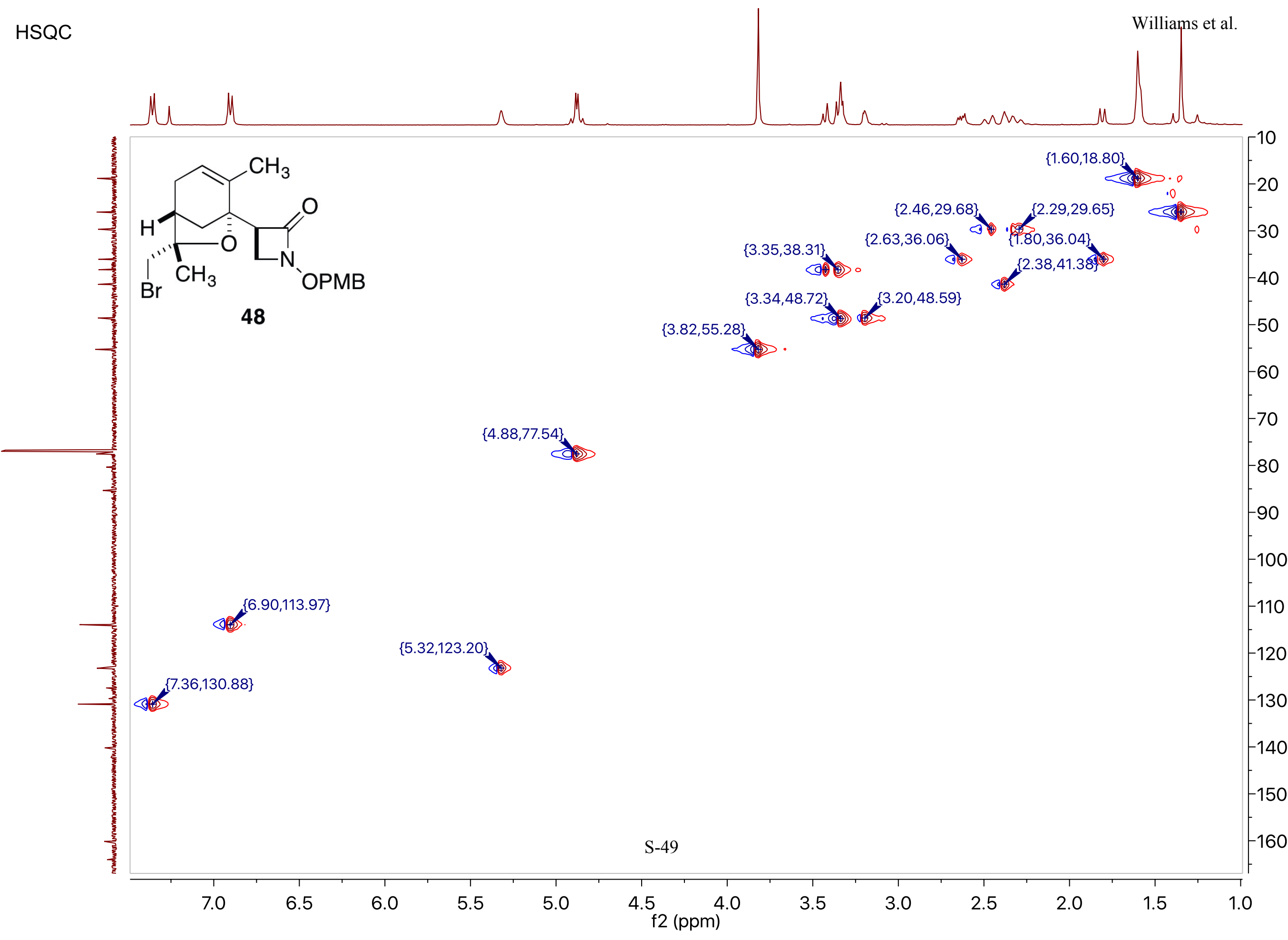




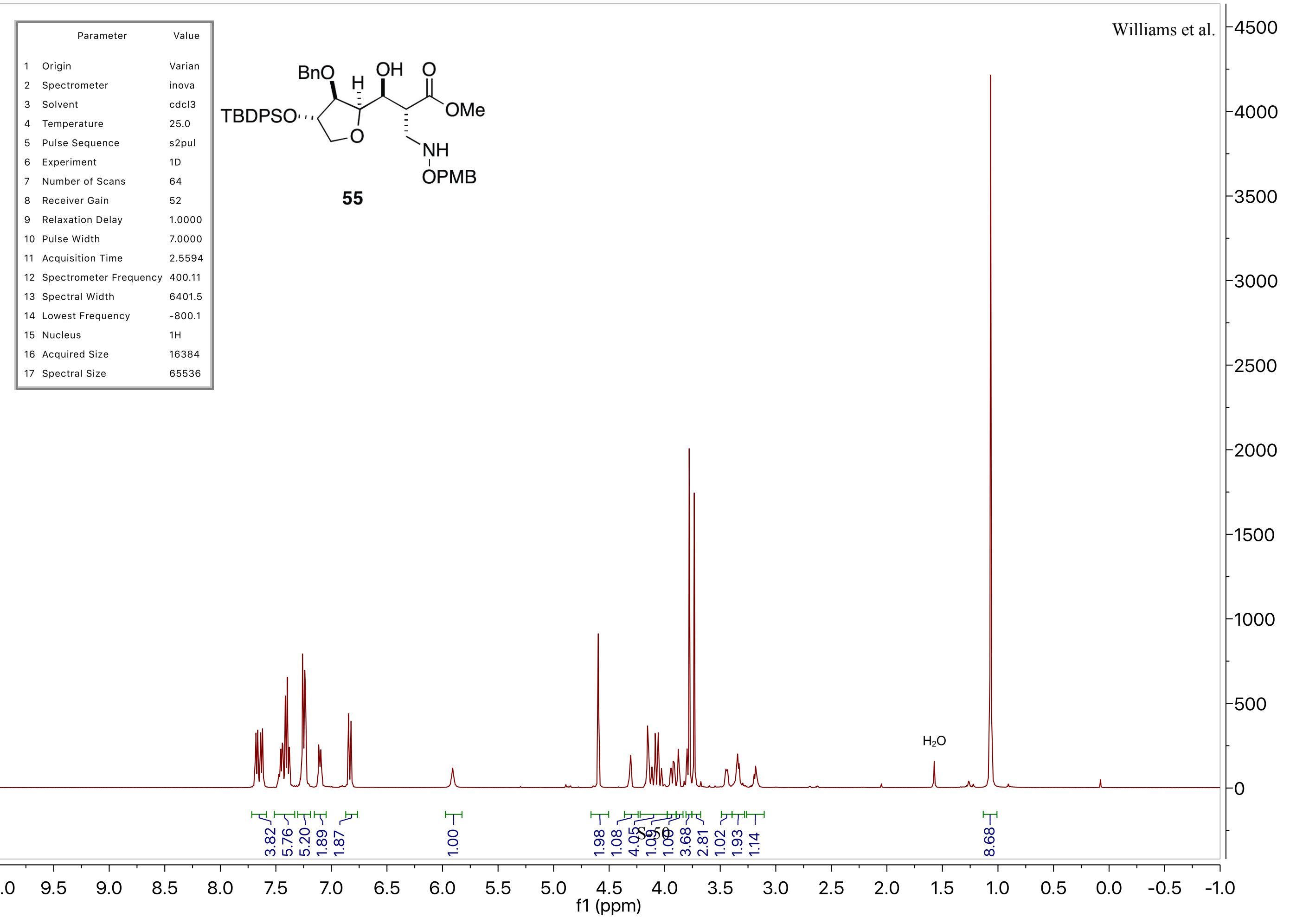




\begin{tabular}{|lll|}
\hline \multicolumn{1}{|c|}{ Parameter } & \multicolumn{1}{c|}{ Value } \\
1 & Origin & Varian \\
2 & Spectrometer & inova \\
3 & Solvent & cdcl3 \\
4 & Temperature & 25.0 \\
5 & Pulse Sequence & s2pul \\
6 & Experiment & $1 \mathrm{D}$ \\
7 & Number of Scans & 624 \\
8 & Receiver Gain & 60 \\
9 & Relaxation Delay & 1.0000 \\
10 & Pulse Width & 4.7000 \\
11 & Acquisition Time & 1.3029 \\
12 & Spectrometer Frequency & 100.62 \\
13 & Spectral Width & 25149.3 \\
14 & Lowest Frequency & -1505.7 \\
15 & Nucleus & $13 \mathrm{C}$ \\
16 & Acquired Size & 32768 \\
17 & Spectral Size & 65536 \\
\hline
\end{tabular}

กำ

吉

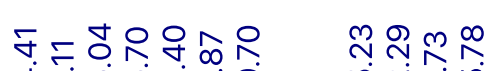

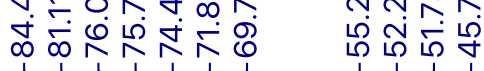

$\begin{array}{ll}\infty & 1 \\ \infty & 0 \\ \infty & 0 \\ \stackrel{0}{N} & 0 \\ 1 & 1\end{array}$

$-3800$

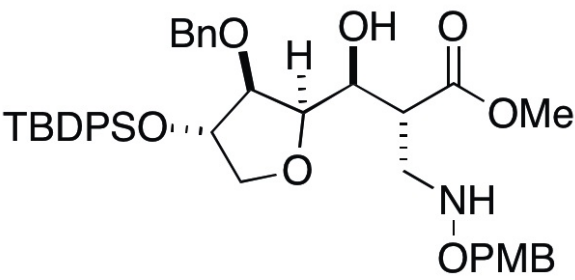

55

OPMB

2600

$-2400$

2200

$-2000$

1800

$-1600$

$-1400$

$-1200$

1000

$-800$

600

$-400$

$-200$

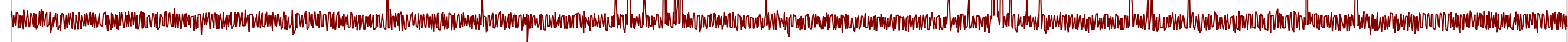

S-51

$\begin{array}{llllllllllllllllllllllll}230 & 220 & 210 & 200 & 190 & 180 & 170 & 160 & 150 & 140 & 130 & 120 \begin{array}{c}110 \\ \mathrm{f} 1(\mathrm{ppm})\end{array} & 100 & 90 & 80 & 70 & 60 & 50 & 40 & 30 & 20 & 10 & 0 & -10\end{array}$




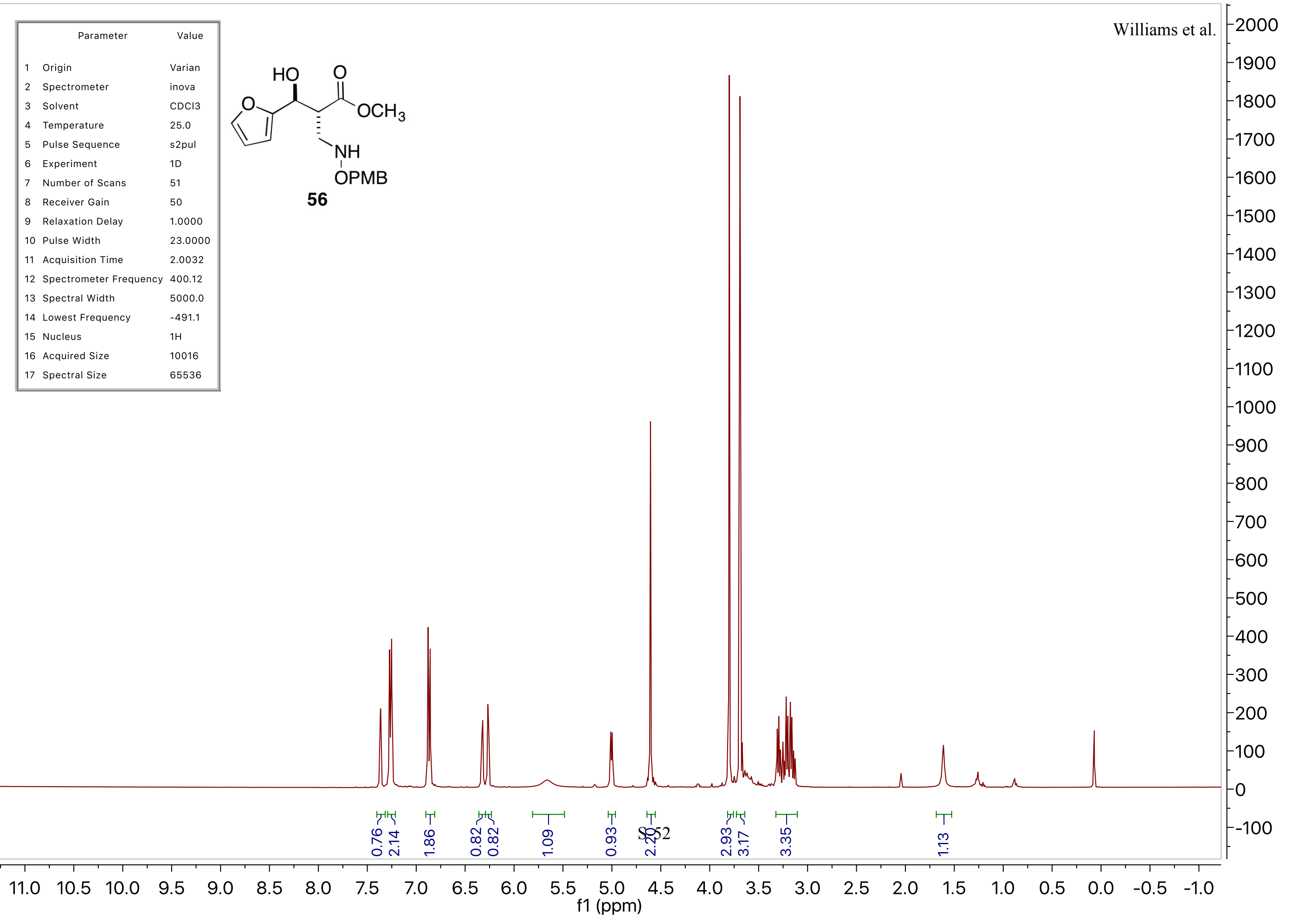




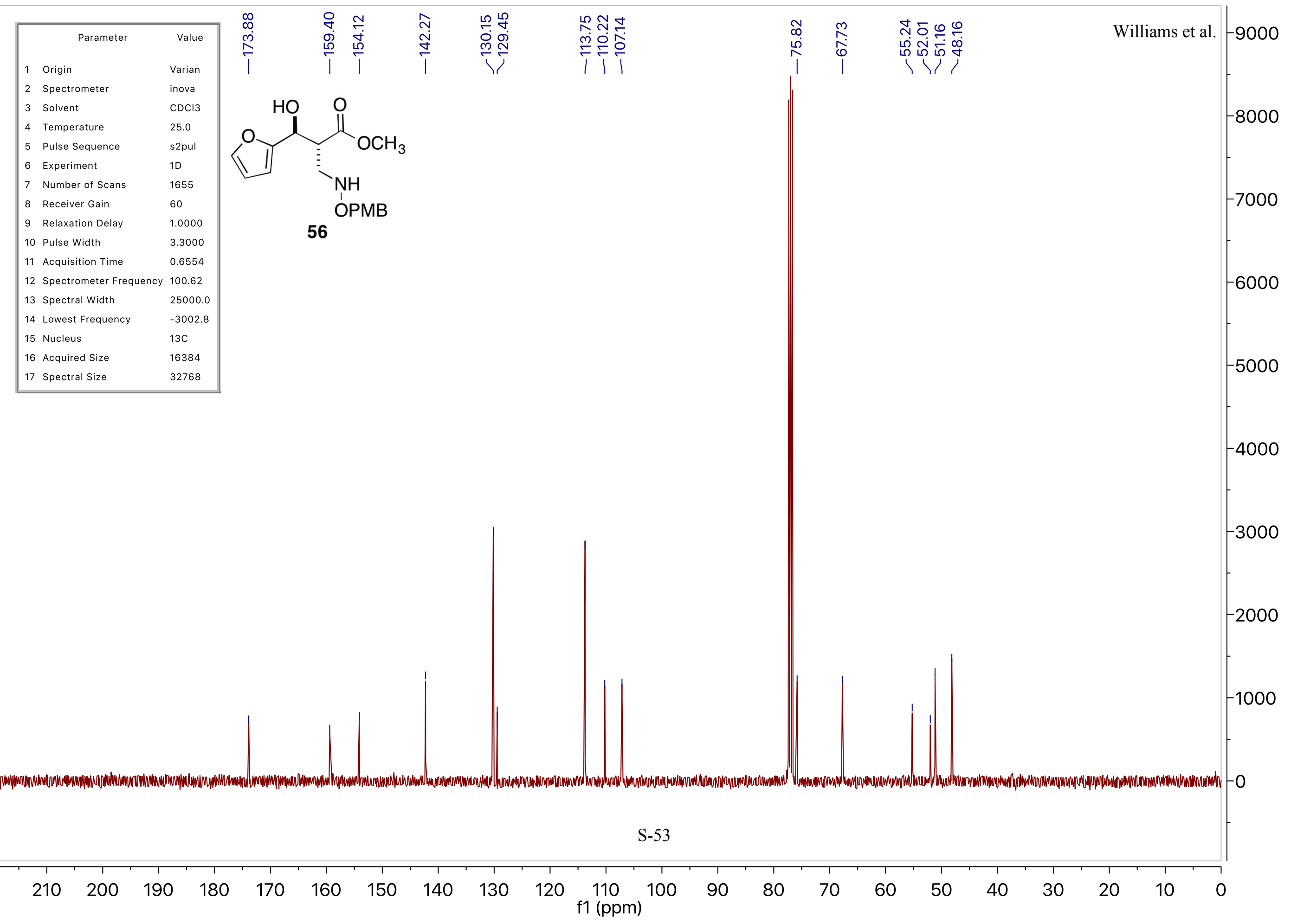




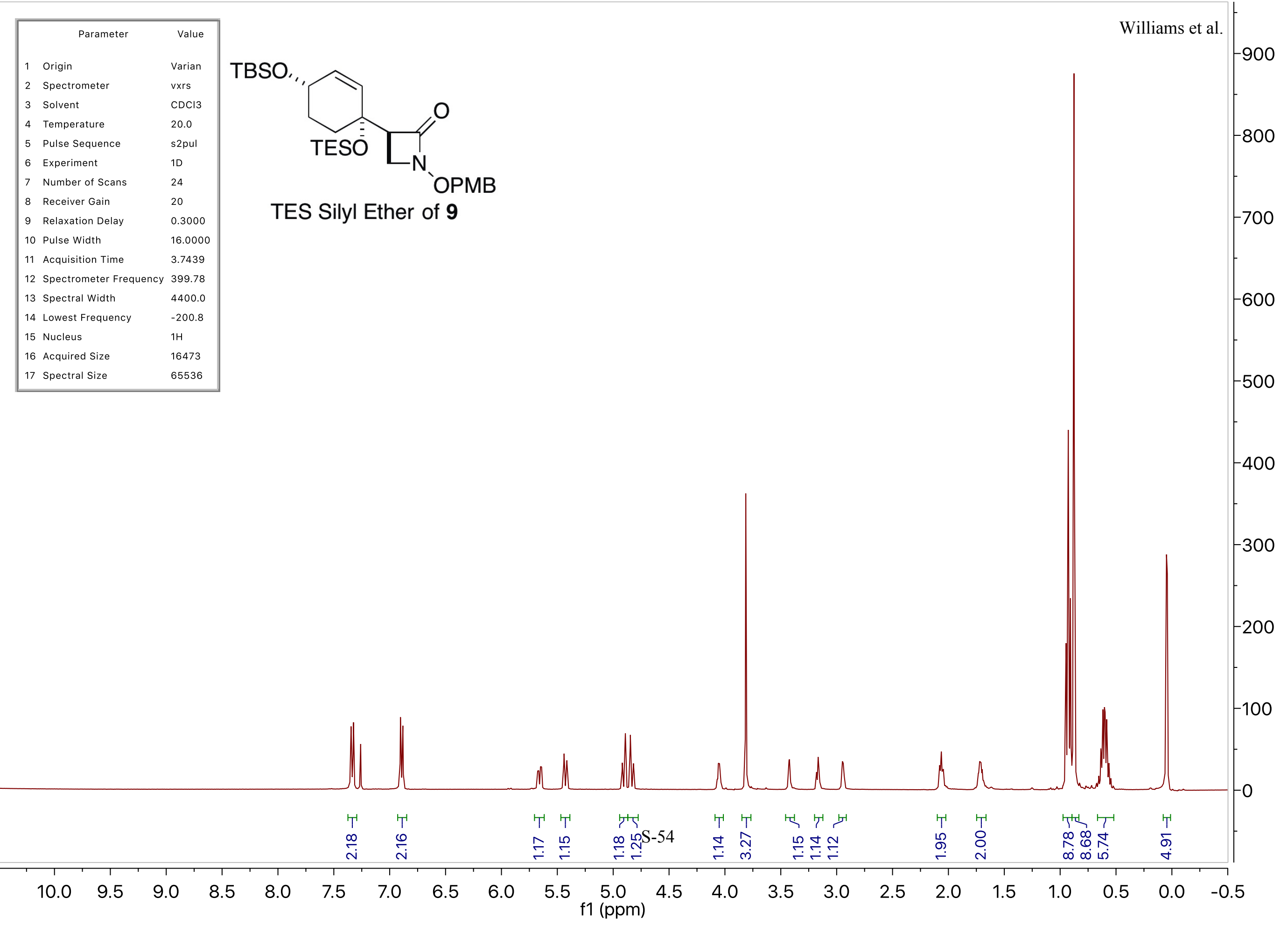




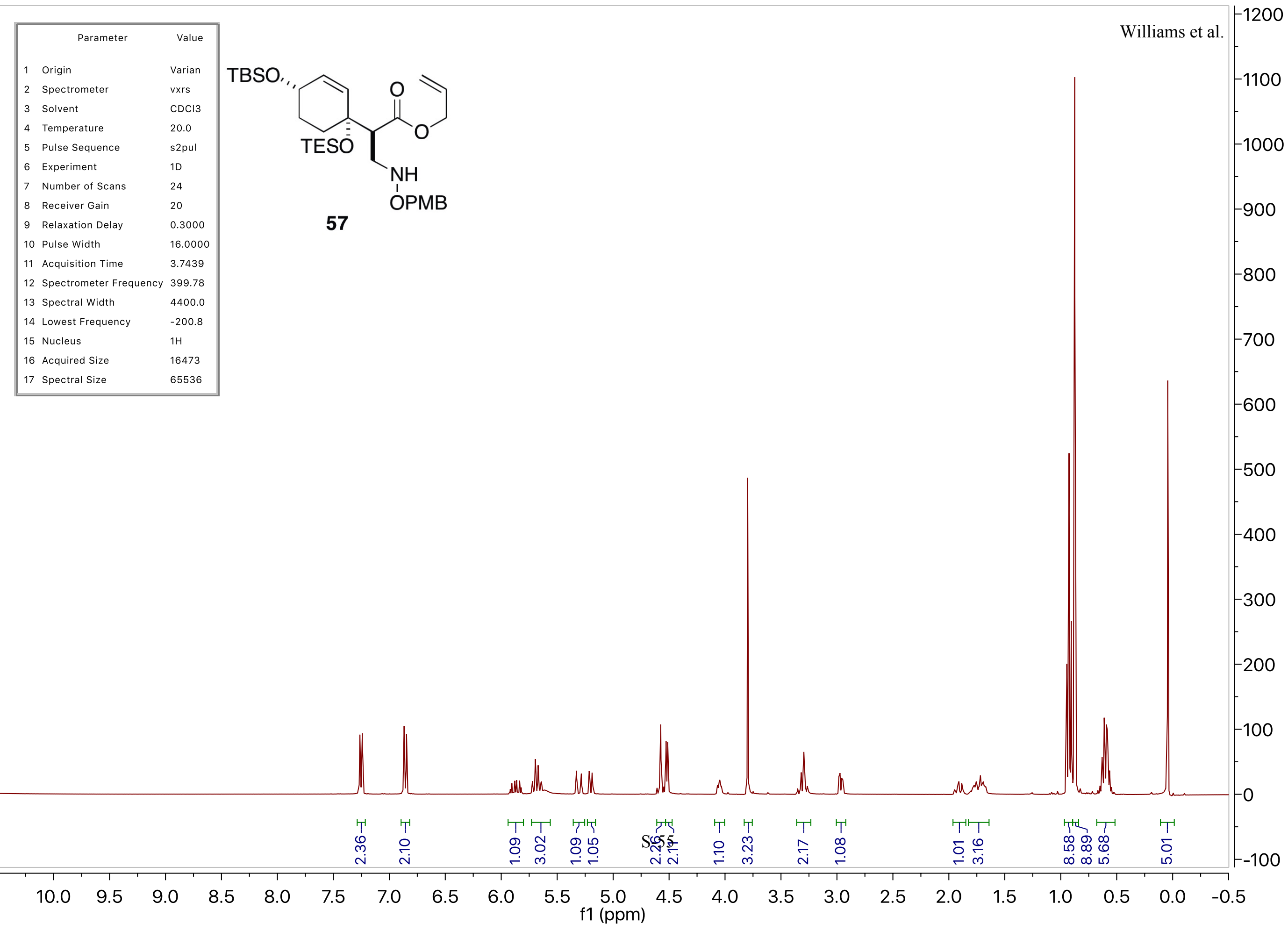




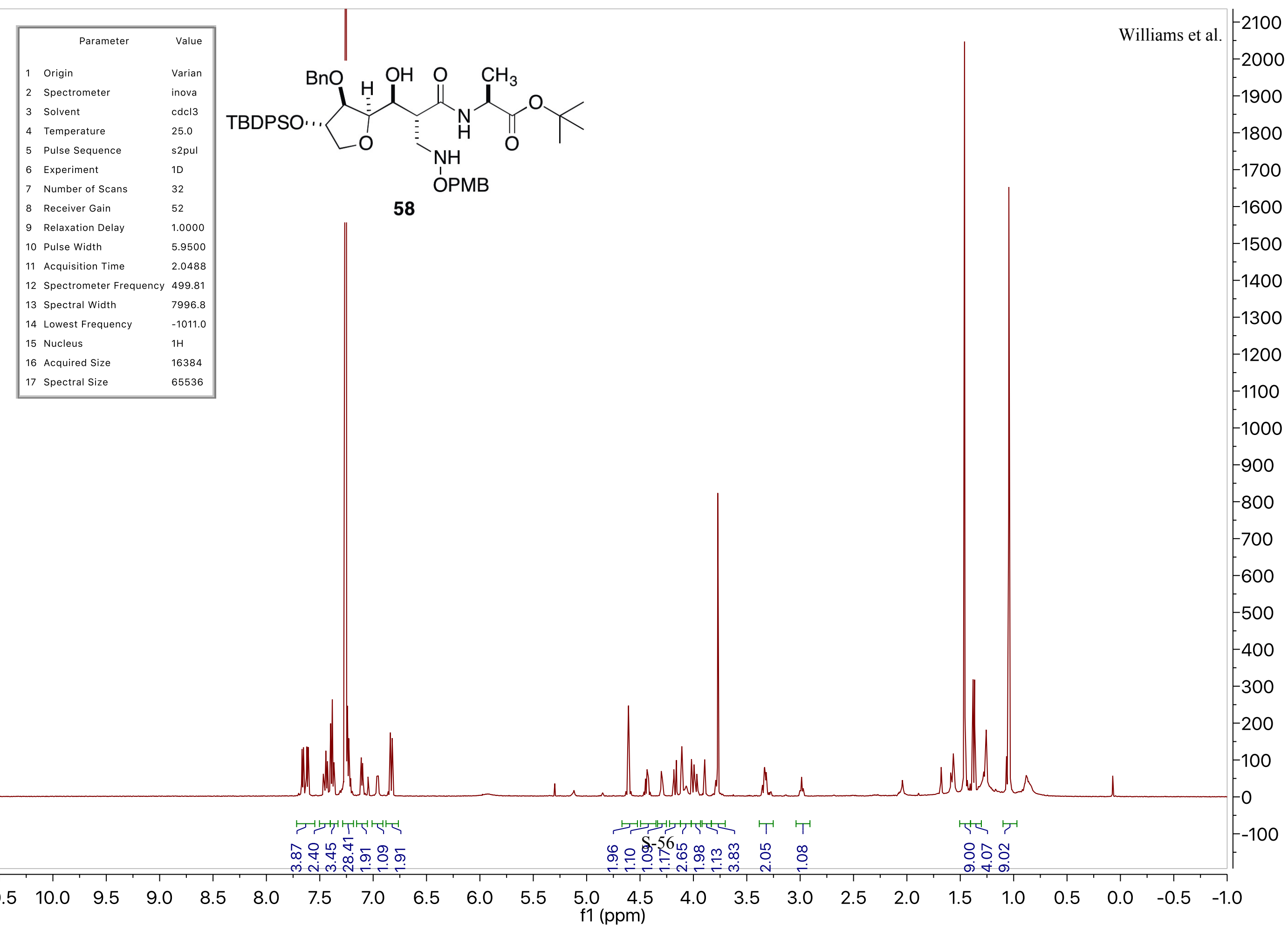




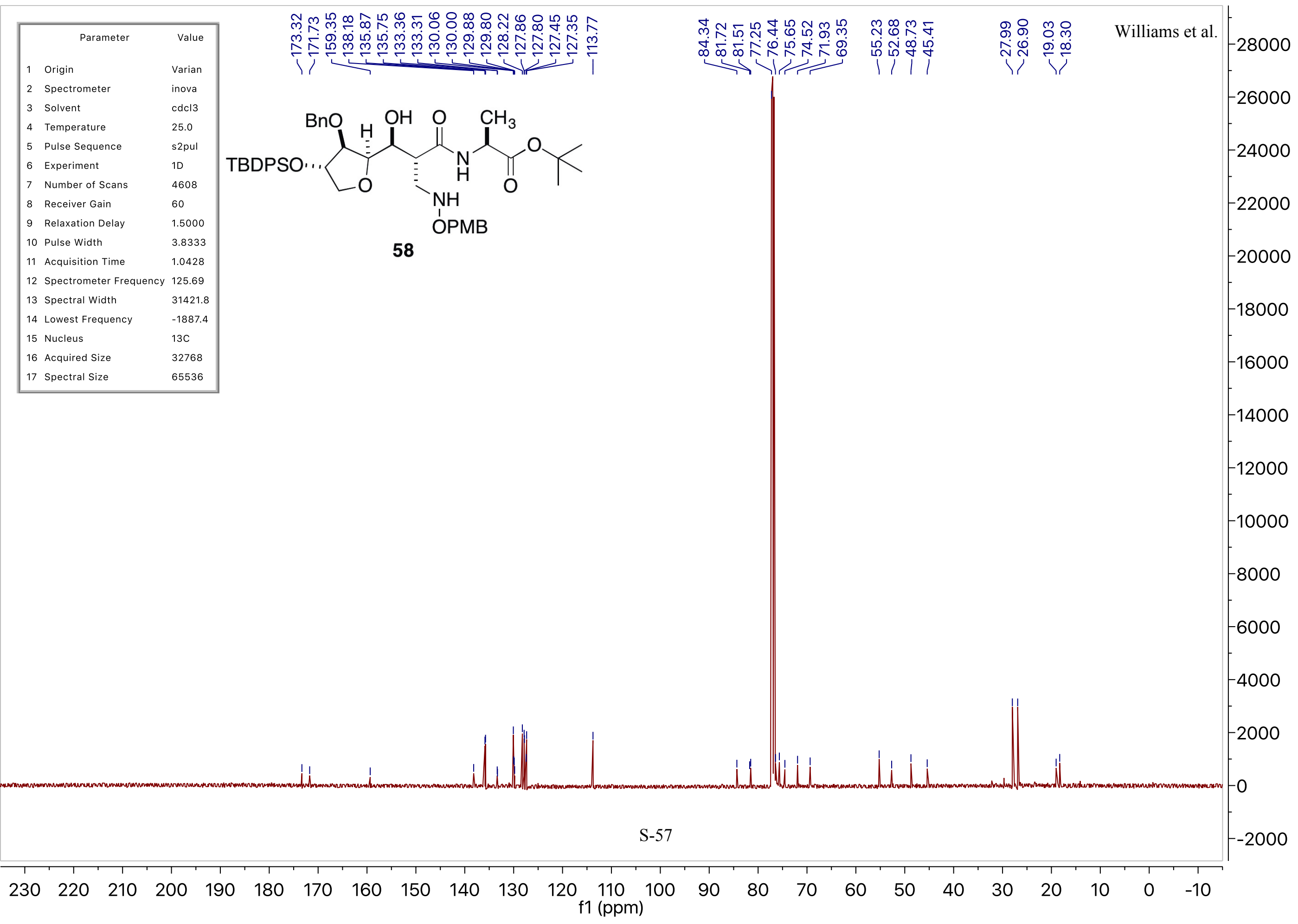




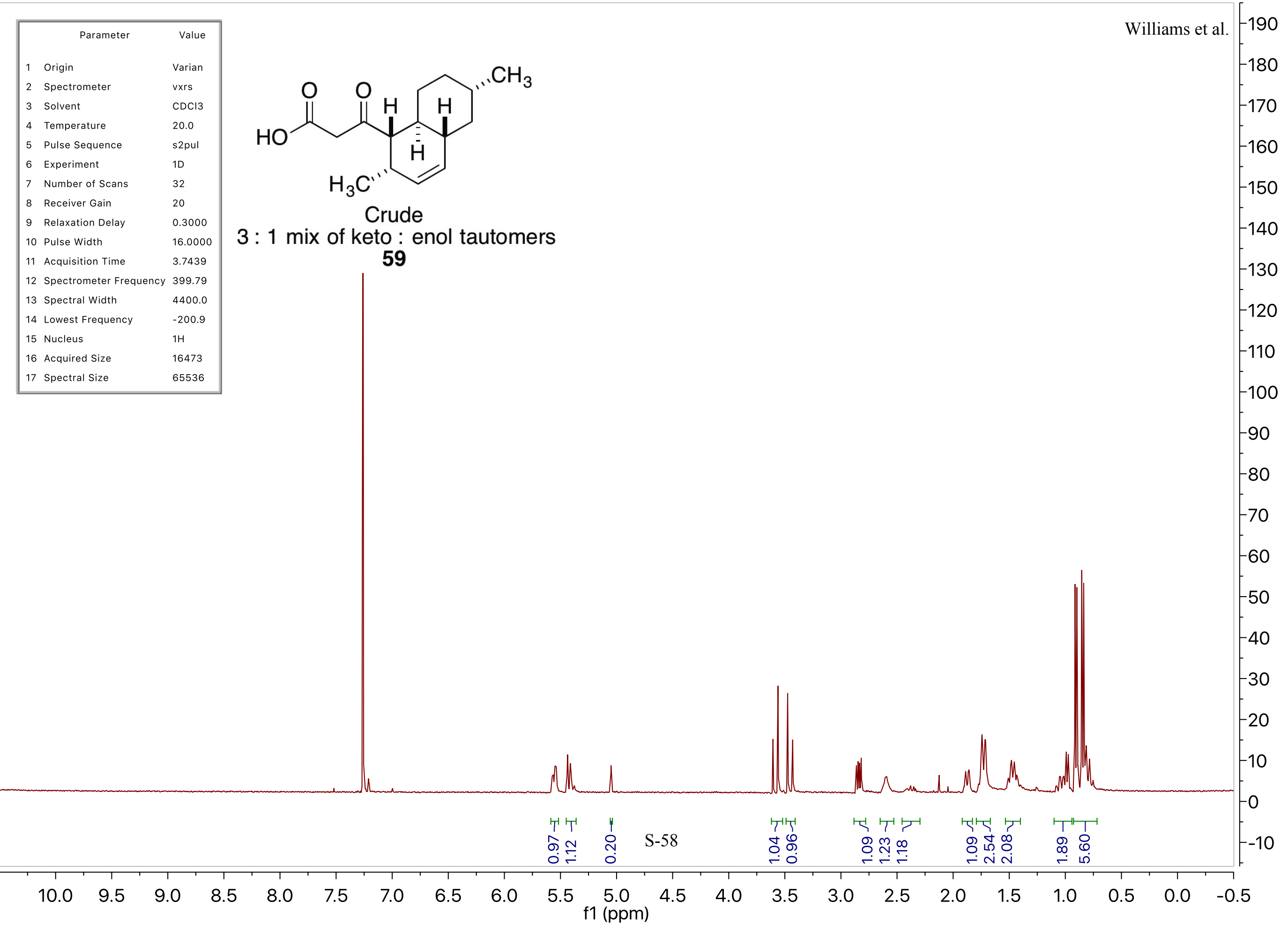




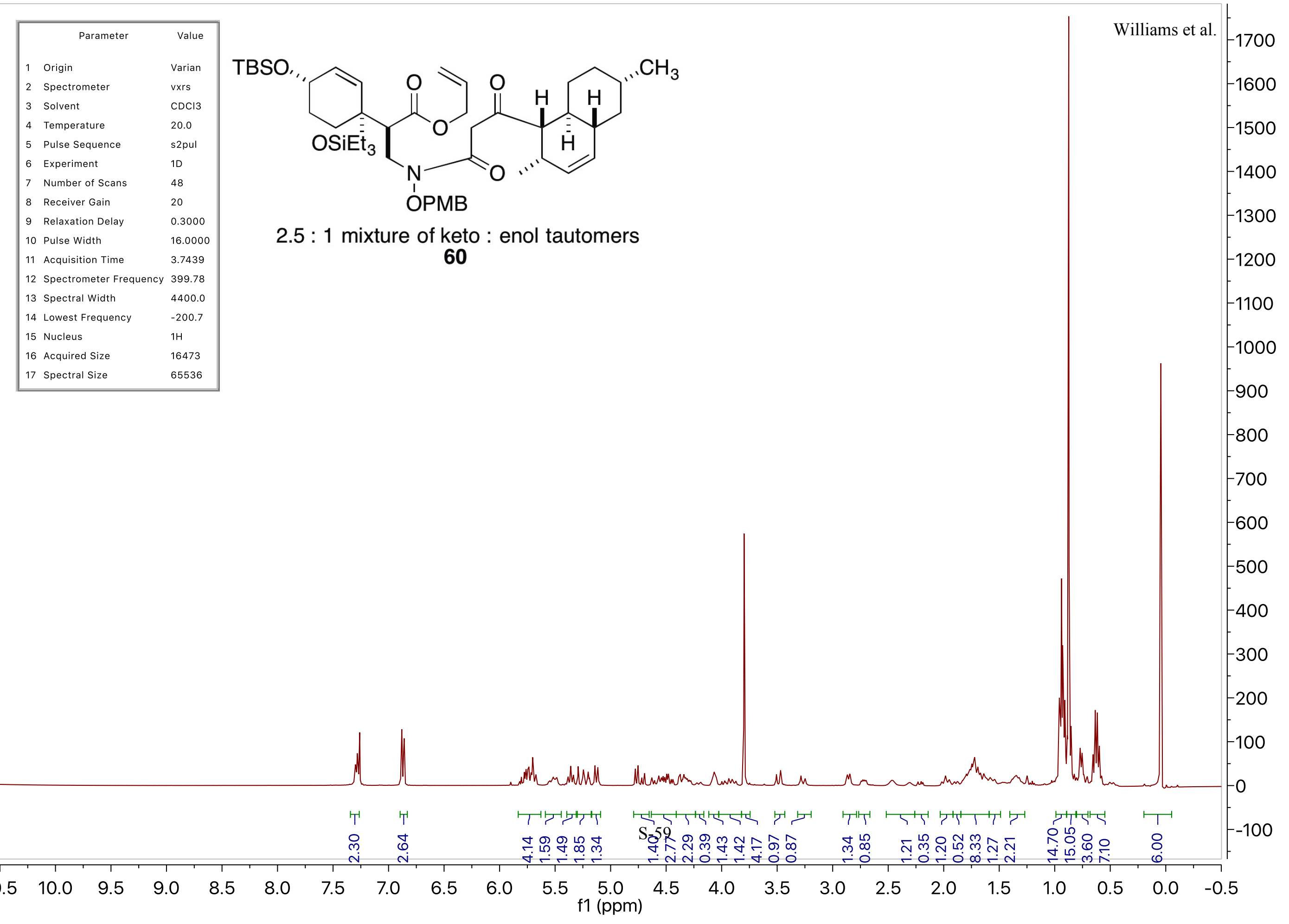




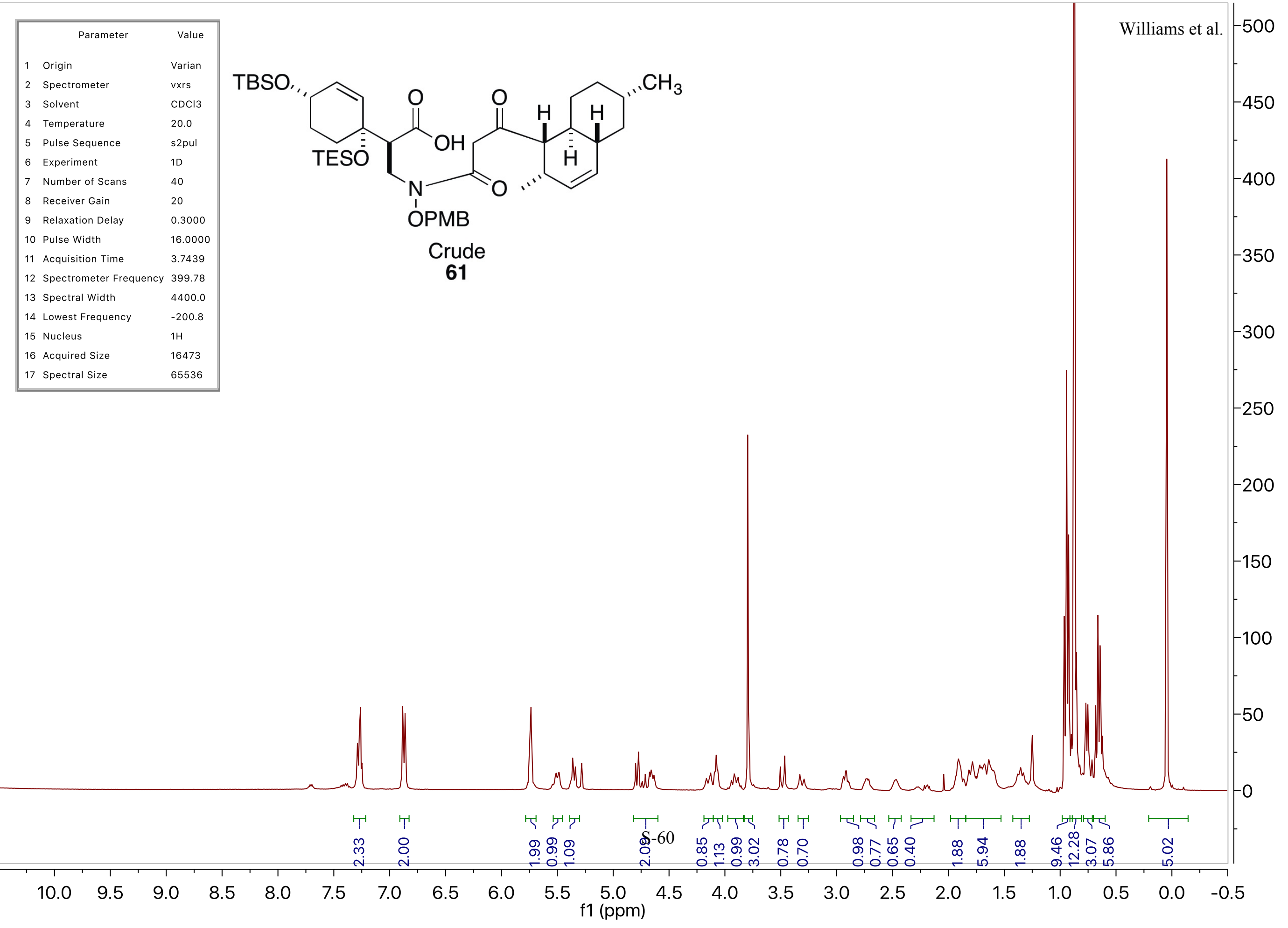




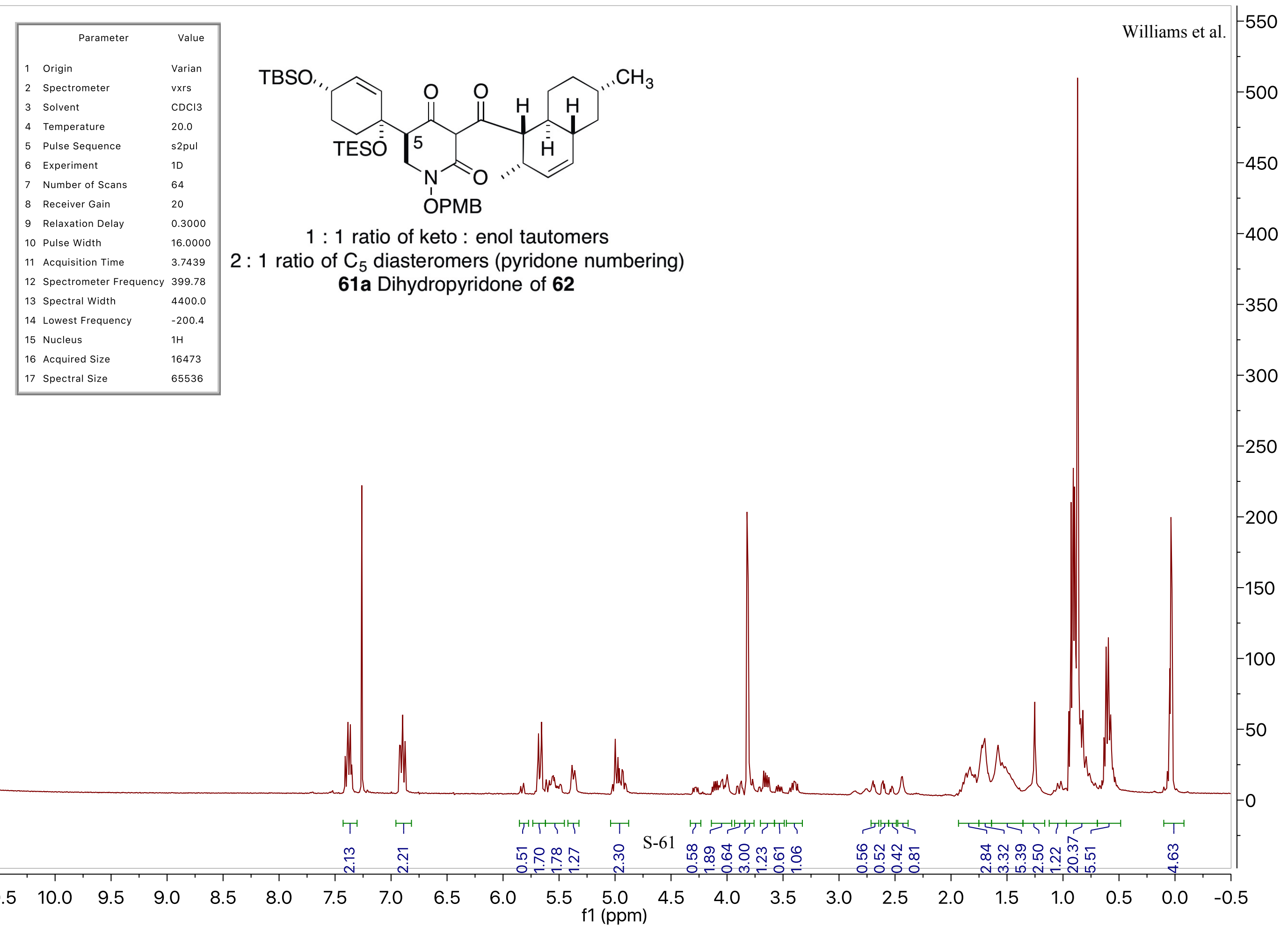


standard ID B1 Experiment

Pulee sequenes: relayh

solvent, CDC13

Temp. $25.0 \mathrm{C} / 298.1 \mathrm{~K}$

I500

PULSE GEQUENCE: xelayh Relax, delay 2.000 $\mathrm{sec}$ cosx $90-90$ - 21000 Aeq. time $0.179 \mathrm{mec}$ $2 \mathrm{D}$ Width 5735.2 Hz 16 repetitione 256 inerementa Dara Droczonsa Gaua: apodiration $0.045 \mathrm{kac}$ 71 DATA PROCESSING

keac1. enhancement $114.0 \mathrm{~Hz}$ Gauna apodization 0.011 sec Total time $2 \mathrm{hr}, 31$ min, 1 aec
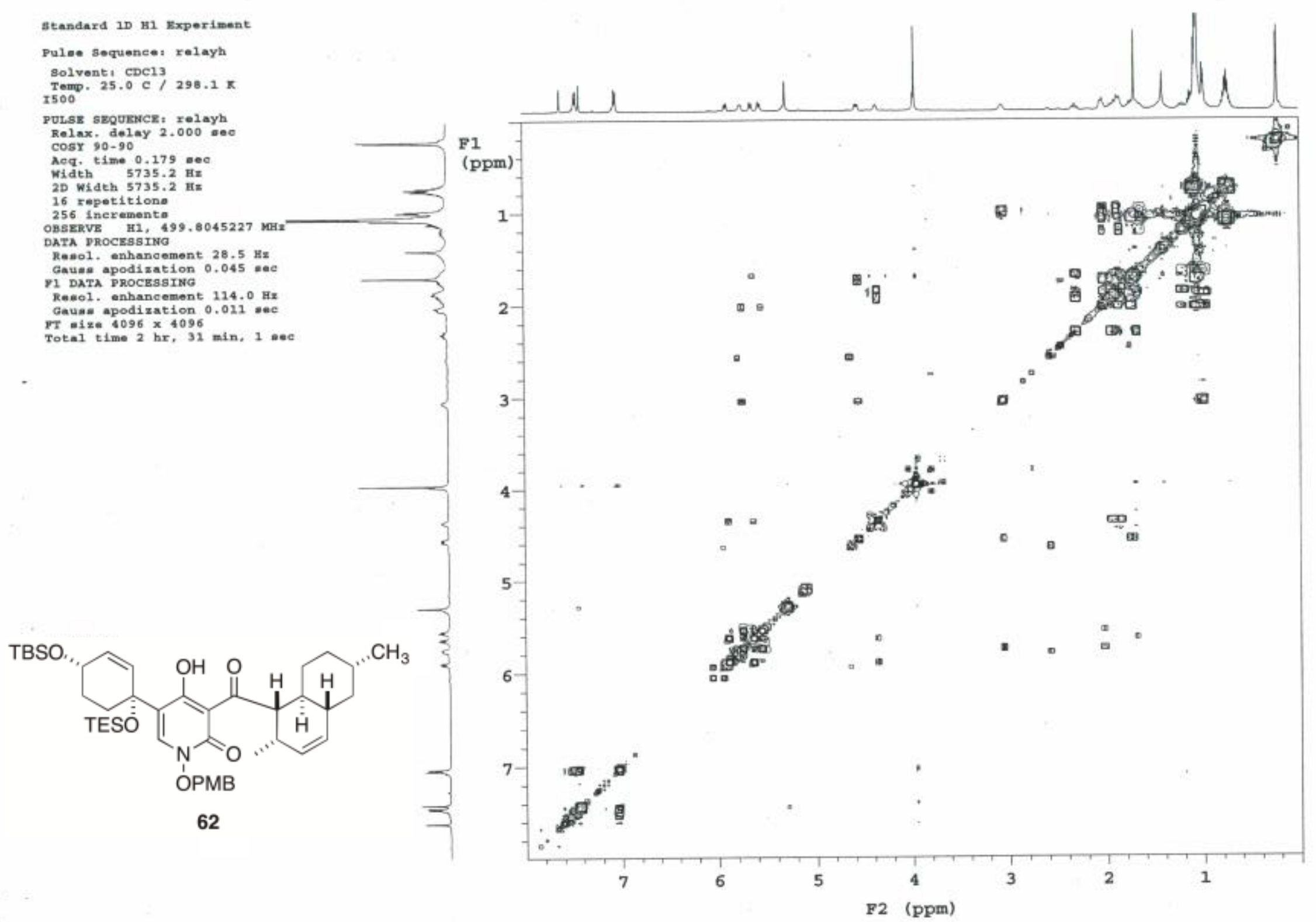


\begin{tabular}{|lll|}
\hline & \multicolumn{1}{|c|}{ Parameter } & \multicolumn{1}{c|}{ Value } \\
1 & Origin & Varian \\
2 & Spectrometer & inova \\
3 & Solvent & CDCl3 \\
4 & Temperature & 29.0 \\
5 & Pulse Sequence & s2pul \\
6 & Experiment & $1 \mathrm{D}$ \\
7 & Number of Scans & 544 \\
8 & Receiver Gain & 50 \\
9 & Relaxation Delay & 0.3000 \\
10 & Pulse Width & 4.0000 \\
11 & Acquisition Time & 3.7885 \\
12 & Spectrometer Frequency & 499.81 \\
13 & Spectral Width & 5735.2 \\
14 & Lowest Frequency & -237.7 \\
15 & Nucleus & $1 \mathrm{H}$ \\
16 & Acquired Size & 21728 \\
17 & Spectral Size & 65536 \\
\hline
\end{tabular}

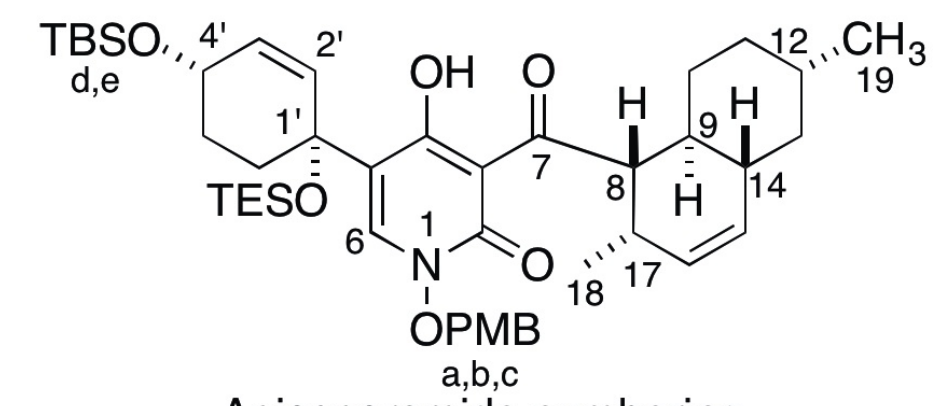

\section{Apiosporamide numbering}

$\mathrm{H}_{\mathrm{x}}$ : assignable using COSY data alone

$\left(H_{\mathrm{x}}\right)$ : assigned by analogy to the natural product

62

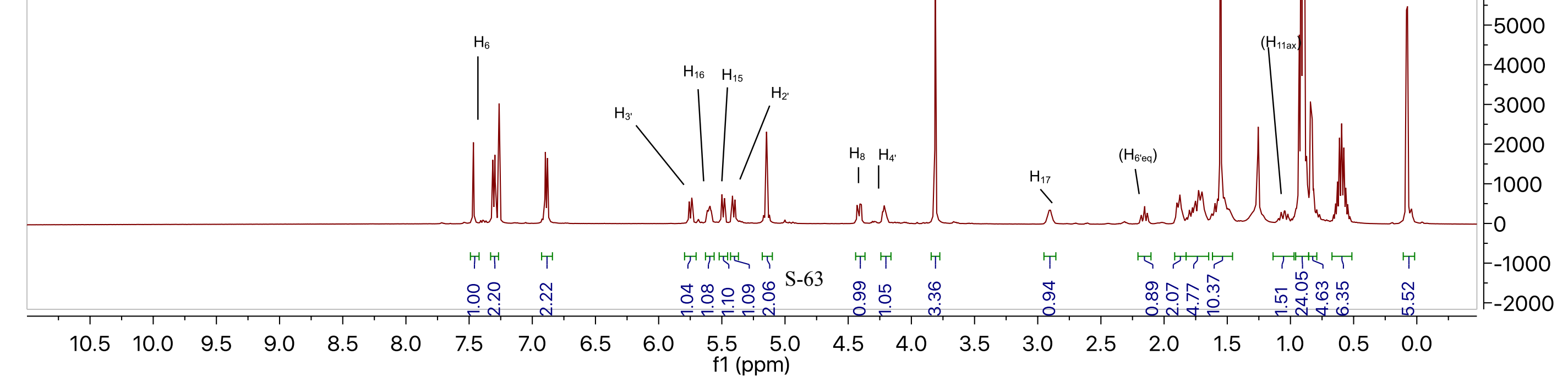




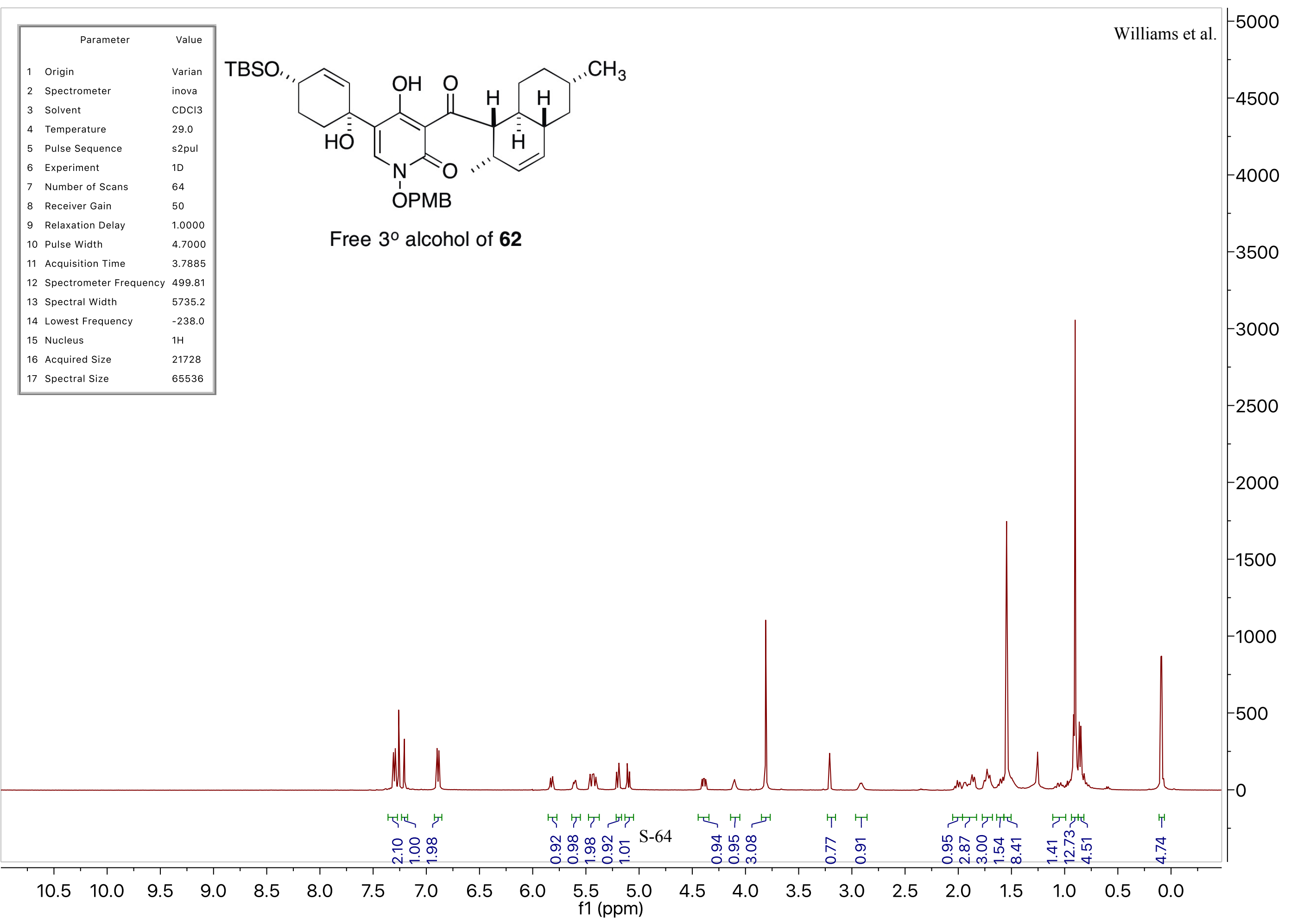


Williams et al.

\section{Crystal Structure Report for 01086: TBS Ether of 9}

A specimen of $\mathrm{C}_{29} \mathrm{H}_{49} \mathrm{NO}_{5} \mathrm{Si}_{2}$, approximate dimensions $0.020 \mathrm{~mm} \times 0.020 \mathrm{~mm} \times 0.500 \mathrm{~mm}$, was used for the X-ray crystallographic analysis. The $\mathrm{X}$-ray intensity data were measured.

The integration of the data using a monoclinic unit cell yielded a total of 11625 reflections to a maximum $\theta$ angle of $27.75^{\circ}(0.76 \AA$ resolution), of which 7200 were independent (average redundancy 1.615 , completeness $\left.=98.0 \%, R_{\text {int }}=28.57 \%, R_{\text {sig }}=65.12 \%\right)$ and $1714(23.81 \%)$ were greater than $2 \sigma\left(F^{2}\right)$. The final cell constants of $\underline{a}=15.739(7) \AA, \underline{b}=6.567(3) \AA, \underline{c}=16.007(7) \AA, \beta=104.164(11)^{\circ}$, volume $=$ 1604.2(12) $\AA^{3}$, are based upon the refinement of the XYZ-centroids of reflections above $20 \sigma(I)$. The calculated minimum and maximum transmission coefficients (based on crystal size) are 0.9308 and 0.9971 .

The structure was solved and refined using the SHELXTL Software Package, using the space group P 121 1 , with $\mathrm{Z}=2$ for the formula unit, $\mathrm{C}_{29} \mathrm{H}_{49} \mathrm{NO}_{5} \mathrm{Si}_{2}$. The final anisotropic full-matrix least-squares refinement on $\mathrm{F}^{2}$ with 345 variables converged at $\mathrm{R} 1=10.99 \%$, for the observed data and $\mathrm{wR} 2=26.95 \%$ for all data. The goodness-of-fit was 0.845 . The largest peak in the final difference electron density synthesis was $0.430 \mathrm{e}^{-} / \AA^{3}$ and the largest hole was $-0.318 \mathrm{e}^{-} / \AA^{3}$ with an RMS deviation of $0.084 \mathrm{e}^{-} / \AA^{3}$. On the basis of the final model, the calculated density was $1.134 \mathrm{~g} / \mathrm{cm}^{3}$ and $F(000), 596 \mathrm{e}$.

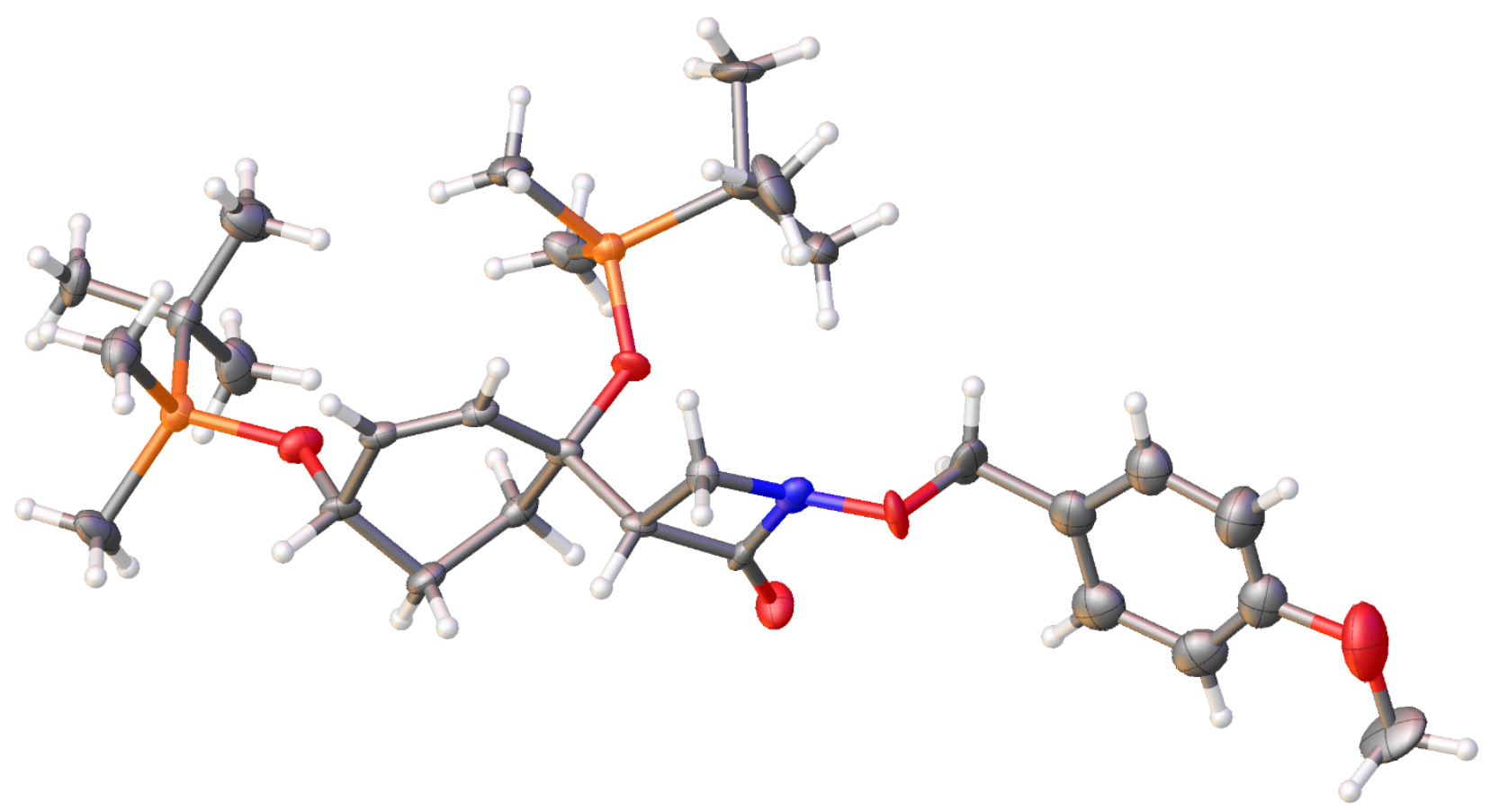

By default, the $(50 \%)$ ellipsoid contour probability level is used for the generation of ORTEPs of the TBS ether of structure 9 

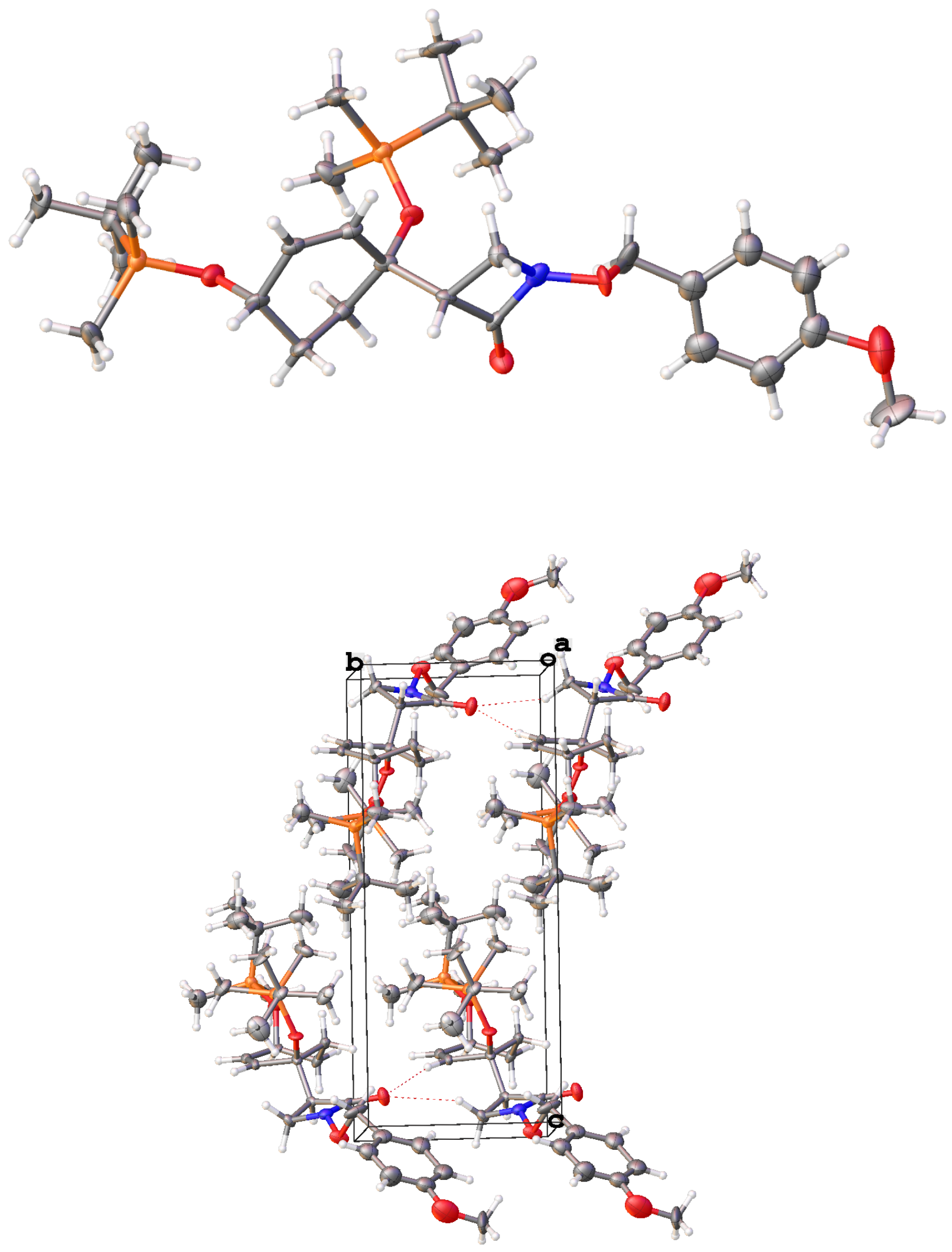

Cell plot, view along $a$ axis.

S-66 
Williams et al.

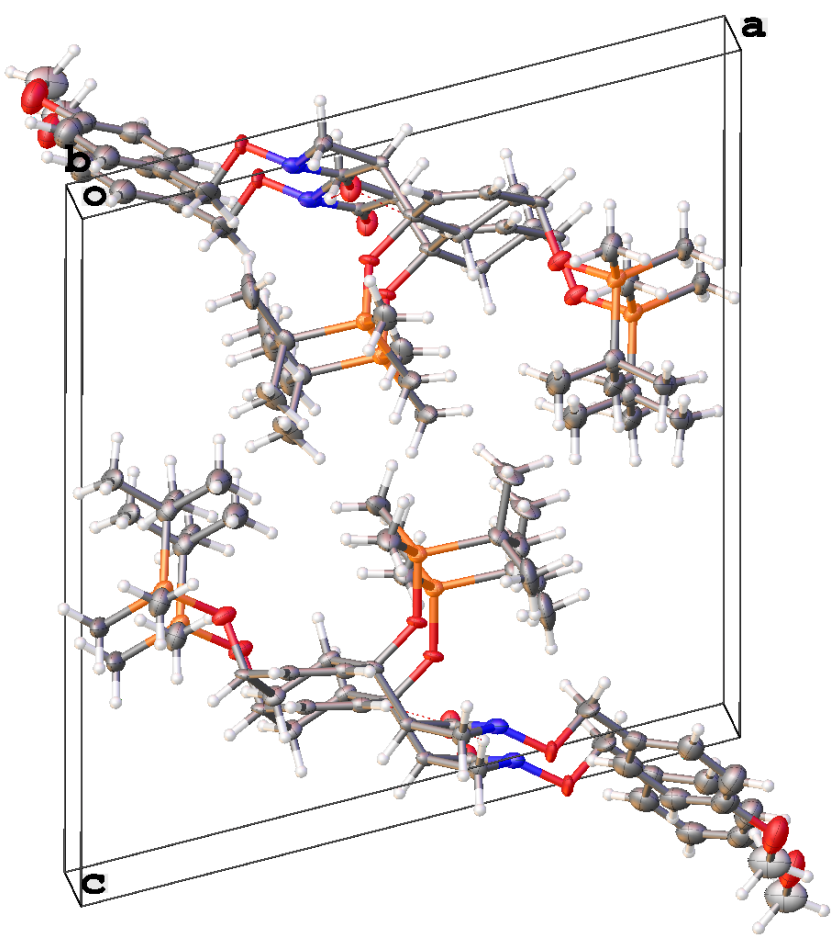

Cell plot, view along $b$ axis.

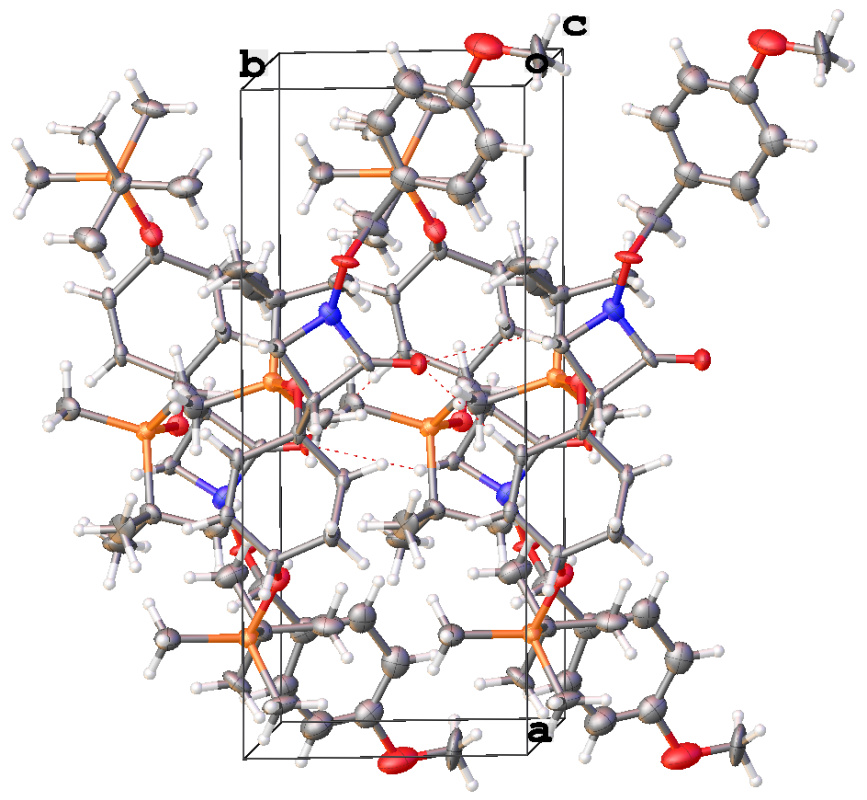

Cell plot, view along $c$ axis. 
Table 1. Sample and crystal data for 01086.

\begin{tabular}{|c|c|c|}
\hline Identification code & \multicolumn{2}{|l|}{01086} \\
\hline Chemical formula & \multicolumn{2}{|l|}{$\mathrm{C}_{29} \mathrm{H}_{49} \mathrm{NO}_{5} \mathrm{Si}_{2}$} \\
\hline Formula weight & \multicolumn{2}{|l|}{$547.87 \mathrm{~g} / \mathrm{mol}$} \\
\hline Temperature & \multicolumn{2}{|l|}{$113(2) \mathrm{K}$} \\
\hline Wavelength & \multicolumn{2}{|l|}{$0.71073 \AA$} \\
\hline Crystal size & \multicolumn{2}{|c|}{$0.020 \times 0.020 \times 0.500 \mathrm{~mm}$} \\
\hline Crystal system & \multicolumn{2}{|l|}{ monoclinic } \\
\hline Space group & \multicolumn{2}{|l|}{ P 1211} \\
\hline \multirow[t]{3}{*}{ Unit cell dimensions } & $a=15.739(7) \AA$ & $\alpha=90^{\circ}$ \\
\hline & $b=6.567(3) \AA$ & $\beta=104.164(11)^{\circ}$ \\
\hline & $c=16.007(7) \AA$ & $\gamma=90^{\circ}$ \\
\hline Volume & \multicolumn{2}{|l|}{$1604.2(12) \AA^{3}$} \\
\hline $\mathbf{Z}$ & \multicolumn{2}{|l|}{2} \\
\hline Density (calculated) & \multicolumn{2}{|l|}{$1.134 \mathrm{~g} / \mathrm{cm}^{3}$} \\
\hline Absorption coefficient & \multicolumn{2}{|l|}{$0.145 \mathrm{~mm}^{-1}$} \\
\hline$F(000)$ & \multicolumn{2}{|l|}{596} \\
\hline
\end{tabular}

Table 2. Data collection and structure refinement for 01086 .

Theta range for data collection

Index ranges

Reflections collected

Independent reflections

Max. and min. transmission

Structure solution technique

Structure solution program

Refinement method

Refinement program

Function minimized

Data / restraints / parameters

Goodness-of-fit on $F^{2}$

Final $\mathbf{R}$ indices

Weighting scheme

Absolute structure parameter

Largest diff. peak and hole

R.M.S. deviation from mean
2.09 to $27.75^{\circ}$

$-20<=\mathrm{h}<=12,-8<=\mathrm{k}<=8,-20<=\mid<=20$

11625

$7200[\mathrm{R}$ (int) $=0.2857]$

0.9971 and 0.9308

direct methods

SHELXS-97 (Sheldrick, 1990)

Full-matrix least-squares on $\mathrm{F}^{2}$

SHELXL-2014/7 (Sheldrick, 2014)

$\Sigma w\left(F_{o}{ }^{2}-F_{c}{ }^{2}\right)^{2}$

$7200 / 75 / 345$

0.845

1714 data; $R 1=0.1099, w R 2=0.2236$

all data $\quad R 1=0.3227, w R 2=0.2695$

$w=1 /\left[\sigma^{2}\left(F_{o}{ }^{2}\right)+(0.0380 P)^{2}\right]$ where $P=\left(F_{o}{ }^{2}+2 F_{c}{ }^{2}\right) / 3$

$-1.9(6)$

0.430 and $-0.318 e^{-3}$

$0.084 \mathrm{e}^{-3}$ 
Williams et al.

Table 3. Atomic coordinates and equivalent isotropic atomic displacement parameters $\left(\AA^{2}\right)$ for 01086. $\mathrm{U}(\mathrm{eq})$ is defined as one third of the trace of the orthogonalized $\mathrm{U}_{\mathrm{ij}}$ tensor.

\begin{tabular}{|c|c|c|c|c|}
\hline & $x / a$ & $y / b$ & $z / c$ & $\mathrm{U}(\mathrm{eq})$ \\
\hline $\mathrm{O} 1$ & $0.5825(7)$ & $0.8886(16)$ & $0.9224(7)$ & $0.031(3)$ \\
\hline $\mathrm{C} 2$ & $0.5875(10)$ & $0.071(2)$ & $0.9338(9)$ & $0.018(4)$ \\
\hline N3 & $0.6611(9)$ & $0.195(2)$ & $0.9597(8)$ & $0.026(3)$ \\
\hline $\mathrm{C} 4$ & $0.6119(10)$ & $0.381(2)$ & $0.9707(10)$ & $0.022(4)$ \\
\hline $\mathrm{C} 5$ & $0.5291(10)$ & $0.258(2)$ & $0.9277(9)$ & $0.017(4)$ \\
\hline C6 & $0.4763(11)$ & $0.325(2)$ & $0.8354(10)$ & $0.018(3)$ \\
\hline $\mathrm{C7}$ & $0.4387(10)$ & $0.539(2)$ & $0.8417(8)$ & $0.020(3)$ \\
\hline $\mathrm{C} 8$ & $0.3543(11)$ & $0.579(2)$ & $0.8257(9)$ & $0.020(4)$ \\
\hline C9 & $0.2856(10)$ & $0.414(3)$ & $0.8032(8)$ & $0.021(3)$ \\
\hline C10 & $0.3231(10)$ & $0.207(2)$ & $0.8331(10)$ & $0.026(4)$ \\
\hline C11 & $0.4049(10)$ & $0.172(2)$ & $0.7985(9)$ & $0.022(3)$ \\
\hline 012 & $0.7419(7)$ & $0.1334(16)$ & $0.0135(7)$ & $0.028(3)$ \\
\hline C13 & $0.7955(11)$ & $0.050(3)$ & $0.9604(10)$ & $0.045(5)$ \\
\hline C14 & $0.8641(12)$ & $0.920(3)$ & $0.0176(10)$ & $0.039(4)$ \\
\hline C15 & $0.9506(12)$ & $0.999(3)$ & $0.0526(11)$ & $0.044(5)$ \\
\hline C16 & $0.0112(15)$ & $0.890(4)$ & $0.1087(13)$ & $0.057(5)$ \\
\hline C17 & $0.9957(14)$ & $0.710(3)$ & $0.1282(12)$ & $0.045(5)$ \\
\hline C18 & $0.9181(13)$ & $0.611(3)$ & $0.0995(11)$ & $0.047(5)$ \\
\hline C19 & $0.8477(14)$ & $0.721(3)$ & $0.0389(12)$ & $0.046(5)$ \\
\hline $\mathrm{O} 20$ & $0.0698(9)$ & $0.615(3)$ & $0.1894(10)$ & $0.072(5)$ \\
\hline C21 & $0.0558(14)$ & $0.420(3)$ & $0.2154(12)$ & $0.063(7)$ \\
\hline $\mathrm{O} 22$ & $0.5430(7)$ & $0.3332(15)$ & $0.7859(6)$ & $0.022(3)$ \\
\hline Si23 & $0.5461(3)$ & $0.4328(7)$ & $0.6927(3)$ & $0.0225(11)$ \\
\hline C24 & $0.4827(12)$ & $0.279(3)$ & $0.5994(10)$ & $0.035(5)$ \\
\hline C25 & $0.5092(11)$ & $0.705(2)$ & $0.6768(10)$ & $0.037(5)$ \\
\hline C26 & $0.6691(11)$ & $0.418(3)$ & $0.6966(10)$ & $0.028(4)$ \\
\hline C27 & $0.6948(11)$ & $0.189(3)$ & $0.7041(11)$ & $0.036(5)$ \\
\hline C28 & $0.6867(12)$ & $0.509(3)$ & $0.6148(11)$ & $0.047(6)$ \\
\hline C29 & $0.7187(11)$ & $0.538(3)$ & $0.7732(12)$ & $0.056(6)$ \\
\hline 030 & $0.2519(7)$ & $0.4133(18)$ & $0.7096(6)$ & $0.029(3)$ \\
\hline Si31 & $0.1624(3)$ & $0.5313(7)$ & $0.6558(3)$ & $0.0227(12)$ \\
\hline C32 & $0.0625(10)$ & $0.414(3)$ & $0.6799(10)$ & $0.041(5)$ \\
\hline C33 & $0.1640(12)$ & $0.808(3)$ & $0.6882(11)$ & $0.041(5)$ \\
\hline C34 & $0.1670(11)$ & $0.495(2)$ & $0.5397(10)$ & $0.031(5)$ \\
\hline C35 & $0.1716(12)$ & $0.269(3)$ & $0.5176(11)$ & $0.046(6)$ \\
\hline C36 & $0.2486(12)$ & $0.604(3)$ & $0.5228(11)$ & $0.050(6)$ \\
\hline C37 & $0.0863(11)$ & $0.591(3)$ & $0.4799(10)$ & $0.037(5)$ \\
\hline
\end{tabular}


Table 4. Bond lengths (Å) for 01086.

\begin{tabular}{|c|c|c|c|}
\hline O1-C2 & $1.212(18)$ & C2-N3 & $1.39(2)$ \\
\hline $\mathrm{C} 2-\mathrm{C} 5$ & $1.52(2)$ & N3-012 & $1.408(16)$ \\
\hline N3-C4 & $1.479(18)$ & $\mathrm{C} 4-\mathrm{C} 5$ & $1.543(19)$ \\
\hline $\mathrm{C} 4-\mathrm{H} 4 \mathrm{~A}$ & 0.99 & $\mathrm{C} 4-\mathrm{H} 4 \mathrm{~B}$ & 0.99 \\
\hline $\mathrm{C} 5-\mathrm{C} 6$ & $1.57(2)$ & $\mathrm{C} 5-\mathrm{H} 5$ & 1.0 \\
\hline $\mathrm{C} 6-022$ & $1.463(17)$ & C6-C11 & $1.52(2)$ \\
\hline $\mathrm{C} 6-\mathrm{C7}$ & $1.54(2)$ & $\mathrm{C} 7-\mathrm{C} 8$ & $1.316(19)$ \\
\hline $\mathrm{C} 7-\mathrm{H} 7$ & 0.95 & $\mathrm{C} 8-\mathrm{C} 9$ & $1.51(2)$ \\
\hline $\mathrm{C} 8-\mathrm{H} 8$ & 0.95 & C9-030 & $1.462(16)$ \\
\hline C9-C10 & $1.51(2)$ & $\mathrm{C} 9-\mathrm{H} 9$ & 1.0 \\
\hline C10-C11 & $1.538(19)$ & $\mathrm{C} 10-\mathrm{H} 10 \mathrm{~A}$ & 0.99 \\
\hline $\mathrm{C} 10-\mathrm{H} 10 \mathrm{~B}$ & 0.99 & $\mathrm{C} 11-\mathrm{H} 11 \mathrm{~A}$ & 0.99 \\
\hline $\mathrm{C} 11-\mathrm{H} 11 \mathrm{~B}$ & 0.99 & O12-C13 & $1.444(17)$ \\
\hline C13-C14 & $1.50(2)$ & $\mathrm{C} 13-\mathrm{H} 13 \mathrm{~A}$ & 0.99 \\
\hline $\mathrm{C} 13-\mathrm{H} 13 \mathrm{~B}$ & 0.99 & C14-C19 & $1.39(3)$ \\
\hline C14-C15 & $1.44(2)$ & C15-C16 & $1.35(3)$ \\
\hline $\mathrm{C} 15-\mathrm{H} 15$ & 0.95 & C16-C17 & $1.26(3)$ \\
\hline $\mathrm{C} 16-\mathrm{H} 16$ & 0.95 & C17-C18 & $1.36(3)$ \\
\hline C17-020 & $1.47(2)$ & C18-C19 & $1.47(2)$ \\
\hline $\mathrm{C} 18-\mathrm{H} 18$ & 0.95 & $\mathrm{C} 19-\mathrm{H} 19$ & 0.95 \\
\hline O20-C21 & $1.38(2)$ & $\mathrm{C} 21-\mathrm{H} 21 \mathrm{~A}$ & 0.98 \\
\hline $\mathrm{C} 21-\mathrm{H} 21 \mathrm{~B}$ & 0.98 & $\mathrm{C} 21-\mathrm{H} 21 \mathrm{C}$ & 0.98 \\
\hline O22-Si23 & $1.641(10)$ & Si23-C25 & $1.875(17)$ \\
\hline Si23-C24 & $1.876(16)$ & Si23-C26 & $1.923(16)$ \\
\hline $\mathrm{C} 24-\mathrm{H} 24 \mathrm{~A}$ & 0.98 & $\mathrm{C} 24-\mathrm{H} 24 \mathrm{~B}$ & 0.98 \\
\hline $\mathrm{C} 24-\mathrm{H} 24 \mathrm{C}$ & 0.98 & $\mathrm{C} 25-\mathrm{H} 25 \mathrm{~A}$ & 0.98 \\
\hline $\mathrm{C} 25-\mathrm{H} 25 \mathrm{~B}$ & 0.98 & $\mathrm{C} 25-\mathrm{H} 25 \mathrm{C}$ & 0.98 \\
\hline C26-C29 & $1.51(2)$ & C26-C28 & $1.53(2)$ \\
\hline C26-C27 & $1.55(2)$ & $\mathrm{C} 27-\mathrm{H} 27 \mathrm{~A}$ & 0.98 \\
\hline $\mathrm{C} 27-\mathrm{H} 27 \mathrm{~B}$ & 0.98 & $\mathrm{C} 27-\mathrm{H} 27 \mathrm{C}$ & 0.98 \\
\hline $\mathrm{C} 28-\mathrm{H} 28 \mathrm{~A}$ & 0.98 & $\mathrm{C} 28-\mathrm{H} 28 \mathrm{~B}$ & 0.98 \\
\hline $\mathrm{C} 28-\mathrm{H} 28 \mathrm{C}$ & 0.98 & C29-H29A & 0.98 \\
\hline $\mathrm{C} 29-\mathrm{H} 29 \mathrm{~B}$ & 0.98 & $\mathrm{C} 29-\mathrm{H} 29 \mathrm{C}$ & 0.98 \\
\hline O30-Si31 & $1.653(11)$ & Si31-C32 & $1.874(16)$ \\
\hline Si31-C33 & $1.886(17)$ & Si31-C34 & $1.892(16)$ \\
\hline $\mathrm{C} 32-\mathrm{H} 32 \mathrm{~A}$ & 0.98 & С $32-H 32 B$ & 0.98 \\
\hline $\mathrm{C} 32-\mathrm{H} 32 \mathrm{C}$ & 0.98 & СЗ3-Н33А & 0.98 \\
\hline
\end{tabular}




$\begin{array}{llll}\text { C33-H33B } & 0.98 & \mathrm{C} 33-\mathrm{H} 33 \mathrm{C} & 0.98 \\ \mathrm{C} 34-\mathrm{C} 37 & 1.53(2) & \mathrm{C} 34-\mathrm{C} 35 & 1.53(2) \\ \mathrm{C} 34-\mathrm{C} 36 & 1.55(2) & \mathrm{C} 35-\mathrm{H} 35 \mathrm{~A} & 0.98 \\ \mathrm{C} 35-\mathrm{H} 35 \mathrm{~B} & 0.98 & \mathrm{C} 35-\mathrm{H} 35 \mathrm{C} & 0.98 \\ \mathrm{C} 36-\mathrm{H} 36 \mathrm{~A} & 0.98 & \mathrm{C} 36-\mathrm{H} 36 \mathrm{~B} & 0.98 \\ \mathrm{C} 36-\mathrm{H} 36 \mathrm{C} & 0.98 & \mathrm{C} 37-\mathrm{H} 37 \mathrm{~A} & 0.98 \\ \mathrm{C} 37-\mathrm{H} 37 \mathrm{~B} & 0.98 & \mathrm{C} 37-\mathrm{H} 37 \mathrm{C} & 0.98\end{array}$

Table 5. Bond angles $\left({ }^{\circ}\right)$ for 01086.

$\begin{array}{llll}\text { O1-C2-N3 } & 129.8(15) & \text { O1-C2-C5 } & 140.5(16) \\ \text { N3-C2-C5 } & 89.7(12) & \text { C2-N3-O12 } & 125.1(12) \\ \text { C2-N3-C4 } & 95.4(12) & \text { O12-N3-C4 } & 125.8(12) \\ \text { N3-C4-C5 } & 85.7(11) & \text { N3-C4-H4A } & 114.4 \\ \text { C5-C4-H4A } & 114.4 & \text { N3-C4-H4B } & 114.4 \\ \text { C5-C4-H4B } & 114.4 & \text { H4A-C4-H4B } & 111.5 \\ \text { C2-C5-C4 } & 87.9(12) & \text { C2-C5-C6 } & 117.3(12) \\ \text { C4-C5-C6 } & 118.0(12) & \text { C2-C5-H5 } & 110.6 \\ \text { C4-C5-H5 } & 110.6 & \text { C6-C5-H5 } & 110.6 \\ \text { O22-C6-C11 } & 112.1(12) & \text { O22-C6-C7 } & 109.8(11) \\ \text { C11-C6-C7 } & 111.7(13) & \text { O22-C6-C5 } & 103.6(12) \\ \text { C11-C6-C5 } & 110.7(12) & \text { C7-C6-C5 } & 108.5(12) \\ \text { C8-C7-C6 } & 123.7(15) & \text { C8-C7-H7 } & 118.2 \\ \text { C6-C7-H7 } & 118.2 & \text { C7-C8-C9 } & 122.3(15) \\ \text { C7-C8-H8 } & 118.8 & \text { C9-C8-H8 } & 118.8 \\ \text { O30-C9-C8 } & 107.9(12) & \text { O30-C9-C10 } & 109.6(13) \\ \text { C8-C9-C10 } & 111.5(13) & \text { O30-C9-H9 } & 109.3 \\ \text { C8-C9-H9 } & 109.3 & \text { C10-C9-H9 } & 109.3 \\ \text { C9-C10-C11 } & 108.6(13) & \text { C9-C10-H10A } & 110.0 \\ \text { C11-C10-H10A } & 110.0 & \text { C9-C10-H10B } & 110.0 \\ \text { C11-C10-H10B } & 110.0 & \text { H10A-C10-H10B } & 108.4 \\ \text { C6-C11-C10 } & 111.5(13) & \text { C6-C11-H11A } & 109.3 \\ \text { C10-C11-H11A } & 109.3 & \text { C6-C11-H11B } & 109.3 \\ \text { C10-C11-H11B } & 109.3 & \text { H11A-C11-H11B } & 108.0 \\ \text { N3-O12-C13 } & 108.6(11) & \text { O12-C13-C14 } & 107.1(13) \\ \text { O12-C13-H13A } & 110.3 & \text { C14-C13-H13A } & 110.3 \\ \text { O12-C13-H13B } & 110.3 & \text { C14-C13-H13B } & 110.3\end{array}$


Williams et al.

\begin{tabular}{|c|c|c|c|}
\hline H13A-C13-H13B & 108.6 & C19-C14-C15 & $117.4(18)$ \\
\hline C19-C14-C13 & $122.4(19)$ & C15-C14-C13 & $120.2(19)$ \\
\hline C16-C15-C14 & 121.(2) & $\mathrm{C} 16-\mathrm{C} 15-\mathrm{H} 15$ & 119.5 \\
\hline C14-C15-H15 & 119.5 & C17-C16-C15 & 121.(2) \\
\hline C17-C16-H16 & 119.4 & $\mathrm{C} 15-\mathrm{C} 16-\mathrm{H} 16$ & 119.4 \\
\hline C16-C17-C18 & 125.(2) & $\mathrm{C} 16-\mathrm{C} 17-\mathrm{O} 20$ & 113.(2) \\
\hline C18-C17-O20 & $121 .(2)$ & C17-C18-C19 & 117.1(19) \\
\hline C17-C18-H18 & 121.4 & $\mathrm{C} 19-\mathrm{C} 18-\mathrm{H} 18$ & 121.4 \\
\hline C14-C19-C18 & $117.9(19)$ & C14-C19-H19 & 121.1 \\
\hline C18-C19-H19 & 121.1 & $\mathrm{C} 21-020-\mathrm{C} 17$ & $116.0(17)$ \\
\hline O20-C21-H21A & 109.5 & $\mathrm{O} 20-\mathrm{C} 21-\mathrm{H} 21 \mathrm{~B}$ & 109.5 \\
\hline $\mathrm{H} 21 \mathrm{~A}-\mathrm{C} 21-\mathrm{H} 21 \mathrm{~B}$ & 109.5 & $\mathrm{O} 20-\mathrm{C} 21-\mathrm{H} 21 \mathrm{C}$ & 109.5 \\
\hline $\mathrm{H} 21 \mathrm{~A}-\mathrm{C} 21-\mathrm{H} 21 \mathrm{C}$ & 109.5 & H21B-C21-H21C & 109.5 \\
\hline $\mathrm{C} 6-\mathrm{O} 22-\mathrm{Si} 23$ & $133.8(10)$ & O22-Si23-C25 & $115.2(6)$ \\
\hline O22-Si23-C24 & $112.3(7)$ & $\mathrm{C} 25-\mathrm{Si} 23-\mathrm{C} 24$ & $108.6(8)$ \\
\hline O22-Si23-C26 & $101.8(6)$ & $\mathrm{C} 25-\mathrm{Si} 23-\mathrm{C} 26$ & $109.2(8)$ \\
\hline C24-Si23-C26 & $109.5(8)$ & $\mathrm{Si} 23-\mathrm{C} 24-\mathrm{H} 24 \mathrm{~A}$ & 109.5 \\
\hline Si23-C24-H24B & 109.5 & $\mathrm{H} 24 \mathrm{~A}-\mathrm{C} 24-\mathrm{H} 24 \mathrm{~B}$ & 109.5 \\
\hline Si23-C24-H24C & 109.5 & $\mathrm{H} 24 \mathrm{~A}-\mathrm{C} 24-\mathrm{H} 24 \mathrm{C}$ & 109.5 \\
\hline $\mathrm{H} 24 \mathrm{~B}-\mathrm{C} 24-\mathrm{H} 24 \mathrm{C}$ & 109.5 & $\mathrm{Si} 23-\mathrm{C} 25-\mathrm{H} 25 \mathrm{~A}$ & 109.5 \\
\hline $\mathrm{Si} 23-\mathrm{C} 25-\mathrm{H} 25 \mathrm{~B}$ & 109.5 & $\mathrm{H} 25 \mathrm{~A}-\mathrm{C} 25-\mathrm{H} 25 \mathrm{~B}$ & 109.5 \\
\hline $\mathrm{Si} 23-\mathrm{C} 25-\mathrm{H} 25 \mathrm{C}$ & 109.5 & $\mathrm{H} 25 \mathrm{~A}-\mathrm{C} 25-\mathrm{H} 25 \mathrm{C}$ & 109.5 \\
\hline $\mathrm{H} 25 \mathrm{~B}-\mathrm{C} 25-\mathrm{H} 25 \mathrm{C}$ & 109.5 & C29-C26-C28 & $109.1(16)$ \\
\hline C29-C26-C27 & $111.7(15)$ & $\mathrm{C} 28-\mathrm{C} 26-\mathrm{C} 27$ & $110.3(14)$ \\
\hline C29-C26-Si23 & $108.5(12)$ & $\mathrm{C} 28-\mathrm{C} 26-\mathrm{Si} 23$ & $110.2(12)$ \\
\hline C27-C26-Si23 & $107.0(11)$ & $\mathrm{C} 26-\mathrm{C} 27-\mathrm{H} 27 \mathrm{~A}$ & 109.5 \\
\hline $\mathrm{C} 26-\mathrm{C} 27-\mathrm{H} 27 \mathrm{~B}$ & 109.5 & $\mathrm{H} 27 \mathrm{~A}-\mathrm{C} 27-\mathrm{H} 27 \mathrm{~B}$ & 109.5 \\
\hline $\mathrm{C} 26-\mathrm{C} 27-\mathrm{H} 27 \mathrm{C}$ & 109.5 & $\mathrm{H} 27 \mathrm{~A}-\mathrm{C} 27-\mathrm{H} 27 \mathrm{C}$ & 109.5 \\
\hline $\mathrm{H} 27 \mathrm{~B}-\mathrm{C} 27-\mathrm{H} 27 \mathrm{C}$ & 109.5 & $\mathrm{C} 26-\mathrm{C} 28-\mathrm{H} 28 \mathrm{~A}$ & 109.5 \\
\hline $\mathrm{C} 26-\mathrm{C} 28-\mathrm{H} 28 \mathrm{~B}$ & 109.5 & $\mathrm{H} 28 \mathrm{~A}-\mathrm{C} 28-\mathrm{H} 28 \mathrm{~B}$ & 109.5 \\
\hline $\mathrm{C} 26-\mathrm{C} 28-\mathrm{H} 28 \mathrm{C}$ & 109.5 & $\mathrm{H} 28 \mathrm{~A}-\mathrm{C} 28-\mathrm{H} 28 \mathrm{C}$ & 109.5 \\
\hline $\mathrm{H} 28 \mathrm{~B}-\mathrm{C} 28-\mathrm{H} 28 \mathrm{C}$ & 109.5 & $\mathrm{C} 26-\mathrm{C} 29-\mathrm{H} 29 \mathrm{~A}$ & 109.5 \\
\hline C26-C29-H29B & 109.5 & H29A-C29-H29B & 109.5 \\
\hline C26-C29-H29C & 109.5 & H29A-C29-H29C & 109.5 \\
\hline H29B-C29-H29C & 109.5 & C9-030-Si31 & $125.5(10)$ \\
\hline O30-Si31-C32 & $110.5(8)$ & O30-Si31-C33 & $110.8(7)$ \\
\hline C32-Si31-C33 & 107.2(9) & O30-Si31-C34 & $102.7(6)$ \\
\hline C32-Si31-C34 & $112.7(8)$ & C33-Si31-C34 & $112.9(8)$ \\
\hline Si31-C32-H32A & 109.5 & $\mathrm{Si} 31-\mathrm{C} 32-\mathrm{H} 32 \mathrm{~B}$ & 109.5 \\
\hline $\mathrm{H} 32 \mathrm{~A}-\mathrm{C} 32-\mathrm{H} 32 \mathrm{~B}$ & 109.5 & $\mathrm{Si} 31-\mathrm{C} 32-\mathrm{H} 32 \mathrm{C}$ & 109.5 \\
\hline
\end{tabular}




$\begin{array}{ll}\text { H32A-C32-H32C } & 109.5 \\ \text { Si31-C33-H33A } & 109.5 \\ \text { H33A-C33-H33B } & 109.5 \\ \text { H33A-C33-H33C } & 109.5 \\ \text { C37-C34-C35 } & 109.5(15) \\ \text { C35-C34-C36 } & 108.5(15) \\ \text { C35-C34-Si31 } & 111.4(11) \\ \text { C34-C35-H35A } & 109.5 \\ \text { H35A-C35-H35B } & 109.5 \\ \text { H35A-C35-H35C } & 109.5 \\ \text { C34-C36-H36A } & 109.5 \\ \text { H36A-C36-H36B } & 109.5 \\ \text { H36A-C36-H36C } & 109.5 \\ \text { C34-C37-H37A } & 109.5 \\ \text { H37A-C37-H37B } & 109.5 \\ \text { H37A-C37-H37C } & 109.5\end{array}$

$\begin{array}{ll}\text { H32B-C32-H32C } & 109.5 \\ \text { Si31-C33-H33B } & 109.5 \\ \text { Si31-C33-H33C } & 109.5 \\ \text { H33B-C33-H33C } & 109.5 \\ \text { C37-C34-C36 } & 107.3(14) \\ \text { C37-C34-Si31 } & 109.7(11) \\ \text { C36-C34-Si31 } & 110.3(12) \\ \text { C34-C35-H35B } & 109.5 \\ \text { C34-C35-H35C } & 109.5 \\ \text { H35B-C35-H35C } & 109.5 \\ \text { C34-C36-H36B } & 109.5 \\ \text { C34-C36-H36C } & 109.5 \\ \text { H36B-C36-H36C } & 109.5 \\ \text { C34-C37-H37B } & 109.5 \\ \text { C34-C37-H37C } & 109.5 \\ \text { H37B-C37-H37C } & 109.5\end{array}$

Table 6. Torsion angles $\left({ }^{\circ}\right)$ for 01086.

$\begin{array}{ll}\text { O1-C2-N3-O12 } & -30 .(2) \\ \text { O1-C2-N3-C4 } & -171.6(16) \\ \text { C2-N3-C4-C5 } & -9.1(11) \\ \text { O1-C2-C5-C4 } & 172 .(2) \\ \text { O1-C2-C5-C6 } & -67 .(3) \\ \text { N3-C4-C5-C2 } & 8.3(10) \\ \text { C2-C5-C6-O22 } & -50.9(16) \\ \text { C2-C5-C6-C11 } & 69.4(18) \\ \text { C2-C5-C6-C7 } & -167.6(13) \\ \text { O22-C6-C7-C8 } & 131.9(14) \\ \text { C5-C6-C7-C8 } & -115.5(15) \\ \text { C7-C8-C9-O30 } & -99.3(16) \\ \text { O30-C9-C10-C11 } & 66.9(16) \\ \text { O22-C6-C11-C10 } & -163.4(12) \\ \text { C5-C6-C11-C10 } & 81.5(15) \\ \text { C2-N3-O12-C13 } & 88.8(17) \\ \text { N3-O12-C13-C14 } & -159.7(14) \\ \text { O12-C13-C14-C15 } & -98.3(17) \\ \text { C13-C14-C15-C16 } & 175.5(17) \\ \text { C15-C16-C17-C18 } & -3 .(3)\end{array}$

$\begin{array}{ll}\text { C5-C2-N3-O12 } & 150.9(12) \\ \text { C5-C2-N3-C4 } & 9.2(11) \\ \text { O12-N3-C4-C5 } & -150.4(13) \\ \text { N3-C2-C5-C4 } & -8.8(11) \\ \text { N3-C2-C5-C6 } & 111.8(14) \\ \text { N3-C4-C5-C6 } & -111.7(13) \\ \text { C4-C5-C6-O22 } & 52.2(16) \\ \text { C4-C5-C6-C11 } & 172.5(12) \\ \text { C4-C5-C6-C7 } & -64.5(17) \\ \text { C11-C6-C7-C8 } & 7 .(2) \\ \text { C6-C7-C8-C9 } & 3 .(2) \\ \text { C7-C8-C9-C10 } & 21.1(19) \\ \text { C8-C9-C10-C11 } & -52.5(16) \\ \text { C7-C6-C11-C10 } & -39.6(17) \\ \text { C9-C10-C11-C6 } & 63.5(17) \\ \text { C4-N3-O12-C13 } & -140.7(15) \\ \text { O12-C13-C14-C19 } & 82 .(2) \\ \text { C19-C14-C15-C16 } & -5 .(3) \\ \text { C14-C15-C16-C17 } & 4 .(3) \\ \text { C15-C16-C17-O20 } & 179.4(17) \\ & \end{array}$




$\begin{array}{llll}\text { C16-C17-C18-C19 } & 2 .(3) & \text { O20-C17-C18-C19 } & 179.5(15) \\ \text { C15-C14-C19-C18 } & 4 .(2) & \text { C13-C14-C19-C18 } & -176.5(15) \\ \text { C17-C18-C19-C14 } & -2 .(2) & \text { C16-C17-O20-C21 } & 178.1(18) \\ \text { C18-C17-O20-C21 } & 0 .(3) & \text { C11-C6-O22-Si23 } & 75.6(16) \\ \text { C7-C6-O22-Si23 } & -49.3(18) & \text { C5-C6-O22-Si23 } & -165.1(10) \\ \text { C6-O22-Si23-C25 } & 49.3(14) & \text { C6-O22-Si23-C24 } & -75.7(14) \\ \text { C6-O22-Si23-C26 } & 167.3(13) & \text { C8-C9-O30-Si31 } & -95.9(14) \\ \text { C10-C9-O30-Si31 } & 142.5(11) & \text { C9-O30-Si31-C32 } & -66.8(15) \\ \text { C9-O30-Si31-C33 } & 51.9(14) & \text { C9-O30-Si31-C34 } & 172.8(13) \\ \text { O30-Si31-C34-C37 } & 178.4(12) & \text { C32-Si31-C34-C37 } & 59.4(14) \\ \text { C33-Si31-C34-C37 } & -62.2(14) & \text { O30-Si31-C34-C35 } & 56.9(14) \\ \text { C32-Si31-C34-C35 } & -62.1(15) & \text { C33-Si31-C34-C35 } & 176.3(12) \\ \text { O30-Si31-C34-C36 } & -63.7(13) & \text { C32-Si31-C34-C36 } & 177.4(13) \\ \text { C33-Si31-C34-C36 } & 55.7(14) & & \end{array}$

Table 7. Anisotropic atomic displacement parameters $\left(\AA^{2}\right)$ for 01086.

The anisotropic atomic displacement factor exponent takes the form: $-2 \pi^{2}\left[h^{2} a^{* 2} U_{11}+\ldots+2 h k\right.$

\begin{tabular}{|c|c|c|c|c|c|c|}
\hline & $U_{11}$ & $U_{22}$ & $U_{33}$ & $U_{23}$ & $U_{13}$ & $U_{12}$ \\
\hline 01 & $0.028(8)$ & $0.019(7)$ & $0.044(7)$ & $-0.007(6)$ & $0.005(6)$ & $0.000(6)$ \\
\hline $\mathrm{C} 2$ & $0.024(11)$ & $0.017(10)$ & $0.012(8)$ & $0.004(7)$ & $0.005(8)$ & $0.010(8)$ \\
\hline N3 & $0.033(10)$ & $0.030(9)$ & $0.017(8)$ & $0.003(6)$ & $0.009(7)$ & $0.007(8)$ \\
\hline C4 & $0.022(10)$ & $0.021(10)$ & $0.021(9)$ & $-0.007(7)$ & $0.004(8)$ & $0.003(8)$ \\
\hline C5 & $0.021(10)$ & $0.016(9)$ & $0.014(8)$ & $-0.001(7)$ & $0.006(8)$ & $-0.007(7)$ \\
\hline C6 & $0.028(8)$ & $0.015(6)$ & $0.014(8)$ & $-0.002(6)$ & $0.010(6)$ & $-0.001(5)$ \\
\hline $\mathrm{C7}$ & $0.034(7)$ & $0.013(6)$ & $0.016(7)$ & $-0.001(6)$ & $0.009(7)$ & $-0.001(6)$ \\
\hline $\mathrm{C} 8$ & $0.032(7)$ & $0.015(7)$ & $0.015(8)$ & $0.001(6)$ & $0.007(7)$ & $-0.001(5)$ \\
\hline C9 & $0.032(8)$ & $0.021(7)$ & $0.012(7)$ & $0.003(6)$ & $0.010(6)$ & $-0.003(6)$ \\
\hline C10 & $0.032(9)$ & $0.017(7)$ & $0.026(9)$ & $0.007(6)$ & $0.004(7)$ & $0.001(6)$ \\
\hline C11 & $0.030(8)$ & $0.016(7)$ & $0.016(8)$ & $0.000(6)$ & $-0.001(6)$ & $0.000(6)$ \\
\hline 012 & $0.010(7)$ & $0.047(9)$ & $0.024(7)$ & $-0.007(6)$ & $0.001(6)$ & $0.007(6)$ \\
\hline $\mathrm{C} 13$ & $0.039(12)$ & $0.072(14)$ & $0.025(9)$ & $0.024(11)$ & $0.008(9)$ & $0.023(12)$ \\
\hline C14 & $0.042(9)$ & $0.051(9)$ & $0.028(9)$ & $-0.001(8)$ & $0.015(7)$ & $0.006(7)$ \\
\hline C15 & $0.042(9)$ & $0.050(10)$ & $0.039(10)$ & $-0.006(7)$ & $0.011(7)$ & $0.006(7)$ \\
\hline C16 & $0.050(10)$ & $0.063(11)$ & $0.054(11)$ & $0.001(8)$ & $0.002(8)$ & $0.009(8)$ \\
\hline C17 & $0.050(10)$ & $0.053(10)$ & $0.031(10)$ & $-0.005(8)$ & $0.008(8)$ & $0.008(8)$ \\
\hline C18 & $0.063(11)$ & $0.049(10)$ & $0.032(10)$ & $-0.002(7)$ & $0.018(8)$ & $0.004(8)$ \\
\hline C19 & $0.055(10)$ & $0.049(9)$ & $0.040(10)$ & $-0.005(7)$ & $0.021(8)$ & $0.003(8)$ \\
\hline 020 & $0.041(10)$ & $0.097(14)$ & $0.068(11)$ & $-0.016(10)$ & $-0.007(9)$ & $0.015(9)$ \\
\hline $\mathrm{C} 21$ & $0.11(2)$ & $0.017(11)$ & $0.069(15)$ & $0.001(12)$ & $0.031(15)$ & $0.017(14)$ \\
\hline 022 & $0.026(7)$ & $0.030(7)$ & $0.011(5)$ & $0.000(5)$ & $0.010(5)$ & $-0.001(5)$ \\
\hline
\end{tabular}




$\begin{array}{lllllll} & U_{11} & U_{22} & U_{33} & U_{23} & U_{13} & U_{12} \\ \text { Si23 } & 0.024(3) & 0.025(3) & 0.019(2) & 0.004(2) & 0.006(2) & 0.002(3) \\ \text { C24 } & 0.035(13) & 0.045(12) & 0.026(10) & -0.012(9) & 0.011(10) & -0.018(9) \\ \text { C25 } & 0.036(12) & 0.037(12) & 0.039(12) & 0.018(9) & 0.012(10) & -0.002(10) \\ \text { C26 } & 0.027(11) & 0.031(10) & 0.028(9) & 0.008(9) & 0.011(8) & -0.005(10) \\ \text { C27 } & 0.024(11) & 0.040(12) & 0.046(12) & 0.017(10) & 0.015(10) & 0.001(10) \\ \text { C28 } & 0.055(15) & 0.048(14) & 0.050(12) & 0.031(10) & 0.034(12) & 0.005(11) \\ \text { C29 } & 0.021(12) & 0.068(15) & 0.081(16) & -0.012(14) & 0.017(12) & -0.007(12) \\ \text { O30 } & 0.034(8) & 0.031(7) & 0.020(6) & 0.003(6) & -0.001(6) & -0.006(7) \\ \text { Si31 } & 0.023(3) & 0.022(3) & 0.020(3) & -0.002(2) & 0.001(2) & 0.001(3) \\ \text { C32 } & 0.022(11) & 0.074(14) & 0.027(10) & 0.009(11) & 0.003(9) & -0.012(12) \\ \text { C33 } & 0.030(13) & 0.042(12) & 0.046(13) & 0.000(10) & -0.001(11) & 0.001(10) \\ \text { C34 } & 0.029(11) & 0.029(12) & 0.032(10) & 0.004(8) & 0.003(9) & 0.007(8) \\ \text { C35 } & 0.029(13) & 0.072(17) & 0.032(11) & -0.003(10) & -0.002(10) & 0.003(11) \\ \text { C36 } & 0.039(14) & 0.067(16) & 0.041(12) & 0.009(10) & 0.005(11) & -0.014(11) \\ \text { C37 } & 0.034(12) & 0.046(13) & 0.029(10) & 0.004(9) & 0.006(10) & 0.023(10)\end{array}$

Table 8. Hydrogen atomic coordinates and isotropic atomic displacement parameters $\left(\AA^{2}\right)$ for 01086.

$\begin{array}{lllll} & \mathbf{x} / \mathbf{a} & \mathrm{y} / \mathrm{b} & \mathrm{z} / \mathrm{c} & \mathrm{U}(\mathrm{eq}) \\ \mathrm{H} 4 \mathrm{~A} & 0.6233 & 0.4992 & 0.9369 & 0.026 \\ \mathrm{H} 4 \mathrm{~B} & 0.6159 & 0.4181 & 1.0315 & 0.026 \\ \mathrm{H} 5 & 0.4893 & 0.2449 & 0.9674 & 0.02 \\ \mathrm{H} 7 & 0.4787 & 0.6490 & 0.8580 & 0.024 \\ \mathrm{H} 8 & 0.3360 & 0.7163 & 0.8284 & 0.024 \\ \text { H9 } & 0.2366 & 0.4460 & 0.8309 & 0.025 \\ \text { H10A } & 0.2790 & 0.1002 & 0.8112 & 0.031 \\ \text { H10B } & 0.3390 & 0.2015 & 0.8968 & 0.031 \\ \text { H11A } & 0.4273 & 0.0326 & 0.8137 & 0.026 \\ \text { H11B } & 0.3886 & 0.1835 & 0.7349 & 0.026 \\ \text { H13A } & 0.8233 & 0.1609 & 0.9347 & 0.054 \\ \text { H13B } & 0.7593 & -0.0329 & 0.9132 & 0.054 \\ \text { H15 } & 0.9652 & 0.1311 & 1.0359 & 0.052 \\ \text { H16 } & 1.0667 & -0.0512 & 1.1338 & 0.069 \\ \text { H18 } & 0.9098 & -0.5238 & 1.1178 & 0.056 \\ \text { H19 } & 0.7928 & -0.3425 & 1.0150 & 0.056 \\ \text { H21A } & 1.0315 & -0.6642 & 1.1647 & 0.094 \\ \text { H21B } & 1.0145 & -0.5756 & 1.2523 & 0.094 \\ \text { H21C } & 1.1115 & -0.6381 & 1.2476 & 0.094 \\ \text { H24A } & 0.4203 & 0.3134 & 0.5884 & 0.052\end{array}$




$\begin{array}{lllll} & x / a & y / b & z / c & \text { U(eq) } \\ \text { H24B } & 0.4906 & 0.1335 & 0.6131 & 0.052 \\ \text { H24C } & 0.5039 & 0.3091 & 0.5481 & 0.052 \\ \text { H25A } & 0.5306 & 0.7800 & 0.7307 & 0.055 \\ \text { H25B } & 0.4450 & 0.7095 & 0.6601 & 0.055 \\ \text { H25C } & 0.5326 & 0.7662 & 0.6314 & 0.055 \\ \text { H27A } & 0.7556 & 0.1739 & 0.7001 & 0.054 \\ \text { H27B } & 0.6561 & 0.1127 & 0.6573 & 0.054 \\ \text { H27C } & 0.6890 & 0.1361 & 0.7597 & 0.054 \\ \text { H28A } & 0.6402 & 0.4677 & 0.5650 & 0.071 \\ \text { H28B } & 0.7433 & 0.4597 & 0.6076 & 0.071 \\ \text { H28C } & 0.6881 & 0.6578 & 0.6193 & 0.071 \\ \text { H29A } & 0.7767 & 0.5733 & 0.7654 & 0.084 \\ \text { H29B } & 0.7252 & 0.4561 & 0.8255 & 0.084 \\ \text { H29C } & 0.6864 & 0.6630 & 0.7785 & 0.084 \\ \text { H32A } & 0.0631 & 0.4375 & 0.7405 & 0.062 \\ \text { H32B } & 0.0624 & 0.2669 & 0.6689 & 0.062 \\ \text { H32C } & 0.0099 & 0.4754 & 0.6430 & 0.062 \\ \text { H33A } & 0.2161 & 0.8738 & 0.6773 & 0.061 \\ \text { H33B } & 0.1656 & 0.8175 & 0.7496 & 0.061 \\ \text { H33C } & 0.1113 & 0.8756 & 0.6544 & 0.061 \\ \text { H35A } & 0.2280 & 0.2130 & 0.5491 & 0.069 \\ \text { H35B } & 0.1657 & 0.2543 & 0.4555 & 0.069 \\ \text { H35C } & 0.1240 & 0.1956 & 0.5339 & 0.069 \\ \text { H36A } & 0.2483 & 0.5915 & 0.4617 & 0.074 \\ \text { H36B } & 0.3019 & 0.5408 & 0.5580 & 0.074 \\ \text { H36C } & 0.2473 & 0.7482 & 0.5380 & 0.074 \\ \text { H37A } & 0.0341 & 0.5125 & 0.4824 & 0.055 \\ \text { H37B } & 0.0932 & 0.5913 & 0.4207 & 0.055 \\ \text { H37C } & 0.0797 & 0.7316 & 0.4982 & 0.055\end{array}$

Table 9. Hydrogen bond distances (Å) and angles $\left(^{\circ}\right)$ for 01086.

$\begin{array}{lllll} & \text { Donor-H } & \text { Acceptor-H } & \text { Donor-Acceptor } & \text { Angle } \\ \text { C4-H4A } \cdots \mathrm{O} 1 & 0.99 & 2.63 & 3.429(18) & 137.6 \\ \mathrm{C} 5-\mathrm{H} 5 \cdots \mathrm{O} 1 & 1.00 & 2.50 & 3.412(18) & 151.4 \\ \mathrm{C} 7-\mathrm{H} 7 \cdots \mathrm{O} 1 & 0.95 & 2.32 & 3.259(19) & 169.5\end{array}$

